\title{
WestVirginiaUniversity
}

THE RESEARCH REPOSITORY @ WVU

Graduate Theses, Dissertations, and Problem Reports

2003

\section{Inhalation exposure system for diesel exhaust particulates}

\author{
Jay Michael Sherman
}

West Virginia University

Follow this and additional works at: https://researchrepository.wvu.edu/etd

\section{Recommended Citation}

Sherman, Jay Michael, "Inhalation exposure system for diesel exhaust particulates" (2003). Graduate Theses, Dissertations, and Problem Reports. 1318.

https://researchrepository.wvu.edu/etd/1318

This Thesis is protected by copyright and/or related rights. It has been brought to you by the The Research Repository @ WVU with permission from the rights-holder(s). You are free to use this Thesis in any way that is permitted by the copyright and related rights legislation that applies to your use. For other uses you must obtain permission from the rights-holder(s) directly, unless additional rights are indicated by a Creative Commons license in the record and/ or on the work itself. This Thesis has been accepted for inclusion in WVU Graduate Theses, Dissertations, and Problem Reports collection by an authorized administrator of The Research Repository @ WVU. For more information, please contact researchrepository@mail.wvu.edu. 
Inhalation Exposure System For Diesel Exhaust Particulates

Jay Michael Sherman

Thesis submitted to the

College of Engineering and Mineral Resources

at West Virginia University

in partial fulfillment of the requirements

for the degree of

Master of Science

in

Mechanical Engineering

Approved by

Charles F. Stanley, Chairperson

Eric K. Johnson

Michael McCawley

Department of Mechanical and Aerospace Engineering

Morgantown, West Virginia

2003

Keywords: Aerosol Generation, Inhalation Exposure System, Diesel Exhaust Particulate, Jet mill, Hazelton, Dry powder 


\section{ABSTRACT \\ Inhalation Exposure System For Diesel Exhaust Particulates Jay Michael Sherman}

The objectives of this research were twofold. First, a Hazleton 2000 Inhalation Chamber was modified to minimize the amount of diesel exhaust particulate (DEP) needed for animal inhalation exposures. Second, instrumentation was evaluated for aerosolizing DEP, monitoring the mass concentration and size distribution, and determining the uniformity of the aerosol.

For aerosolizing the DEP, a TSI 9300 fluidized bed and a Jet-O-Mizer model 00 jet mill with a vibratory feeder were considered. A Parallel Flow Diffusion Battery (PFDB) and a Micro Orifice Uniform Deposit Impactor (MOUDI) were tested for finding the aerosol size distribution. For monitoring the mass concentration, a Tapered Element Oscillating Microbalance (TEOM) was evaluated. The uniformity of the aerosol was monitored with Marple personal impactors.

The jet mill with a grinding nozzle pressure of 80 PSI produced a single mode size distribution and a resulting combined DEP mass median diameter (MMD) of $0.33 \mu \mathrm{m}$ while maintaining a relatively steady mass concentration of $10 \mathrm{mg} / \mathrm{m}^{3}$. The PFDB was found to be unsatisfactory at measuring the aerosol size distribution. The uniformity of a carbon black aerosol was found to vary from $9.9 \mathrm{mg} / \mathrm{m}^{3}$ in the front part of the chamber, to $10.4 \mathrm{mg} / \mathrm{m}^{3}$ in the center, and $11.7 \mathrm{mg} / \mathrm{m}^{3}$ in the rear of the chamber. The TEOM was found to satisfactorily monitor the mass concentration but the filter lifetime of the TEOM at high mass concentrations would necessitate periodic observations. 


\section{ACKNOWLEDGEMENT}

The author would like to thank his graduate advisor, Dr. Charles F. Stanley for all

of his help and knowledge; to Dr. Eric K. Johnson and Dr. Michael McCawley for their assistance; and to his wife Joanna for all her love and support. 


\section{Table of Contents}

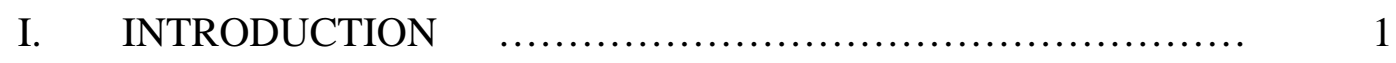

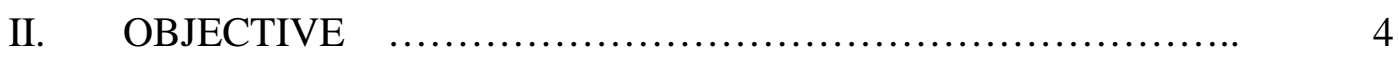

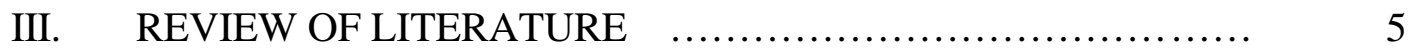

3.1 Rat Lung Depostion with Relation to Particle Size ........ 5

Inhalation Studies Using Diesel Exhuast Particulate and
Carbon Black $\ldots \ldots \ldots \ldots \ldots \ldots \ldots \ldots \ldots \ldots \ldots \ldots \ldots \ldots \ldots \ldots \ldots \ldots \ldots$

3.3 Modifying the Hazleton 2000 Chambers $\quad$.................. 10

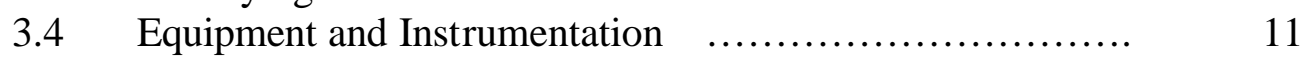

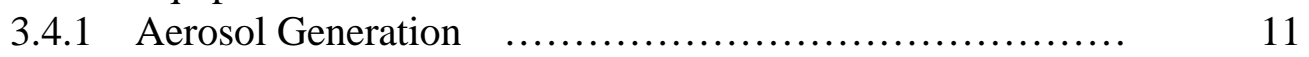

3.4.2 Tapered Element Oscillating Microbalance $\ldots . . . \ldots \ldots \ldots . . . .12$

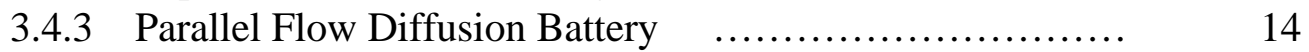

3.4.4 Micro Orifice Uniform Deposit Impactor $\ldots \ldots \ldots \ldots \ldots . . . . .16$

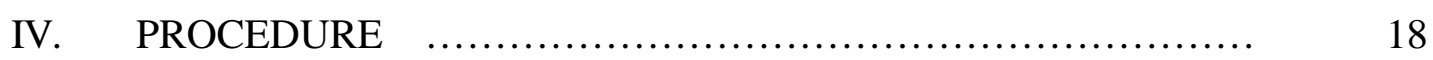

4.1 Procedures to Modity the Inhalation Chamber $\ldots \ldots \ldots \ldots \ldots . . . .18$

4.1.1 Inhalation System Schematic $\ldots \ldots \ldots \ldots \ldots \ldots \ldots \ldots \ldots . . . \ldots \ldots$

4.1.2 Modifying an Inhalation Chamber to Reduce DEP and CB

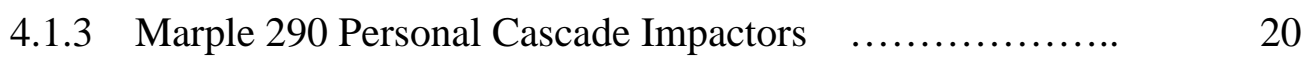

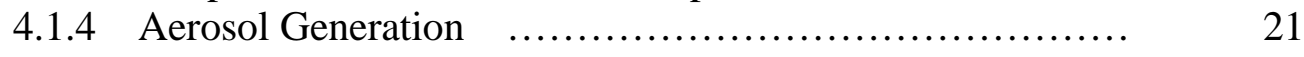

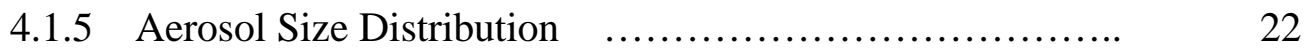

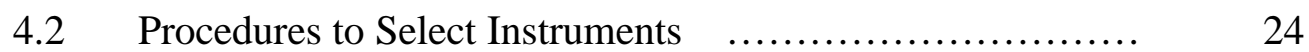

4.2.1 Tapered Element Oscillation Microbalance $\ldots . . . . . . . . . .24$

4.2.2 Micro Orifice Uniform Deposit Impactor ................ 26

4.2.3 Parallel Flow Diffusion Battery with Cascade Impactor .. 27

4.2.4 Humidity, Temperature, and Noise Level ............... 28

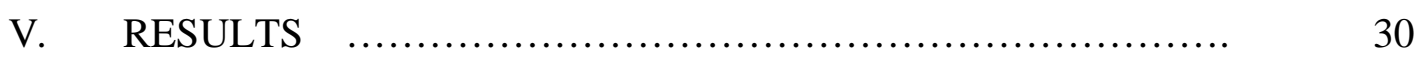

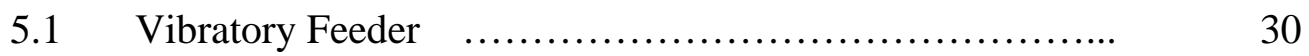

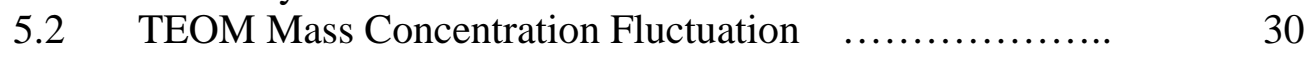

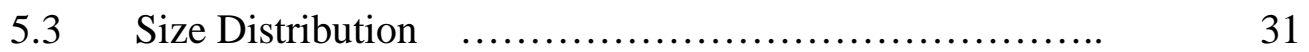

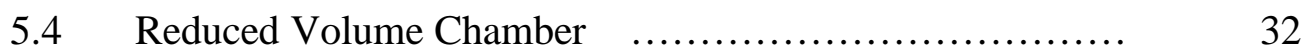

5.5 Comparison of TEOM with Gravimetric Methods ........ 33

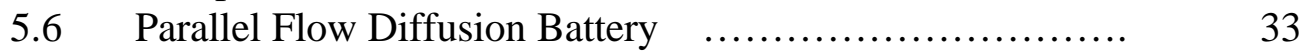

5.7 Noise Level, Temperature, and Humidity $\ldots \ldots \ldots \ldots \ldots \ldots . . . . . .34$

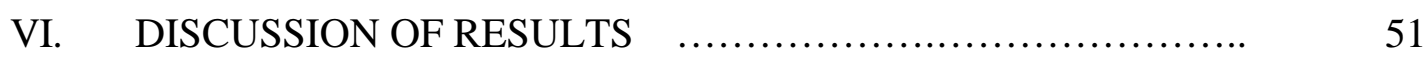

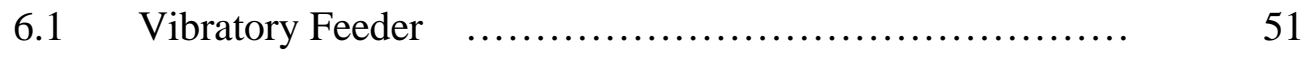

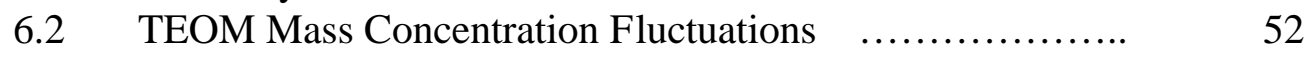

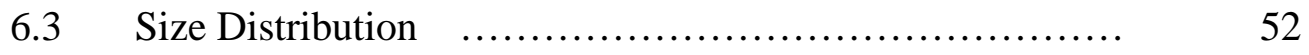




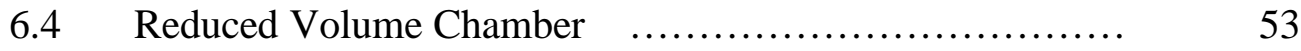

6.5 Comparison of TEOM with Gravimetric Methods ........ 54

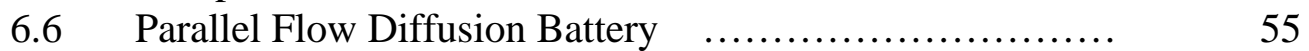

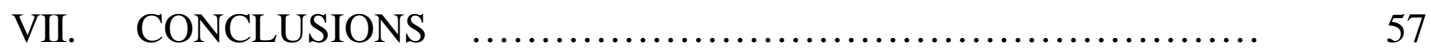

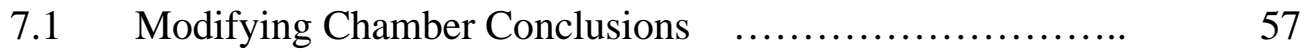

7.1.1 Reducing the Aerosolized Material ..................... 57

7.1.2 Uniform Dispersion of Aerosol ............................ 57

7.2 Equipment and Instrumentation Conclusions $\ldots \ldots \ldots \ldots \ldots . \ldots . \ldots . \ldots . \ldots$

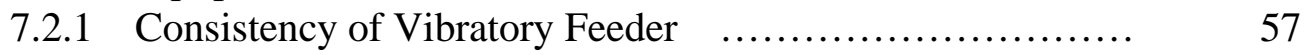

7.2.2 TEOM Mass Concentration Fluctuations $\quad$.................. 58

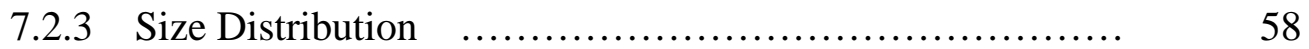

7.2.4 Comparison of TEOM with Gravimetric Methods ........ 58

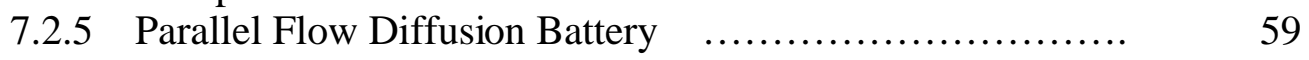

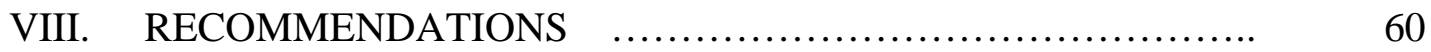

APPENDIX A - Histograms and curve fitting for MOUDI size

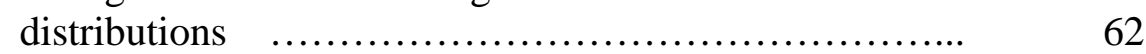

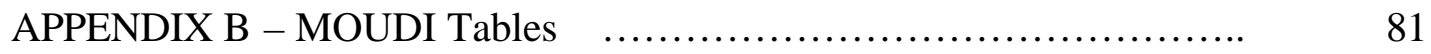

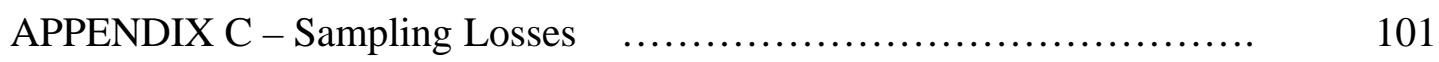

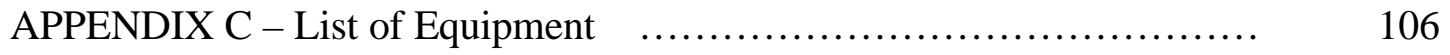

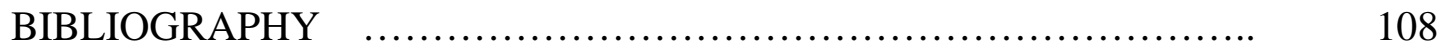




\section{LIST OF TABLES}

Tables Page

$1 \quad$ Regional Lung Deposition of Aerosols $\quad \ldots \ldots \ldots \ldots \ldots \ldots \ldots \ldots \ldots \ldots \ldots$

2 Deposition Percentages in Rat body $\quad \ldots \ldots \ldots \ldots \ldots \ldots \ldots \ldots \ldots \ldots \ldots . \ldots \ldots$

MMD, GSD, and Mass Fraction of CB and DEP Aerosols $\quad \ldots . . . . \quad 54$

3 MMD, GSD, and mass fraction for CB and DEP aerosols $\quad \ldots \ldots \ldots \ldots . . .43$

$4 \quad$ Marple's mass concentration relative to TEOM $\quad \ldots \ldots \ldots \ldots \ldots \ldots . . . . . \quad 50$

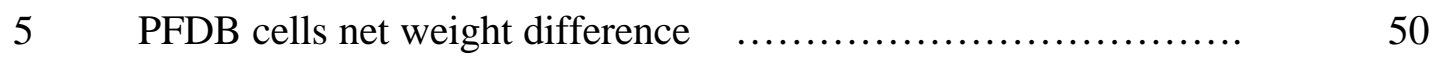

6-11 MOUDI Size Distribution at 80 PSI for CB $\ldots \ldots \ldots \ldots \ldots \ldots \ldots . \ldots 2$

12-16 MOUDI Size Distribution at 40 PSI for CB $\ldots \ldots \ldots \ldots \ldots \ldots \ldots . \ldots . \ldots$

17-20 MOUDI Size Distribution at 80 PSI for DEP $\ldots \ldots \ldots \ldots \ldots \ldots \ldots \ldots$

21-23 MOUDI Size Distribution at 40 PSI for DEP $\ldots \ldots \ldots \ldots \ldots \ldots \ldots . \ldots 7$

24-25 Consistency of Mass Concentration Level $\quad \ldots \ldots \ldots \ldots \ldots \ldots \ldots \ldots . \ldots \ldots$ 


\section{LIST OF FIGURES}

$\begin{array}{lll}\text { Figures } & \text { Page }\end{array}$

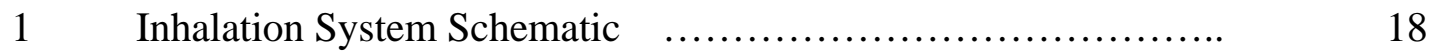

2 Side View of Hazleton 2000 Chamber $\quad \ldots \ldots \ldots \ldots \ldots \ldots \ldots \ldots \ldots \ldots . . \ldots \ldots$

3 Overhead View of Reduced Volume Chamber with inlet

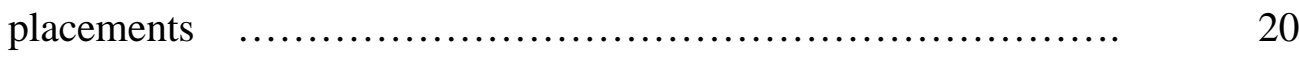

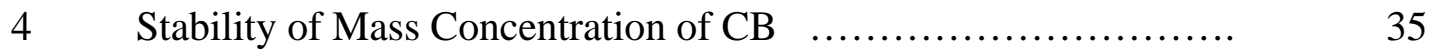

5 Stability of Mass Concentration of DEP $\quad \ldots \ldots \ldots \ldots \ldots \ldots \ldots \ldots \ldots \ldots \ldots$

6-7 TEOM Mass Concentration Fluctuations $\quad \ldots \ldots \ldots \ldots \ldots \ldots \ldots \ldots . \ldots \ldots$

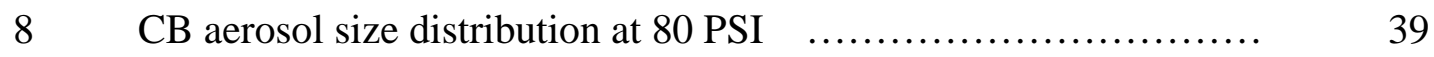

$9 \quad \mathrm{CB}$ aerosol size distribution at 40 PSI $\quad \ldots \ldots \ldots \ldots \ldots \ldots \ldots \ldots \ldots \ldots \ldots \ldots . \ldots \ldots$

10 DEP aerosol size distribution at 80 PSI $\quad \ldots \ldots \ldots \ldots \ldots \ldots \ldots \ldots \ldots \ldots \ldots \ldots \ldots$

11 DEP aerosol size distribution at 40 PSI $\quad \ldots \ldots \ldots \ldots \ldots \ldots \ldots \ldots \ldots \ldots \ldots . \ldots \ldots$

12 Combined MMD for CB Aerosols at 80 PSI $\ldots \ldots \ldots \ldots \ldots \ldots \ldots \ldots . \ldots . \ldots$

13 Combined MMD for CB Aerosols at 40 PSI $\ldots \ldots \ldots \ldots \ldots \ldots \ldots \ldots \ldots$

14 The Resulting Mass Concentration from $36 \mathrm{mg}$ of DEP $\quad \ldots \ldots \ldots \ldots . . . .46$

15-17 Comparison of Mass Concentration of TEOM vs Marples $\quad . . . . . . \quad 47$

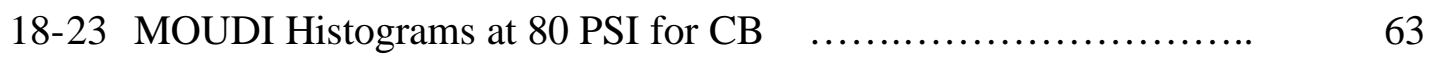

24-28 MOUDI Histograms at 40 PSI for CB $\ldots \ldots \ldots \ldots \ldots \ldots \ldots \ldots \ldots \ldots \ldots$

29-32 MOUDI Histograms at 80 PSI for DEP $\ldots \ldots \ldots \ldots \ldots \ldots \ldots \ldots \ldots \ldots \ldots$

33-35 MOUDI Histograms at 40 PSI for DEP $\ldots \ldots \ldots \ldots \ldots \ldots \ldots \ldots \ldots \ldots \ldots$

36 Plot of transmission efficiency in inertial deposition in a bend $\ldots . \quad 101$

37 Plot of transmission efficiency for a thin walled nozzle $\quad . . \ldots \ldots \ldots . . . \quad 103$ 


\section{Introduction}

The health community is increasingly focusing its attention on the health effects of diesel exhaust. This is partially due to the growing popularity of diesel engines (1). It is also due to the increasing realization of the detrimental health effects caused by the inhalation of diesel exhaust particulate (DEP) (2). This is in part because much more attention is being paid to the inhalation of ultrafine particles (10 to $100 \mathrm{~nm}$ in diameter), and there is generally a high fraction of ultrafine particles emitted from diesel engines (3, $4,5)$.

An aerosol, such as DEP, is a collection of particles that are small enough to remain airborne where they can be inhaled into the lungs. Aerosols, including DEP, are often inhaled in the environment and work places. Serious health effects have been associated with acute and chronic exposures of many aerosols.

Many studies have been performed that expose rats in inhalation exposure chambers to aerosols. These studies have indicated that both the chemical components and the physical size of aerosol particles may play a role in the development of pulmonary diseases. For example, many aerosols with very low fractions of mutagenic material, such as carbon black (CB) have been shown to cause the same inflammation and eventual lung tumors in rat inhalation studies as $\operatorname{DEP}(6,7,8)$. This seems to be a result of a process called lung overload which occurs when the deposition of the aerosol occurs at a higher rate then the lung particle clearance rate. This suggests the physical size of aerosol particles can play a major role in inducing disease. On the other hand, the organic mutagenic fraction of DEP, which is the fraction that can cause mutations and lead to cancer, seems to be involved in aggravating bacteria infections in rats $(9,10,11)$. 
The best exposure system for animals is a whole body inhalation exposure system. This is also a difficult and potentially costly type of exposure system. Other methods of exposure include exposing cells in vitro and although important information can be obtained this way, certain cell to cell interactions which would occur in the animal are changed. Intra-tracheal instillation of aerosols is another method that is easier than whole body inhalation, but the amount and regional deposition of aerosol throughout the lungs is different than that following a whole body exposure.

A whole body inhalation system needs many components to work properly. The animal housing chamber must be capable of maintaining a uniform dispersion of the aerosol. The aerosol generating instruments must be capable of generating an aerosol of the size required and also must be capable of maintaining a relatively constant mass concentration of the aerosol in the chamber. The instruments selected for monitoring the mass concentration must have sufficient accuracy and be capable of long term monitoring. The instruments selected for monitoring the particle size distribution must be capable of accurately monitoring the aerosol, in particular, the size distribution analyzing instruments must cover the entire size range of the aerosol. The inhalation chamber must be kept close to 70 degrees Fahrenheit and 50\% humidity. The rats must not be overly agitated, for example by excessive noise, throughout the inhalation study.

Hazleton 2000 chambers, which are used by many inhalation toxicology institutes, were used for housing the rats. These chambers are part of the $500 \mathrm{sq} . \mathrm{ft}$ facility that was constructed in 1983 as part of a Generic Center established by the U. S. Bureau of Mines. Multidisciplinary projects have been conducted at this facility among researchers from Penn State University, West Virginia University, University of 
Minnesota, and the Hershey Medical Center from 1983 unt il 1997, when the Bureau of Mines was re-organized. In 1998, the facility received funding from NIOSH to participate in a study of asphalt fume inhalation. Presently, the facility is being modified as part of a three year study funded by the National, Heart, Lung, and Blood institute of the National Institute of Health.

In this study the rat exposure area was modified to reduce the amount of dust used as it is anticipated that collecting sufficient DEP could be costly. As of October 2002, NIST SRM 1650a Heavy Duty DEP cost 1000 dollars a gram and NIST SRM 2975 industrial forklift DEP is 216 dollars a gram. Directly collecting DEP from a diesel engine might also prove expensive and directly running diesel exhaust fumes and diesel exhaust particulate into the inhalation chamber from a diesel engine is beyond the scope of this research. 


\section{Objectives}

The principle objective of this research is to modify and characterize the existing whole body Small Animal Inhalation Testing Facility at West Virginia University. This will be accomplished in order to investigate the effects of NIST SRM 2975 industrial forklift diesel exhaust particulate and Elftex-12 carbon black on the development of chronic lung diseases in animal models.

The objective is divided into two parts:

1. modifying the facility physically to reduce the amount of dust, and

2. selecting, applying, and evaluating the instrumentation in order to expose animals to ultrafine diesel exhaust particulate and carbon black aerosol at a mass median diameter of $0.5 \mu \mathrm{m}$ or less and at a relatively constant mass concentration of up to $10 \mathrm{mg} / \mathrm{m}^{3}, 4 \mathrm{hr} /$ day, 5 days / wk for up to 4 weeks. 


\section{Review of Literature}

\subsection{Rat Lung Deposition with Relation to Particle Size}

The fractional deposition of an aerosol is the fraction of aerosol particles which are inhaled into the lungs and become deposited. This fractional deposition of aerosol particles differs from specie to specie. When generating an aerosol, it is useful to have knowledge of the fractional deposition of particles in the rat lung. Obtaining a high fractional deposition rate will conserve the material to be aerosolized.

It may be most desirable to generate a DEP or CB aerosol of the same size distribution that is generally emitted from diesel engines. With current engine technology, such an aerosol will generally have a mass median diameter of $0.1 \mu \mathrm{m}$ or less and has not been simulated by mechanical means as of this time.

Table 1 indicates the percentage of regional deposition in the nose, oesophagus, stomach, and lung in a study by Dahlback and Eirefelt (12). In this study, Male Sprague Dawley rats were exposed by nose only inhalation to nebulized monodisperse fluorescent polystyrene latex microspheres.

\begin{tabular}{|c|c|c|c|c|}
\hline Particle size & Nose & Oesophagus & Stomach & Lung \\
\hline (um) & $\%$ & $\%$ & $\%$ & $\%$ \\
\hline 0.63 & 3 & 12 & 68 & 17 \\
\hline 1.09 & 9 & 14 & 64 & 13 \\
\hline 1.16 & 23 & 14 & 37 & 26 \\
\hline 1.91 & 25 & 5 & 60 & 10 \\
\hline 3.41 & 11 & 1 & 86 & 2 \\
\hline 4.3 & 10 & 0 & 90 & 0 \\
\hline 5.7 & 0 & 0 & 100 & 0 \\
\hline
\end{tabular}

Table 1. Deposition of monodisperse particles in the nose, oesophagus, stomach, and lung of rats. 
The percentage of deposition in the lungs versus the stomach, nose, and oesophagus was determined by dissection immediately after exposure. The best particle size for deposition in the rat lung was found to be between $0.63 \mu \mathrm{m}$ and $1.16 \mu \mathrm{m}$ in particle diameter.

In a study by Raabe, et al., (13) Fischer 344 rats were exposed nose only to monodisperse ${ }^{169} \mathrm{Yb}$ aluminosilicate aerosols of $0.29,1.03,3.11,4.26,6.15$ and $10.16 \mu \mathrm{m}$ in diameter. The regional deposition percentages were determined through dissection. Table 2 below indicates that the best particle size for deposition in the lungs was from $0.29 \mu \mathrm{m}$ to $1.03 \mu \mathrm{m}$.

\begin{tabular}{|c|c|c|c|c|c|c|}
\hline $\mathrm{D}_{\mathrm{ar}}$ & Lung & Trachea & Larnyx & Skull & G. I. & Total \\
\hline$? \mathrm{~m}$ & $\%$ & $\%$ & $\%$ & $\%$ & $\%$ & $\%$ \\
\hline 0.29 & $21.4 \pm 0.8$ & $0.3 \pm 0.03$ & $0.8 \pm 0.1$ & $2.7 \pm 0.3$ & $1.4 \pm 1.0$ & $26.6 \pm 0.36$ \\
\hline 1.02 & $11.3 \pm 0.4$ & $0.14 \pm 0.03$ & $0.5 \pm 0.1$ & $2.9 \pm 0.4$ & $4.0 \pm 0.6$ & $18.9 \pm 1.91$ \\
\hline 1.03 & $19.2 \pm 0.5$ & $0.14 \pm 0.02$ & $1.3 \pm 0.3$ & $1.1 \pm 0.2$ & $7.6 \pm 1.6$ & $29.4 \pm 1.9$ \\
\hline 3.11 & $10.5 \pm 0.8$ & $0.50 \pm 0.08$ & $1.3 \pm 0.3$ & $4.0 \pm 0.9$ & $82.5 \pm 2.3$ & $98.8 \pm 0.89$ \\
\hline 4.26 & $16.5 \pm 3.1$ & $3.3 \pm 2.3$ & $8.9 \pm 1.6$ & $31.0 \pm 5.4$ & $40.4 \pm 7.0$ & 100 \\
\hline 6.15 & $1.2 \pm 0.11$ & $0.21 \pm 0.08$ & $2.4 \pm 0.89$ & $25.6 \pm 4.7$ & $70.6 \pm 5.3$ & 100 \\
\hline 10.16 & $0.99 \pm 0.43$ & $0.63 \pm 0.37$ & $4.3 \pm 1.11$ & $83.7 \pm 7.7$ & $10.4 \pm 8.1$ & 100 \\
\hline
\end{tabular}

Table 2. Mean Deposition percentages and observed standard errors of inhaled monodisperse ${ }^{169} \mathrm{Yb}$ aluminosilicate aerosols in Fischer 344 rats.

These two tables indicate that the highest and most efficient lung deposition fraction occurs at or below a particle diameter of $1 \mu \mathrm{m}$. It should be noted that it cannot be assumed that even smaller particles will have even greater lung fractional depositions. At some point below $1 \mu \mathrm{m}$ in particle diameter the fractional deposition may begin to decrease. This is because the vast majority of particles deposit by three mechanisms: 
sedimentation, impaction, and diffusion. Sedimentation is the effect of gravity on the particle. Impaction is the effect of inertia. Diffusion is the effect of Brownian motion causing the particle to "wander" from its gas streamline. The primary deposition mechanisms for particles above 1 micrometer are sedimentation and impaction. As particles decrease below one micrometer in aerodynamic diameter, they are affected less and less by gravity and inertia. This means that less fractional deposition might occur. At approximately $0.4 \mu \mathrm{m}$ in diameter and less, the mechanism of diffusion begins to take over and fractional deposition increases again (14).

This leads to the conclusion that the optimum mass median diameter for obtaining a high fractional deposition of the aerosol should be $1 \mu \mathrm{m}$ or less. If possible, less than $0.1 \mu \mathrm{m}$ would be preferable in that this would more closely simulate the particle size of DEP as directly emitted from an engine.

\subsection{Inhalation studies using diesel exhaust particulate and carbon black}

It is planned to expose rats to NIST SRM 2975 industrial forklift diesel exhaust

particulate (DEP) and Elftex-12 carbon black (CB) at mass concentrations of $10 \mathrm{mg} / \mathrm{m}^{3}$. The two main medical effects from this are the effects caused by the organic residue on the DEP and also the effects the physical size of the particles within the lungs may cause.

Concerning the effects of the organic residue, Yang, et al., (9) found that in vitro DEP and/or its organic extracts may play a role in increasing the susceptibility to pulmonary infection. 
Yang, et al., (10) found that when rats received a single intratracheal dose of DEP, $\mathrm{CB}$, or saline, exposure to $\mathrm{DEP}$ but not $\mathrm{CB}$ increased the susceptibility of rats to Listeria lung infections.

Al Humadi, et al., (11) found that DEP and CB exposed rats exhibited an aggravated allergic response to ovalbumin exposure. In particular the carbonaceous particle alone induces an adjuvant effect on allergic asthma while the organic component of DEP may also contribute to further aggravating the disease.

The physical size of particles in a sufficiently high concentration can also cause detrimental health effects. In past inhalation studies rats have been exposed to $\mathrm{DEP}, \mathrm{CB}$, and other substances at levels which have caused lung overload. Lung overload occurs in rats when the rate at which particles are cleared from the lungs is less than the rate at which particles are being deposited in the lungs (15). When this occurs, the particle clearance mechanism becomes "overloaded" and the rats begin experiencing inflammation and increased lung loads that can ultimately lead to lung tumors. Other rodent species have not been studied as extensively as the rat, but available data suggest that mice and Syrian hamsters are not as susceptible as rats to lung overload. Humans and other species such as dogs and monkeys seem to be even less susceptible to lung overload (16).

An interesting finding is that even though DEP may have approximately 50 to 100 times as much mutagenic material as $\mathrm{CB}$, they can both cause similar levels of inflammation eventually leading to lung tumors in rats $(6,8)$. But it is has also been discovered that DEP can additionally cause aggravation of bacterial infections that $\mathrm{CB}$ does not cause. 
As it is planned to expose rats to high enough concentrations to cause lung overload so that this effect can be studied more closely, (along with studying the increased susceptibility to infection effect), it is necessary to review past lung overload studies to determine the aerosol mass concentration needed to cause lung overload in rats for a short term study.

Nikula, et al., (6) reported that F344 rats were chronically exposed to diluted whole DE or aerosolized CB for $16 \mathrm{hr} /$ day, 5 day / week at $2.5 \mathrm{mg} / \mathrm{m}^{3}$ and $6.5 \mathrm{mg} / \mathrm{m}^{3}$ for 2 years at a MMD of $0.54 \mu \mathrm{m}$ for the DEP and $1.34 \mu \mathrm{m}$ for the CB aerosol. DE and CB caused similar dose related nonneoplastic lesions. DE and CB caused increases of similar magnitudes in the incidences and prevalences of the same types of malignant and benign lung neoplasms in female rats. (The incidence of tumors was much lower in males, but survival was shortened in males and they may have simply died before they could develop tumors.)

Creutzenberg, et al., (7) found the same lung overload condition occurring as a result of diesel exhaust particulate at a mass median diameter (MMD) of $0.25 \mu \mathrm{m}, \mathrm{TiO} 2$ at $0.8 \mu \mathrm{m}$, and carbon black at $0.64 \mu \mathrm{m}$. The concentrations of DEP was $7.5 \mathrm{mg} / \mathrm{m}^{3}$ throughout the study. For the first eight months, $15 \mathrm{mg}$ of $\mathrm{TiO} 2$ was used, then $10 \mathrm{mg}$ for the last 16 months. For the first 4 months, $7.5 \mathrm{mg}$ of $\mathrm{CB}$ was used, then $12 \mathrm{mg}$ for the remaining 20 months. This was with 19 hours a day exposure, 5 days a week for 24 months total. 


\subsection{Modifying the Hazleton 2000 Chambers}

Because of the high cost of obtaining some types of DEP such as NIST Standard Reference Material 1650a, which as of October 2002 cost \$1000 / gram and SRM 2975, which costs $\$ 216$ dollars / gram, the first objective of this study is to the modify the Hazleton 2000 chambers to reduce the amount of dust used.

The inhalation chambers have 6 sections designed so that the aerosol will flow uniformly throughout all six. But below a certain minimum flowrate depending upon the aerosol size, the aerosol will not flow uniformly throughout the 6 sections of the inhalation chambers.

In determining the uniformity of the aerosol when using the entire chamber, Moss, et al., (17) measured the concentration of aerosol in the center of the space above each of the six catch pans in the Hazleton chamber. Using a flow rate of 10 CFM (283 LPM, or 10 air changes per hour in $2 \mathrm{~m}^{3}$ chamber) and an aerosol with mass median aerodynamic diameter of $0.8 \mu \mathrm{m}$ and a geometric standard deviation of 2.2, (which is a measure of the uniformity of the aerosol particle size,) there was uniform mixing of air throughout the chamber. In 5 experiments the aerosol concentration throughout the Hazleton chamber sections varied by $8.5 \%, 14.1 \%, 9.9 \%, 7.5 \%$ and $5.8 \%$.

Pisano, et al., (18) found that in order to obtain an even concentration and size distribution for particles greater than $5 \mu \mathrm{m}$, a flow rate of 30 to 40 CFM was necessary.

The uniformity of aerosol dispersion has not been tested when the Hazleton chamber has been altered in the manner that it will be altered in this research. 


\subsection{Equipment and Instrumentation}

The second objective of this study is to choose equipment and instrumentation to expose the rats to DEP and CB. A TSI fluidized bed and a Fluid Energy jet mill were to be investigated for aerosolizing the carbon black powder. The jet mill is a Jet-O-Mizer sometimes referred to as a torus or doughnut mill. A Tapered Element Oscillating Microbalance (TEOM) will be considered for monitoring the aerosol mass concentration. A Cascade Impactor / Parallel Flow Diffusion Battery and a Micro Orifice Uniform Deposit Impactor (MOUDI) will investigate the size distribution and mass median diameter of the aerosol. For determining the uniformity of the dispersion of the aerosol, Marple Personal Cascade Impactors will be compared to the MOUDI, TEOM, and Multijet Cascade Impactor / Parallel Flow Diffusion Battery.

\subsubsection{Aerosol Generation}

For generating a fine aerosol from dry powders such as carbon black or collected diesel exhaust particulate, Hinds (14) reported that the most common method of dry dispersion of dust is using a high velocity airstream. Fluidized beds are also used. The most common method for feeding powder to be aerosolized is the Wright dust feeder which slowly scraps off a constant amount of dust from a packed cylinder. The device works best for materials such as silica, uranium dioxide or other mineral dusts. It has been found unsatisfactory for soft sticky dusts such as coal and carbon black.

Mauderly, et al., (8) aerosolized carbon black (Elftex-12, Cabot, Boston, MA) in a carbon black versus diesel exhaust rat lung overload inhalation study using air jet dust generators (Jet-O-Mizer Model 0101, Fluid Energy, Hatfield, PA). The resulting mass 
median diameter of the carbon black was $1.34 \mu \mathrm{m}$. These air jet dust generators are usually referred to as jet mills and are an example of a high velocity airstream.

A Jet-O-Mizer was used for generating the aerosols in this research. The Jet-OMizer jet mill is sometimes also referred to as a torus mill or a doughnut mill. Inside the hollow oval of this mill, particles pass in front of two grinding jet nozzles. These nozzles produce a high velocity gas that accelerates the particles into violent collisions that reduce the size of the particles. Particles whose mass and inertia have been reduced enough will make a sharp turn and exit the jet mill while larger particles will continue to be grinded.

A third nozzle which is called a "pusher" nozzle ensures that the material is efficiently fed into the jet mill.

\subsubsection{Tapered Element Oscillating Microbalance (TEOM)}

The Tapered Element Oscillating Microbalance (TEOM) Series 1400a was evaluated to measure the real time mass concentration of aerosol in the chamber. The TEOM works by pulling a constant flowrate across a high efficiency filter that is attached to an oscillating beam. As the filter gains weight, the oscillations of the beam slow. The decrease in oscillation frequency is related to aerosol mass concentration.

Patashnick and Rupprecht (19) reported that the TEOM ambient particulate monitor was compared to the Sierra-Anderson dichotomous PM-10 sampler and the Wedding high volume PM-10 sampler. The correlation results were well within the U.S. EPA requirements for certification as an equivalent method. 
Meyer, et al., (20) operated two TEOMs, one with the measurement stage heated to 50 degrees and the other heated to 30 degrees Celcius and compared these to a HiVol PM10. The conclusion was that partial volatilization of semi- volatile aerosol components was caused by the sample heating employed in the TEOMs.

Allen, et al., (21) found more comprehensive results from 10 urban sites across the US and Mexico, that in urban areas a substantial fraction of ambient PM can be semivolatile material. A larger fraction of this component of PM10 may be lost from the TEOM-heated filter than by a gravimetric weighing of a high efficiency filter.

Soutar (22) found that although the TEOM is an internationally accepted method for measuring mass concentrations at fixed locations, it consistently measured a lower concentration than that found with gravimetric weighing. (Approximately 50 percent lower.)

Ayers, et al., (23) compared the TEOM to mass concentration found gravimetrically from a MOUDI and Solar-Vol. Despite the fact that the TEOM has achieved US EPA "Equivalent method" status for PM 10 measurements (EPA, 1990; Chow, 1995) and has been demonstrated to meet German regulatory performance requirements for total suspended particulate, they found that the TEOM systematically measured more than $30 \%$ percent lower mass concentrations. And that these lower measurements are probably explained by the heated filter stage in the TEOM. This heated filter stage is designed to reduce the changes in the instruments response due to temperature fluctuations and also to volatize water from the aerosols being sampled. This heated filter stage seems to also volatize semi-volatile material from aerosols. 


\subsubsection{Parallel Flow Diffusion Battery (PFDB)}

The Parallel Flow Diffusion Battery (PFDB) works by pulling a constant flowrate across stainless steel mesh screens. Depending upon the fraction of aerosol that either deposits by diffusion in the mesh or penetrates through the mesh to deposit in a high efficiency filter, the size distribution and mass median diameter of the aerosol can be computed (within the size range where particle's deposition mechanics are controlled by diffusion).

The fractional penetration for an aerosol passing through a series of diffusion battery screens is given by Cheng, et al., (24).

$$
\log \mathrm{P}=-\mathrm{nm}
$$

where $\mathrm{P}$ in the penetration fraction, $\mathrm{n}$ is the number of screens and $\mathrm{m}$ is the slope of the penetration curve vs. particle diameter.

The slope $\mathrm{m}$ is given by the following equation:

$$
\mathrm{m}=\left(\mathrm{AoPe}^{\wedge} 2 / 3+\mathrm{A} 1 \mathrm{R}^{\wedge} 2+\mathrm{A} 2 \mathrm{Pe}^{\wedge}-0.5^{*} \mathrm{R}^{\wedge}-2 / 3\right)
$$

where $\mathrm{A} 0, \mathrm{~A} 1$ and $\mathrm{A} 2$ are constants based on the screen characteristics. $\mathrm{R}=\mathrm{dp} / \mathrm{df}$ is the interception parameter, where $\mathrm{dp}$ is the particle diameter and $\mathrm{df}$ is the screen diameter and Pe is Peclet number,

$$
\mathrm{Pe}=\mathrm{Udf} / \mathrm{D}
$$

where $\mathrm{U}$ is the superficial velocity, which is the velocity before the air traverses the diffusion screen, and D is the diffusion coefficient. 
Barr, et al., (25) compared a PFDB with a TSI model 3040 diffusion battery and found good agreement between the two. In measuring submicrometer aerosols of $\mathrm{CsCl}$ tagged with uranium, the geometric mean diameter measured by the PFDB was $0.15 \mu \mathrm{m}$ with geometric standard deviation of 2.2 while the TSI/DB was 0.13 with a GSD of 2.3.

Mauderly, et al., (4) used a Multi-jet Cascade Impactor and Parallel Flow Diffusion Battery for finding the size distribution of aerosolized carbon black in a rat inhalation study. In that study the health effects of carbon black were being compared to those of diesel exhaust. As diesel exhaust was considered to have a bimodal size distribution, the carbon black was also divided into a bimodal size distribution with a fraction occurring in both the impactor and diffusion battery. In this study the average mass median aerodynamic diameter of the carbon black particles depositing in the impactor was $1.95 \mu \mathrm{m}$. The mass median diffusive diameter of the fraction deposited in the PFDB was $0.1 \mu \mathrm{m}$. Approximately $67 \%$ of the total mass was collected in the larger mode. Unfortunately no actual aerosol size distribution was given. Combining the two size fractions results in a mass median diameter of $1.34 \mu \mathrm{m}$. This study is of much significance considering that the same general approach considered by Mauderly will be used for aerosolizing carbon black in this research.

There is a very substantial body of research concerning reducing the data in order to find the actual size distribution from a diffusion battery. The primary problems are that the equations for reducing the data are ill-posed and non-linear. They are ill-posed in that small errors, occurring either from the gravimetric analysis or many other possible sources, can result in very large errors in the resulting size distribution. 
For instance with the PFDB there are six stages, if this is simply reduced to six equations with six unknowns, (where the coefficients are based on the fractional penetration or diffusion characteristics of the six particle sizes that are arbitrarily picked, and the six unknowns are the concentrations of each particle size), the resulting particle size concentrations will be highly oscillatory with some high negative values. Also the equations are non- linear because depending upon the particle sizes picked, there can be an infinite number of solutions.

\subsubsection{Micro Orifice Uniform Deposit Impactor (MOUDI)}

The MOUDI, which is a type of cascade impactor, is one of the most common and reliable instruments used in finding aerosol size distributions. Impactors classify particles by their inertia. Marple (26) showed that a particle in a gas streamline will hit a body if the stokes number is greater than 1 for the following equation:

$$
\mathrm{Stk}={ }_{\mathrm{p}} \mathrm{C}_{\mathrm{cdp}} \wedge 2 \mathrm{U} / 18 ? \mathrm{db}
$$

where ? $\mathrm{p}$ is the density of the particle, $\mathrm{C}_{\mathrm{c}}$ is the slip correction factor, $\mathrm{d}_{\mathrm{p}}$ is the particle diameter, $\mathrm{U}$ is the relative velocity of the body to the air, ? is the viscosity of air, and $\mathrm{db}$ is the diameter of the of the body.

On this basis, impactors find the size distribution of aerosols by inertial classification. The particle cut-point size for each successive stage of an impactor comes from the equation:

$$
\mathrm{d} 50=\left(9 ? \mathrm{~W} / ? \mathrm{p} \mathrm{C}_{\mathrm{c}} \mathrm{U}\right)^{\wedge} 0.5(\mathrm{Stk})^{\wedge} 0.5
$$

where $\mathrm{W}$ is the nozzle diameter of the particular stage of the impactor and $\mathrm{d} 50$ is the particle diameter $50 \%$ cutpoint. 
In order for an impactor to measure particles as low as $0.05 \mu \mathrm{m}$ in aerodynamic diameter, either the pressure must be reduced to increase the value of the slip correction factor or the nozzle diameters must be reduced to "micro-orifices." These orifices must be cut with lasers which greatly increases the expense of the impactor.

The MOUDI utilizes micro-orifices and in addition every other stage of the MOUDI rotates causing uniform deposits of particulate upon each impaction stage. This reduces particle bounce which can occur when too much particulate impacts upon a stage. 


\section{Procedures}

\subsection{Procedures to Modify the Inhalation Chamber}

\subsubsection{Inhalation System Schematic}

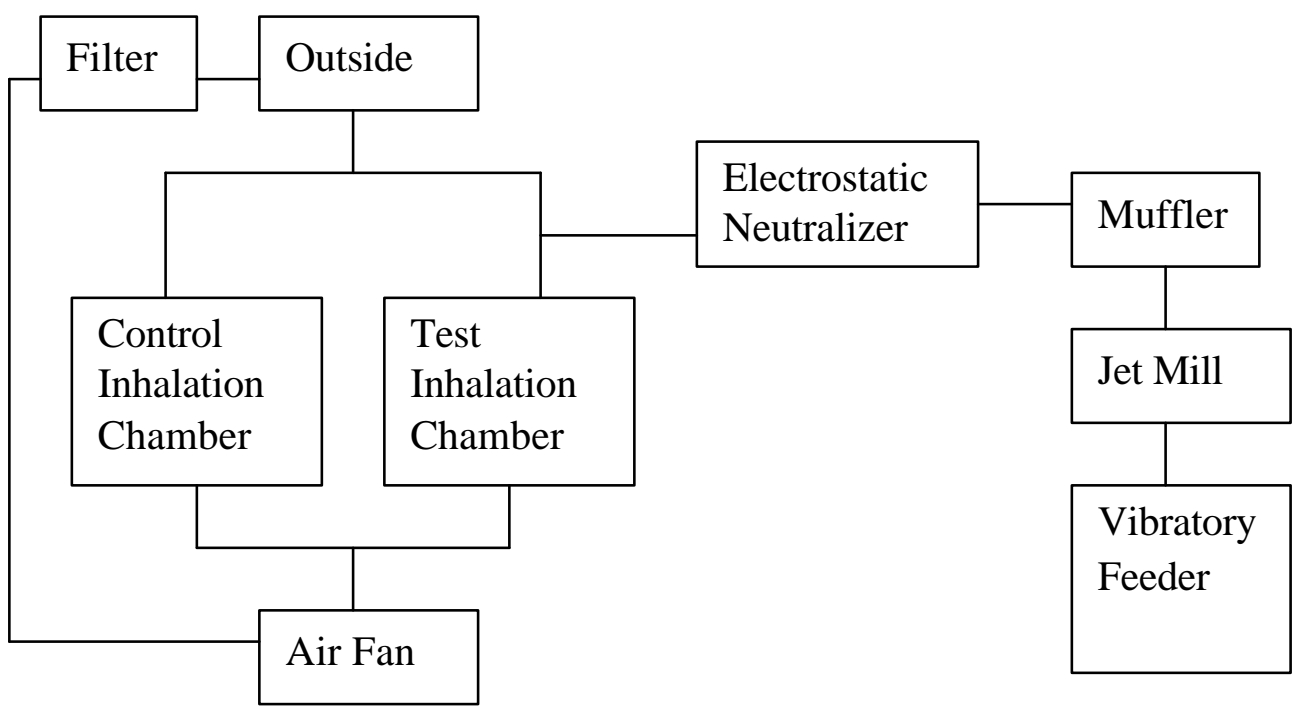

Figure 1. Inhalation system schematic.

Figure 1 indicates the basic schematic of the inhalation system with an air fan pulling air from outside the laboratory into the control and test inhalation chambers. The air is then leaves the chambers, passes through the air fan, through a high efficiency filter and back outside. Meanwhile, the vibratory feeder sends the material to be aerosolized to the jet mill. The aerosolized material then passes through a car muffler to reduce the noise produced by the jet mill. The aerosol then passes through an electrostatic neutralizer to remove any static charge that could cause particles to aggregate and increase the coarseness of the aerosol. The instrumentation for characterizing the aerosol is placed inside the chambers. 


\subsubsection{Modifying an Inhalation Chamber to Reduce DEP and CB used.}

The Hazleton 2000 inhalation cha mber has a volume of $2.1 \mathrm{~m}^{3}$. It was desired to reduce the amount of $\mathrm{DEP}$ or $\mathrm{CB}$ powder used relative to the air changes per hour through the chamber. This was accomplished by putting a stainless steel partition for dividing the chamber in two at the top portion of the chamber. This should keep the aerosol more concentrated in the first section as labeled in Figure 2 where the aerosol will first enter the chamber. This partitio ned section had a volume of $0.45 \mathrm{~m}^{3}$.

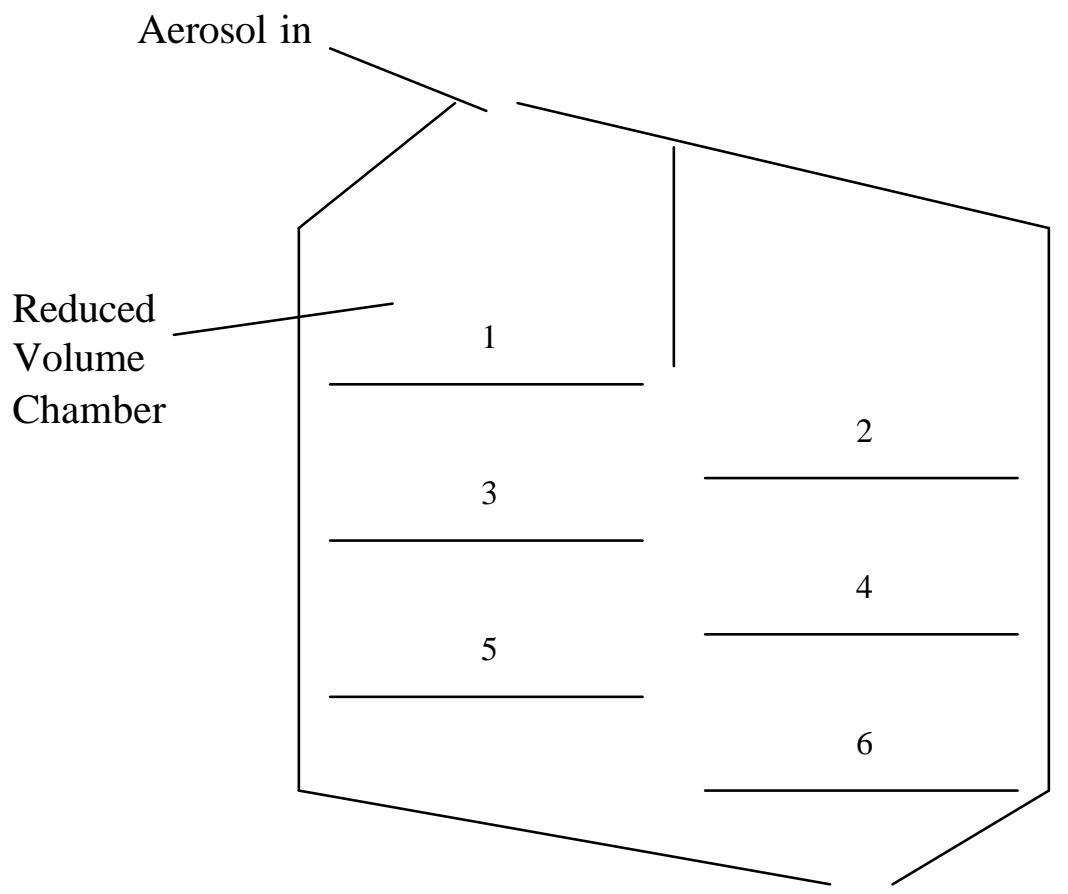

Figure 2. Side view of Hazleton 2000 inhalation chamber.

There are 6 sections to the Hazleton chamber. Each section can hold one cage that can house 24 rats. For this experiment only section 1 was used and it was partitioned off in order to conserve materials. It is hoped that the partition may interrupt the flow of air and impede a uniform mixing of the aerosol throughout the entire chamber and will 
instead keep a relatively higher concentration of aerosol in the reduced volume chamber. The flow rate through the chamber was reduced from the 283 LPM at which Moss et al., (17) found uniform mixing of a $0.8 \mathrm{MMD}$ aerosol, down to approximately 60 LPM. With this reduction in volume of the chamber, the reduced flow rate still results in 10 air changes per hour as was used previously by Moss.

\subsubsection{Marple 290 Personal Cascade Impactors}

Three Marple impactors were used to determine the uniformity of the aerosol inside the chamber and to check the accuracy of the TEOM.

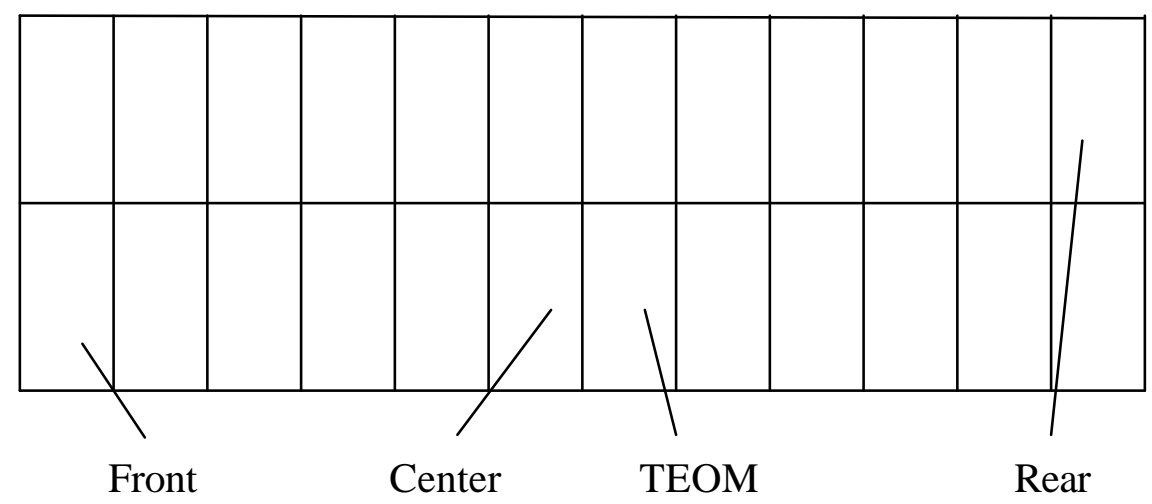

Figure 3. Overhead view of the 24 cage reduced volume chamber showing placement of Marple impactors and the position of all aerosol inlets that are labeled front, center, or rear.

The Marple impactors were placed at the front, center, and rear area of the reduced volume chamber.

Normally the Marple personal impactor is an 8 stage impactor with a final filter. For finding the uniformity of the aerosol the impactor stages were removed from the 
impactor and only the final filter was left in place. The flowrate through the Marple impactor was 2LPM. The final filters were $34 \mathrm{~mm}$ PVC GLA-5000. They were pre- and post conditioned for at least 8 hours. They were weighed using a Cahn 32 Microbalance. They were placed upon a polonium electrostatic neutralizer to remove any electrostatic charge that could influence the weight. The pre- and post weights were compared to preand post tare weights. If the pre- and post tares changed weight by more than 3 micrograms, the results were discarded.

\subsubsection{Aerosol Generation}

After a few preliminary tests with a TSI fluidized bed model 9310, in which the mass median diameter of carbon black was found to be above $10 \mu \mathrm{m}$ when using the maximum grinding nozzle pressure of 80 PSI, a jet mill from Fluid Energy (Model 00 Jet-O-Mizer Serial \#Z1277E) was used to aerosolize the DEP and CB powder.

The jet mill was attached to a pressurized air source which could maintain the grinding and pusher nozzle pressures at $80 \pm 5$ PSI.

The CB and DEP powders were fed into the jet mill using a Syntron Magnetic vibratory feeder, Model F-30-C, Serial No. GPMF58288. There is some difficulty in obtaining a constant concentration using a vibratory feeder with CB or DEP powder. Unlike ordinary sand for example, these CB and DEP particles will easily stick or clump together. Once they clump together they are much less likely to be moved by the vibratory feeder. As the magnitude of the vibrations of the vibratory feeder increase, the larger aggregates of particles will make a sudden transition from stationary to an undesirably high feed rate, therefore it is necessary to stop the particles from clumping 
together. This was accomplished by straining the powder through a wire mesh screen followed by passing the powder through a small orifice approximately 1 millimeter in diameter.

It was hoped that using this method the carbon black could be kept at a constant concentration when aiming for a mass concentration of $10 \mathrm{mg} / \mathrm{m}^{3}$ with as low as 10 air changes per hour through the reduced volume chamber. This equals a carbon powder feed rate of approximately $0.35 \mu \mathrm{g} /$ second, which is an extremely small amount. But instead of attempting to measure the feed rates in the experiments it was decided to monitor the aerosol mass concentration which should be approximately proportional to whatever the feed rate might be, assuming the air changes per hour flow rate is kept constant.

After the aerosolized DEP and carbon black leave the jet mill, they are passed through an electrostatic neutralizer. This should neutralize any electrostaticity that could cause the CB or DEP aerosol particles to aggregate together. This aggregation of particles is undesirable once again because it could increase the size of the aerosol to a point where it no longer has a sufficient fractional deposition into the lungs of a rat.

\subsubsection{Aerosol Size Distribution}

The size distribution of the aerosol was to be found using the Cascade Impactor/Parallel Flow Diffusion Battery (CI/PFDB) and the Micro Orifice Uniform Deposit Impactor (MOUDI).

The various feed rates and grinding nozzle pressures of the jet mill may change the size distribution of the aerosolized powder. While keeping the grinding nozzle 
pressures relatively constant (they will vary plus or minus 5 PSI) at 80 PSI, the size distribution was obtained at feed rates that produced various mass concentrations. The feed rates used to produce these concentrations can be somewhat variable due to limitations in the precision of the vibratory feeder and the fact that all of these feed rates are extremely fine relative to what the jet mill is capable of handling. The size distribution of carbon black was found using a MOUDI while the vibratory feed rate was run at rates producing mass concentrations ranging from $27 \mathrm{mg} / \mathrm{m}^{3}$ to $7 \mathrm{mg} / \mathrm{m}^{3}$. The mass concentration was taken to such high values beyond the $10 \mathrm{mg} / \mathrm{m}^{3}$ which is planned to be used eventually for exposing rats, in order to investigate how changing the feed rate could result in a change in aerosol size distribution.

The effect of grinding nozzle pressure on size distribution was also examined. Grinding nozzle pressures of 80 PSI and 40 PSI were investigated. The pressures were chosen because 80 PSI is the highest pressure that can currently be supplied at this facility. 40 PSI was chosen as a dramatically lower pressure that should hopefully result in a larger aerosol mass median diameter.

To calculate the size distribution using the MOUDI's, each impaction substrate was weighed in order to produce histograms. Size distribution curves were then fitted to these histograms. The mass median diameter, geometric standard deviation, and number of modes were calculated from these resulting curves using a excel spreadsheet program. The histograms with fitted curves appear in Appendix A. 


\subsection{Procedures to Select Instruments}

\subsubsection{Tapered Element Oscillation Microbalance (TEOM)}

The Tapered Element Oscillating Microbalance Series 1400a was used for real time monitoring of the mass concentration of the carbon black and DEP aerosols.

The theory behind a TEOM is that aerosol particulate is collected on a filter that is attached to an oscillating beam. As the particulate collects on the filter, the oscillations slow. The slowing of the oscillations is converted to a mass concentration.

In attempting to monitor concentrations up to $10 \mathrm{mg} / \mathrm{m}^{3}$ or higher for many hours at a time using this technique, there is a problem in that the filter can be overloaded with particulate relatively fast, (in approximately a few hours). To overcome this, the following changes were made:

1. The TEOM flow rate was reduced from 3LPM to 1LPM.

2. The TEOM was used to periodically monitor the mass concentration for 5 minutes to 10 minutes out of every hour instead of continuously.

3. The total mass averaging time and mass rate / mass concentration averaging times were reduced from 300 seconds to 16 seconds.

The manufacturers of the TEOM, Rupprecht and Patashnick, have advised that with high mass concentrations, decreasing the flow rate to increase the lifetime of the filter of the TEOM is acceptable. When using the PM-10 TEOM or PM-2.5 TEOM, changing the flow rate can change the inlet cut point of the machine but in this study no inlet cut point was used. 
For periodic monitoring of the inhalation chamber air, the TEOM control unit and sensor unit were placed outside of the inhalation chamber and a sampling line made of copper tubing with an inner diameter of $1 / 2$ inch was extended from the TEOM into the inhalation chamber. The sampling line valve was periodically switched from the laboratory air to the air of the interior of the chamber. This sampling line to the chamber consisted of 8 inches of vertical tubing, a 90 degree bend, 4 feet of horizontal tubing, and a second 90 degree bend back to the vertical direction inside the chamber. The sampling losses resulting from diffusion, horizontal sedimentation, anisoaxial, and anisokinetic sampling have been estimated in Appendix C. (Note: The sampling losses were negligible.)

The TEOM sampling inlet was placed in approximately the center of the reduced volume chamber.

The mass averaging times were reduced to increase the filter lifetime of the TEOM.

The total mass averaging time is the time over which the data points are smoothed to compute the total mass. The mass rate / mass concentration averaging time is the time over which the data between successive total mass data points are averaged together to compute mass concentration. The time for both is 300 seconds. This means that when switching the TEOM from the laboratory air to inhalation air, the TEOM would be averaging the two different atmospheres together for 300 seconds. With this averaging time, 5 minutes of TEOM filter lifetime would be lost for each periodic measurement of the inhalation chamber air. By changing the mass averaging time to 16 seconds, 
approximately 4 minutes 44 seconds of filter lifetime was saved with every periodic measurement.

With a 16 second averaging time, the TEOM will have a degree of oscillation in its measuring of the mass concentration. The degree of these oscillations was investigated by achieving approximately a $10 \mathrm{mg} / \mathrm{m}^{3}$ chamber aerosol mass concentration. The vibratory feeder was then turned off so that there should not be any actual fluctuation in the chamber aerosol concentration beyond a gradual decrease in the concentration. This fluctuation was then visually recorded by monitoring the aerosol mass concentration every 60 seconds.

The accuracy of the TEOM was also compared to the standard gravimetric method of the Marple personal impactors.

\subsubsection{Micro Orifice Uniform Deposit Impactor (MOUDI)}

The 8 stage MOUDI model 110 and 10 stage MOUDI model 110 was used in finding the size distribution for the aerosolized carbon black in this study. The impactor cutpoints for the model 1108 stage are: 18, 6.1, 3.1, 1.8, 1.0, 0.56, 0.30, 0.15, $0.56 \mu \mathrm{m}$, and a high efficiency final filter (PTFE Membrane R2PJ037). For the 10 stage MOUDI, the cutpoints are $18,10,5.6,3.2,1.8,1,0.56,0.32,0.18,0.1,0.056 \mu \mathrm{m}$ and a high efficiency final filter.

The pressure throughout the MOUDI was monitored during every run to ensure there were no leaks present nor were any of the micro orifices blocked by collected particulate. 
Each stage of the MOUDI consists of orifices that the aerosol passes through followed by an impaction plate. Upon the impaction plates were $47 \mathrm{~mm}$ impaction substrates made of aluminum foil. They were sprayed with silicone grease to decrease particle bounce. They were heated to $65 \pm 15$ degrees Celsius for 90 minutes and then preconditioned and post conditioned for at least 8 hours at $21 \pm 3$ degrees Celsius and 50 $\pm 5 \%$ humidity. They were weighed using a Cahn 32 Microbalance using a resolution of

$1 \mu \mathrm{g}$. The substrates and final filter were passed over a polonium electrostatic neutralizer before pre- and post weighing. This radioactive source removed any electrostatic charge that could affect the weight of the substrates or filters.

The TEOM was always run while the MOUDI was run and the MOUDI was placed inside the inhalation chamber at the front, middle or rear of the reduced volume chamber. The MOUDI, which is a long cylinder about half a meter tall, was placed directly underneath holes that were cut into the catch tray of the reduced volume chamber. In this way the inlet of the MOUDI was parallel with the very bottom of the reduced volume chamber. The duration of time the MOUDI was run was recorded in order to gravimetrically find the mass concentration while the average mass concentration of the TEOM was visually recorded.

\subsubsection{Parallel Flow Diffusion Battery with Cascade Impactor}

The purpose of the Parallel Flow Diffusion Battery (PFDB) with Cascade Impactor is to measure the size distribution of an aerosol from $13.5 \mu \mathrm{m}$ down to approximately $0.01 \mu \mathrm{m}$. The impactor had cutpoints of 13.5, 8.49, 5.34, 3.36, 2.11, 1.33, $0.83 \mu \mathrm{m}$. Partic les smaller than $0.83 \mu \mathrm{m}$ will then enter into the PFDB. 
The flow rate through the Cascade Impactor and Parallel Flow Diffusion Battery should be 14 LPM at which point choked flow should be produced but it was found using a bubble meter that choked flow actually occurred at 17 LPM.

The mesh size for the stainless steel screens was 200 count / inch and 145 count / inch. The aerosol passes through these screens while a fraction of the aerosol deposits by diffusion onto the screens. The aerosol that penetrates through the screens deposits onto a high efficiency filter. The filters are analyzed gravimetrically to determine the size distribution of the aerosol.

In between runs, a flow meter is placed before the impactor while a pressure gage monitors the degree of partial vacuum after the PFDB. Choked flow and the flow rate of PFDB are then verified. The flow meter used was a bubble flowmeter (Model No. VA22439 150mm flowmeter stainless steel frame, glass float, Serial No. 124088-34.)

In between every run the mesh screens were washed using a Bransonic 200 ultrasonic cleaner. They were washed for 30 minutes using warm water and soap, and then rinsed repeatedly by using the ultrasonic cleaner and distilled water.

For collecting the aerosol in the PFDB, $25 \mathrm{~mm}$ PVC filters were used. These filters were pre and post conditioned for 8 or more hours at $21 \pm 2.8$ degrees Celsius and $50 \pm 5 \%$ humidity. They were placed above a polonium electrostatic neutralizer before weighing. If the tare weights indicated a change in weight of greater than $3 \mu \mathrm{g}$, the results were discarded.

The nozzles for producing choked flow were inspected for blockages in between runs. During runs the pressure across the reference filter was measured and the PFDB was always turned off before a $20 \%$ increase in back pressure. 


\subsubsection{Humidity, Temperature, and Noise Level}

The standard for humidity and temperature for rats in inhalation studies is $50 \%$ and 21 degrees Celsius. There was no feedback system for regulating the humidity and temperature in this study but the temperature was kept within $21 \pm 4$ degrees Celsius simply by turning the air conditioner in the laboratory on or off. The humidity is designed to stay at $50 \% \pm 10 \%$ during the daily 4 hour exposure period. This humidity is controlled by a Kenmore evaporative table top cool air humidifier (Model 437.14113) that has been placed inside the inhalation chamber but on the opposite side of the reduced volume chamber. This humid air flows into the reduced volume chamber through a stainless steel pipe connecting the humidifier to the reduced volume chamber.

Rats in an inhalation study should not be exposed to excessive noise that could agitate them. Unfortunately, it was found that the jet mill could produce an unacceptable 93 decibels of noise traveling through the piping into the inhalation chamber. To muffle this noise, a Defender 8 x 13 x 3.5 inch car muffler purchased from Auto Zone was attached directly at the outle t of the Jet-O-Mizer jet mill. 


\section{Results}

\subsection{Vibratory Feeder}

Figures 4 and 5 indicate the consistency of the vibratory feeder in keeping a constant concentration. Before visually recording the concentrations, the vibratory feeder was monitored and adjusted until the TEOM reading stabilized around $10 \mathrm{mg} / \mathrm{m}^{3}$. With the start of recording the mass concentrations in figure 4 and 5 the vibratory feeder was no longer adjusted as the mass concentration varied or in other words the vibratory feeder was no longer supervised. Figure 4 is for carbon black and figure 5 is for DEP. In figure 4 the average mass concentration for the 36 minute run is $10.5 \mathrm{mg} / \mathrm{m}^{3}$. In figure 5 the average mass concentration for the 50 minute run was $11.6 \mathrm{mg} / \mathrm{m}^{3}$. The mass concentration aimed for in both runs was $10 \mathrm{mg} / \mathrm{m}^{3}$.

\subsection{TEOM Mass Concentration Fluctuation}

Figures 6 and 7 are shown here to indicate the degree of fluctuation in the TEOM when the mass averaging time was lowered to a very short 16 seconds. In both graphs the feeder was only turned on long enough to reach a mass concentration of $10 \mathrm{mg} / \mathrm{m}^{3}$, and was turned off after approximately 18 minutes in both cases. As the introduction of new aerosolized particulate into the chamber is the main factor that will cause a fluctuation in the mass concentration, when the vibratory feeder is turned off the true mass concentration in the chamber should remain relatively smooth. The degree of fluctuation as recorded from the TEOM indicates the uncertainty in the TEOM when the mass averaging time is lowered to 16 seconds. It can be seen from the time of 18 minutes 
and on in figures 6 and 7 that this fluctuation varied from a negligible amount to no more than approximately $1.5 \mathrm{mg} / \mathrm{m}^{3}$.

\subsection{Size Distribution}

Figure 8 indicates the size distribution of the carbon black aerosol when using a jet mill grinding nozzle pressure of 80 PSI. The size distribution stayed relatively constant and bimodal for mass concentrations of $13 \mathrm{mg} / \mathrm{m}^{3}$ up to $27 \mathrm{mg} / \mathrm{m}^{3}$. Only the size distribution at $7 \mathrm{mg} / \mathrm{m}^{3}$ was anomalous in that the finer mode was far less pronounced. This figure corresponds to the curved fitted histograms in Appendix A, figures 18 to 23 .

Figure 9 indicates the size distribution of the carbon black aerosol when using a grinding nozzle pressure of 40 PSI and mass concentrations of 14, 10, 9, 6.1, and $3.6 \mathrm{mg}$ / $\mathrm{m}^{3}$. This figure corresponds to the curved fitted histograms in Appendix A, figures 24 through 28 .

Figure 10 indicates the size distribution of the DEP aerosol when using a grinding nozzle pressure of 80 PSI and mass concentrations of $11,4,3.2,2.5 \mathrm{mg} / \mathrm{m}^{3}$. This figure corresponds to the figures 29 through 32 in Appendix A.

Figure 11 indicates the size distribution of the DEP aerosol when using a grinding nozzle pressure of 40 PSI and mass concentrations of 5.2, 3.5, and $2 \mathrm{mg} / \mathrm{m}^{3}$.

Table 3 indicates the mass median diame ters, and mass fraction (Coeff.) for both modes 1 and 2 of the carbon black aerosol and for the single mode of the DEP aerosol. The size distribution of the carbon black was bimodal. The DEP had only one mode in its size distribution. 
Figures 12 and 13 indicate that at both 40 and 80 psi grinding nozzle pressures there is no discernible trend towards increasing or decreasing in the total mass median diameters for the carbon black aerosol as the feed rate and subsequently the mass concentration is decreased. The one higher mass median diameter aerosol in figure 12 corresponds to the $7 \mathrm{mg} / \mathrm{m}^{3}$ mass concentration carbon black aerosol whose finer mode was absent. The two slightly higher data mass median diameter data points in figure 13 were collected while using the 8 stage MOUDI while the other data was collected using the 10 stage.

The combined mass median diameter for both modes of the carbon black aerosol did decrease from $0.78 \mu \mathrm{m}$ to $0.54 \mu \mathrm{m}$ as the grinding nozzle pressure was increased from 40 to 80 psi.

The same result is seen with the DEP aerosol where at 40 psi the average mass median diameter is $0.53 \mu \mathrm{m}$ and at 80 psi the mass median diameter decreases to 0.33 $\mu \mathrm{m}$.

\subsection{Reduced Volume Chamber}

With a grinding nozzle pressure of 40 PSI and 10 air changes per hour, figure 14 indicates the resulting mass concentration caused by $36 \mathrm{mg}$ of diesel exhaust particulate. This $36 \mathrm{mg}$ conservatively maintained a $10 \mathrm{mg} / \mathrm{m}^{3}$ concentration for 16 minutes. It was found that at 80 PSI, much more DEP was needed because this high grinding pressure caused some DEP to be blown backwards through the system into the control chamber.

The uniformity in the reduced volume chamber was tested using the Marple personal impactors. Given approximately 25 minutes for the CB aerosol to disperse 
throughout the chamber, compared to a TEOM mass concentration of $10.9 \mathrm{mg} / \mathrm{m}^{3}$ averaged over 10 tests, the mass concentration measured gravimetrically by the Marples was $9 \%$ lower $\left(9.9 \mathrm{mg} / \mathrm{m}^{3}\right)$ than the TEOM in the front part of the chamber, $4.6 \%$ less $\left(10.4 \mathrm{mg} / \mathrm{m}^{3}\right)$ in the center, and $7.4 \%$ higher $\left(11.7 \mathrm{mg} / \mathrm{m}^{3}\right)$ in the rear of the chamber.

Given approximately 5 minutes for the DEP aerosol to disperse, and compared to a mass concentration of the $2.9 \mathrm{mg} / \mathrm{m}^{3}$ measured by the TEOM over 8 tests, the mass concentration measured gravimetrically by the Marples was $22 \%$ lower $\left(2.3 \mathrm{mg} / \mathrm{m}^{3}\right)$ than the TEOM in the front part of the chamber, $1.2 \%$ higher $\left(3.0 \mathrm{mg} / \mathrm{m}^{3}\right)$ in the center, and $3.9 \%$ lower $\left(2.8 \mathrm{mg} / \mathrm{m}^{3}\right)$ in the rear of the chamber.

\subsection{Comparison of TEOM with Gravimetric Methods}

Figures 15, 16, 17, and table 4 indicate that the TEOM measured the mass concentration of the carbon black aerosol 2\% higher than the Marple impactors did using gravimetric weighing. Table 4 also indicates that the TEOM measured the DEP aerosol 7.2\% higher than the Marple impactors found using gravimetric analysis.

\subsection{Parallel Flow Diffusion Battery}

Upon subtracting the pre filter weights from post filter weights of the diffusion battery cells, it was impossible to reduce the data into size distributions. The cells with increasing numbers of screens should always have less net weight increase in mass.

Table 5 indicates that this was not the case. 


\subsection{Noise Level, Temperature, and Humidity}

The noise level was reduced from 93 decibels to 65 decibels as a result of adding the car muffler. The temperature can be maintained within 5 degrees of 70 degrees Fahrenheit with simple periodic monitoring and turning of the air conditioner on and off. The humidifiers could keep the humidity within $10 \%$ of $50 \%$ humidity but only with supervision. 


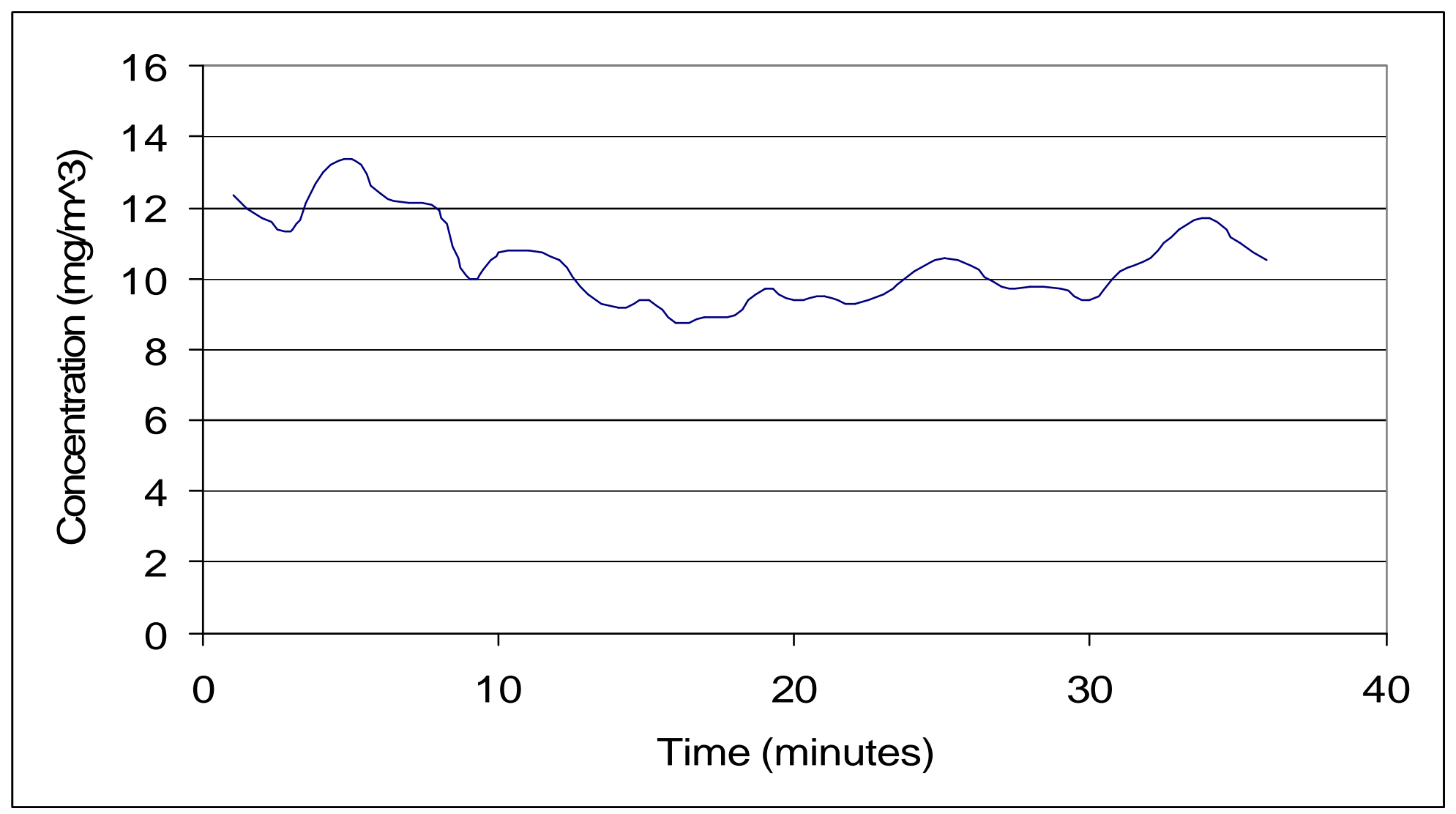

Figure 4. Stability of mass concentration at 10 air changes per hour of carbon black without supervision of vibratory feeder. 


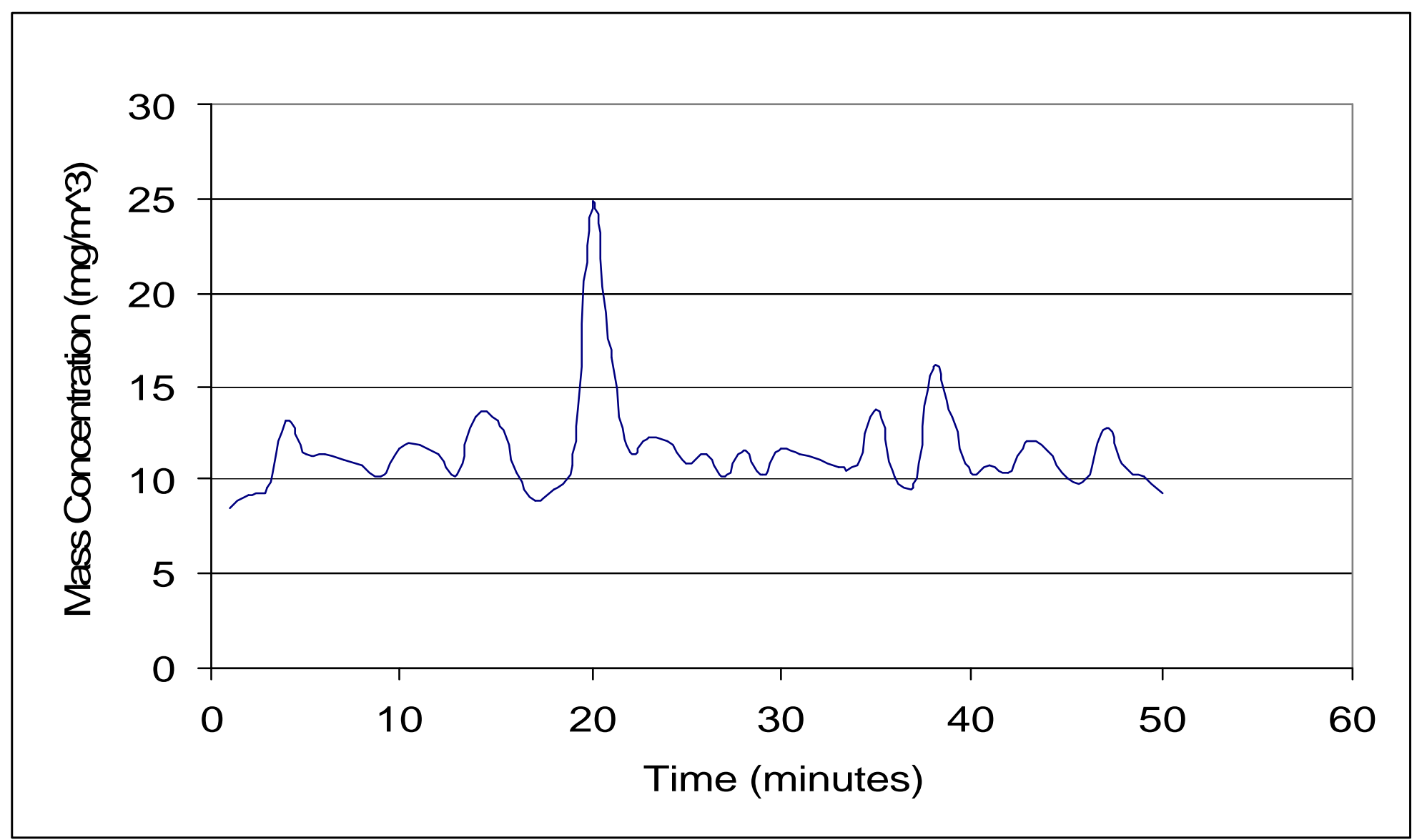

Figure 5. Stability of mass concentration at 10 air changes per hour of DEP without supervision of vibratory feeder. 


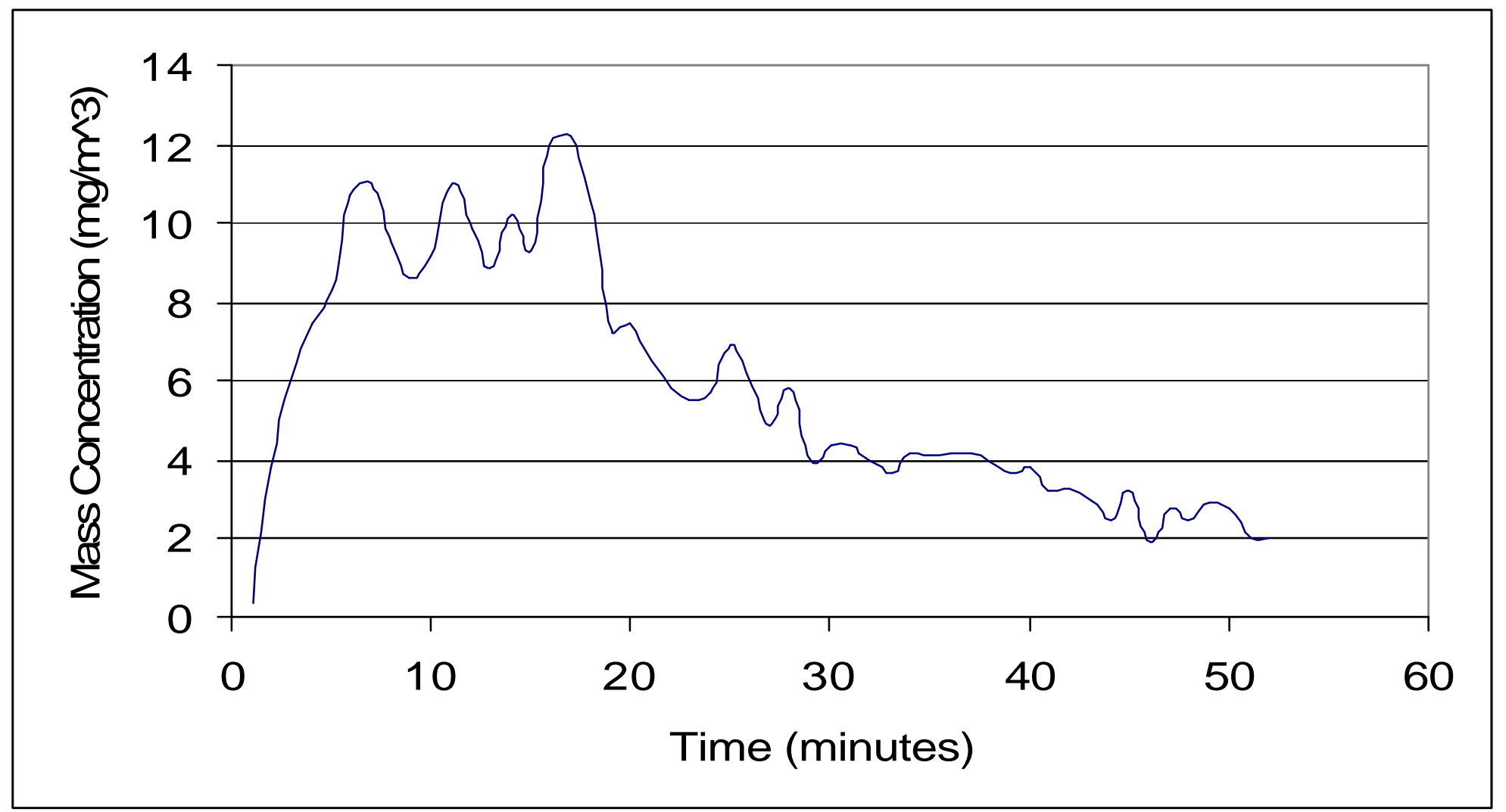

Figure 6. Tapered Element Oscillating Microbalance mass concentration fluctuations when using a 16 second mass averaging time. 


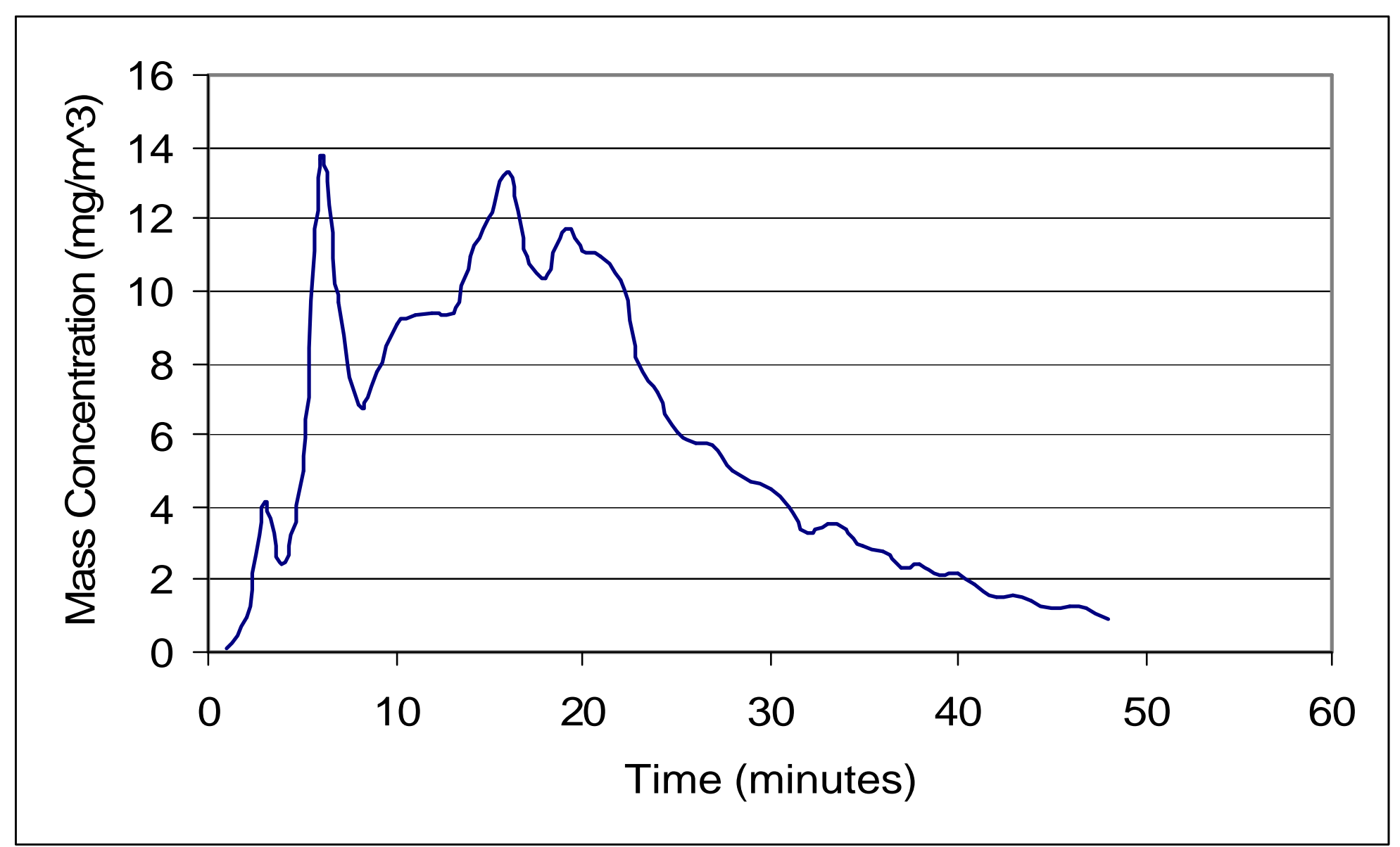

Figure 7. Tapered Element Oscillating Microbalance mass concentration fluctuations when using a 16 second mass averaging time. 


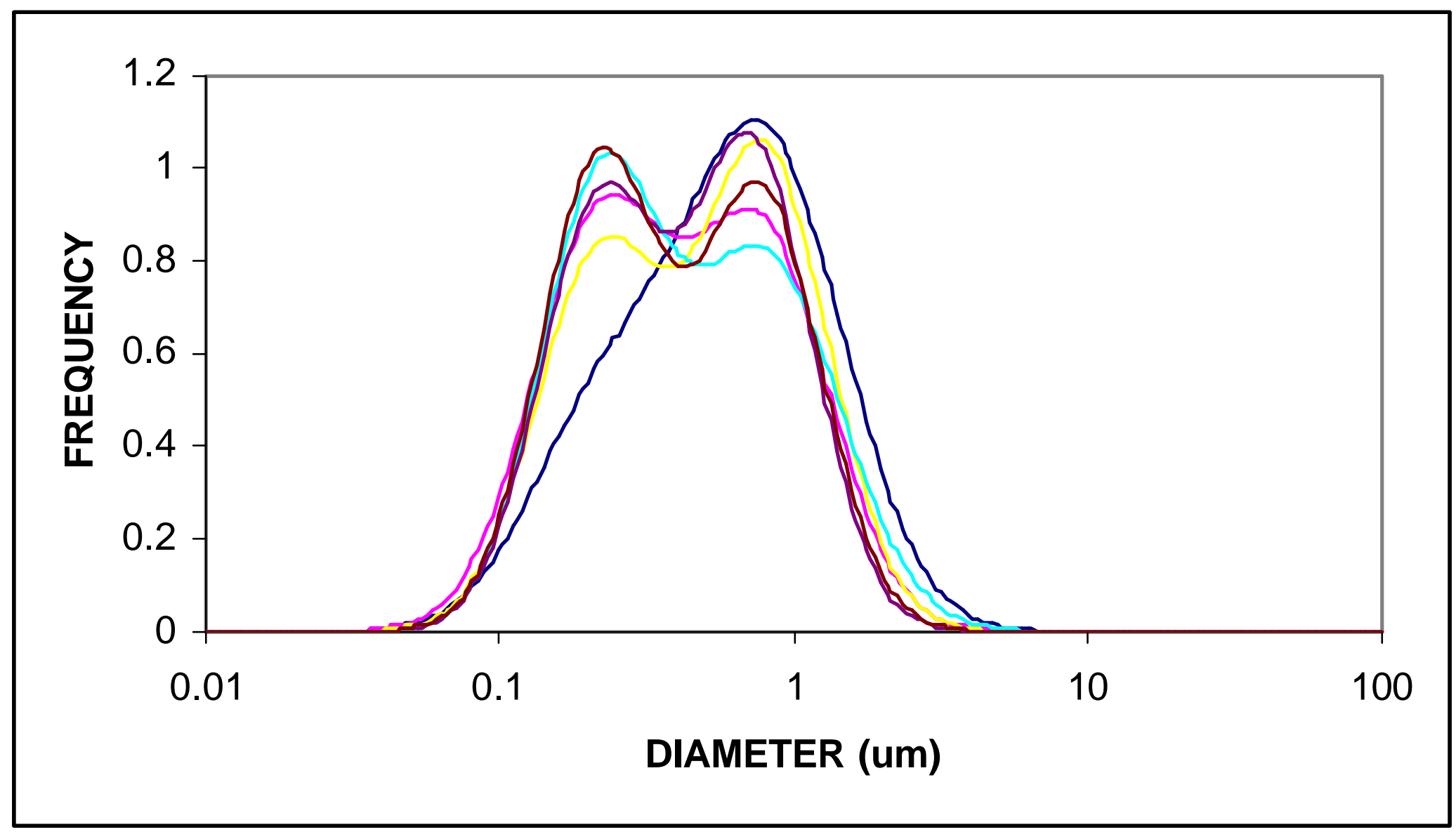

Figure 8. Bimodal CB aerosol at 80 PSI and a mass concentration of 7, 13, 15, 16, 25, $27 \mathrm{mg} / \mathrm{m}^{3}$ using the ten stage MOUDI. (At $7 \mathrm{mg} / \mathrm{m}^{3}$, the first mode was not as pronounced.) 


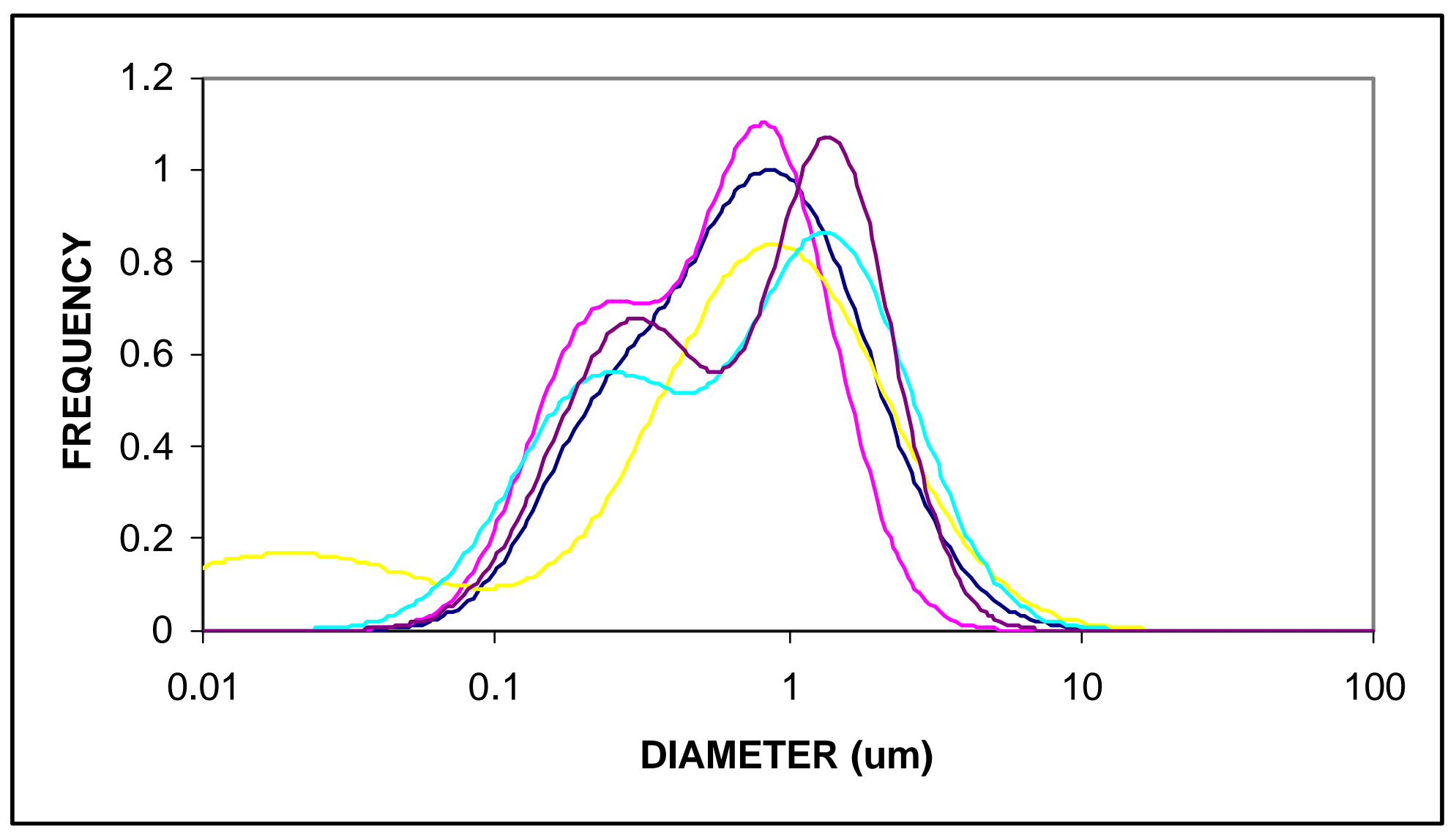

Figure 9. Bimodal CB aerosol at 40 PSI and mass concentrations of $14,10,9,6.1$, and $3.6 \mathrm{mg} / \mathrm{m}^{3}$. The two curves slightly shifted to the right were using an 8 stage MOUDI while the others were obtained with a ten stage MOUDI.) 


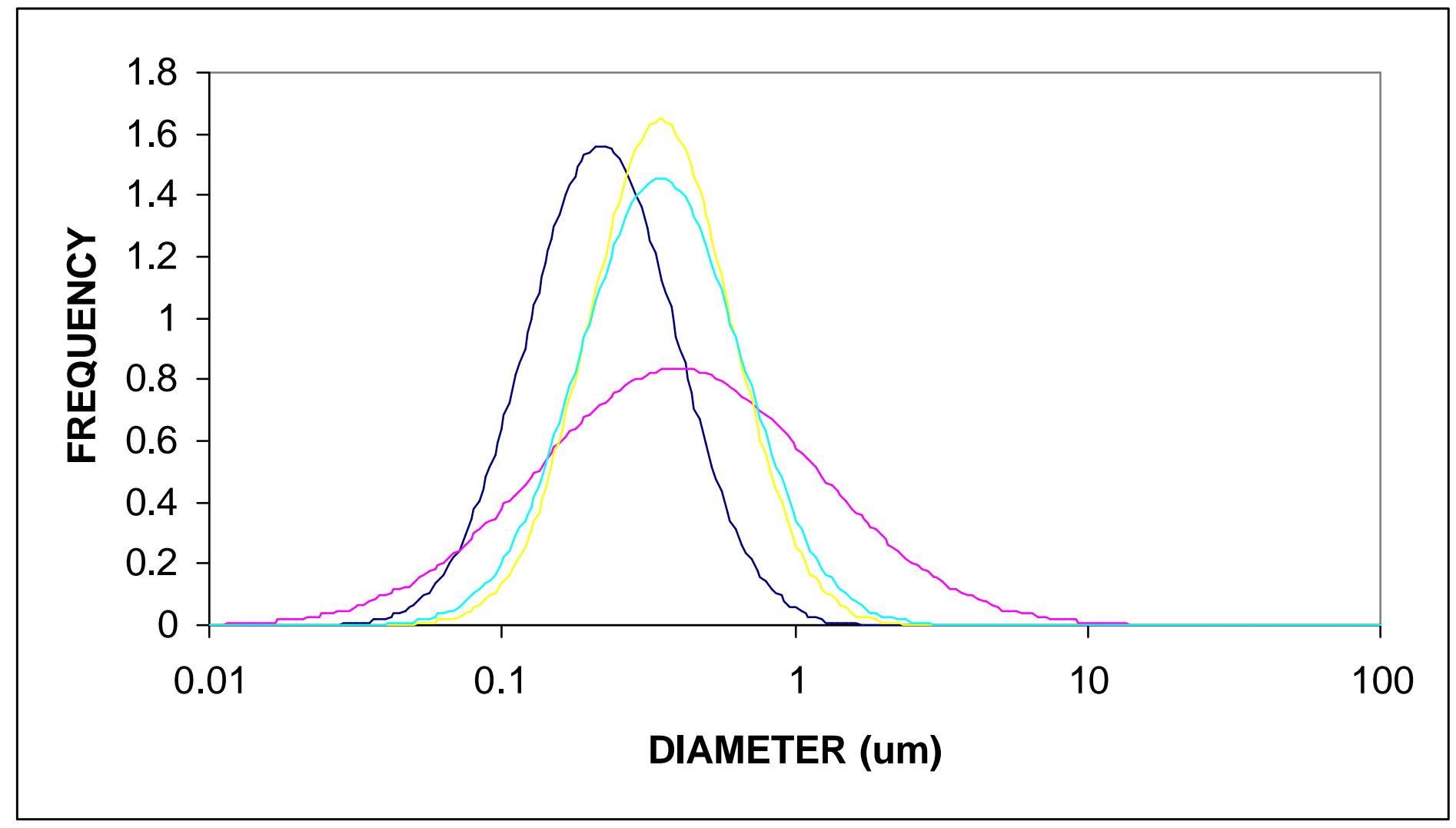

Figure 10. Single moded DEP aerosol at $80 \mathrm{PSI}$ and mass concentrations of $11,4,3.2$, and $2.5 \mathrm{mg} / \mathrm{m}^{3}$. (The curve with the much greater GSD of 3 was obtained from the 10 stage MOUDI. The three curves with the GSD's of $1.8,1.75$, and 1.85 were obtained with the 8 stage MOUDI.) 


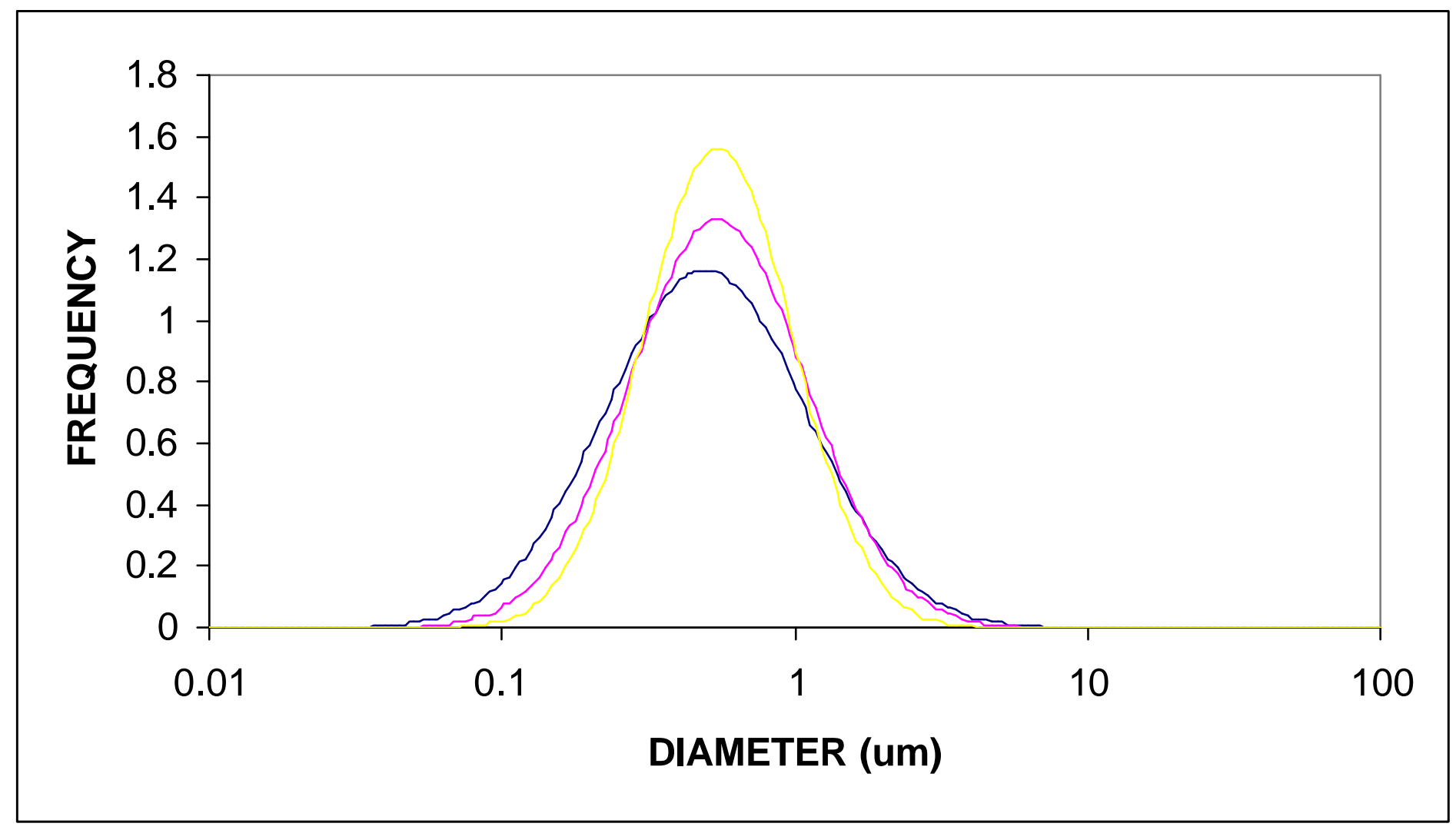

Figure 11. Single moded DEP aerosol at 40 PSI and mass concentrations of 5.2, 3.5, and $2 \mathrm{mg} / \mathrm{m}^{3}$ using the ten stage MOUDI. 


\begin{tabular}{|c|c|c|c|c|c|c|c|c|c|}
\hline \multirow[t]{2}{*}{ Figure } & $\begin{array}{l}\text { Mass } \\
\text { Conc. } \\
\end{array}$ & $\begin{array}{c}\text { Particulate } \\
\text { Type }\end{array}$ & $\begin{array}{l}\text { Grinding } \\
\text { Pressure }\end{array}$ & Mode 1 & Mode 1 & Mode 1 & Mode 2 & Mode 2 & Mode 2 \\
\hline & $\left(\mathrm{mg} / \mathrm{m}^{\wedge} 3\right)$ & & (psi) & MMD (um) & GSD & Coeff. & MMD (um) & GSD & Coeff. \\
\hline 9 & 27 & $\mathrm{CB}$ & 80 & 0.22 & 1.6 & 0.52 & 0.78 & 1.6 & 0.48 \\
\hline 10 & 25 & $\mathrm{CB}$ & 80 & 0.22 & 1.6 & 0.47 & 0.73 & 1.6 & 0.53 \\
\hline 11 & 16 & CB & 80 & 0.22 & 1.6 & 0.485 & 0.8 & 1.8 & 0.515 \\
\hline 12 & 15 & $\mathrm{CB}$ & 80 & 0.22 & 1.65 & 0.44 & 0.8 & 1.65 & 0.56 \\
\hline 13 & 13 & CB & 80 & 0.22 & 1.7 & 0.51 & 0.78 & 1.7 & 0.49 \\
\hline 14 & 7 & CB & 80 & 0.23 & 1.8 & 0.3 & 0.85 & 1.85 & 0.7 \\
\hline 15 & 10 & CB & 40 & 0.22 & 1.7 & 0.2 & 0.9 & 2.1 & 0.8 \\
\hline 16 & 13 & CB & 40 & 0.22 & 1.7 & 0.38 & 0.85 & 1.7 & 0.62 \\
\hline 17 & 10 & CB & 40 & 0.02 & 3 & 0.2 & 0.9 & 2.4 & 0.8 \\
\hline 18 & 6 & $\mathrm{CB}$ & 40 & 0.23 & 2 & 0.41 & 1.4 & 1.9 & 0.59 \\
\hline 19 & 3.5 & CB & 40 & 0.3 & 1.9 & 0.47 & 1.43 & 1.6 & 0.53 \\
\hline 20 & 3.2 & DEP & 80 & 0.22 & 1.8 & 1 & & & \\
\hline 21 & 11 & DEP & 80 & 0.4 & 3 & 1 & & & \\
\hline 22 & 2.5 & DEP & 80 & 0.35 & 1.75 & 1 & & & \\
\hline 23 & 4 & DEP & 80 & 0.35 & 1.88 & 1 & & & \\
\hline 24 & 5.2 & DEP & 40 & 0.5 & 2.2 & 1 & & & \\
\hline 25 & 3.5 & DEP & 40 & 0.55 & 2 & 1 & & & \\
\hline 26 & 2.5 & DEP & 40 & 0.55 & 1.8 & 1 & & & \\
\hline
\end{tabular}

Table 3. The mass median diameter, geometric standard deviation, and mass fraction (Coeff.) of modes one and two of the carbon black and DEP aerosols. 


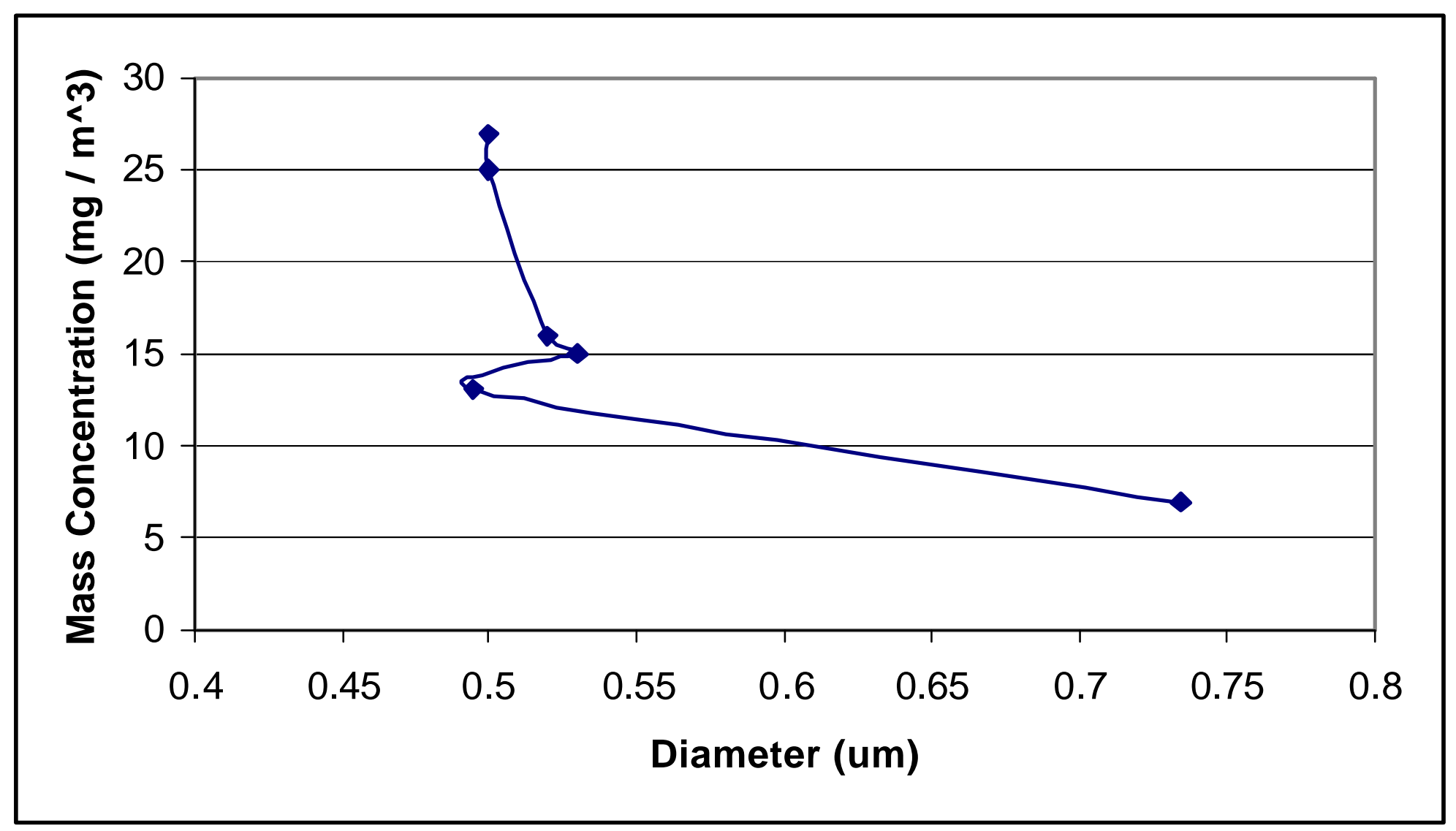

Figure 12. The combined mass median diameter for the bi-modal carbon black aerosols at 80 psi grinding nozzle pressure for various aerosol mass concentrations. (From figure ). 


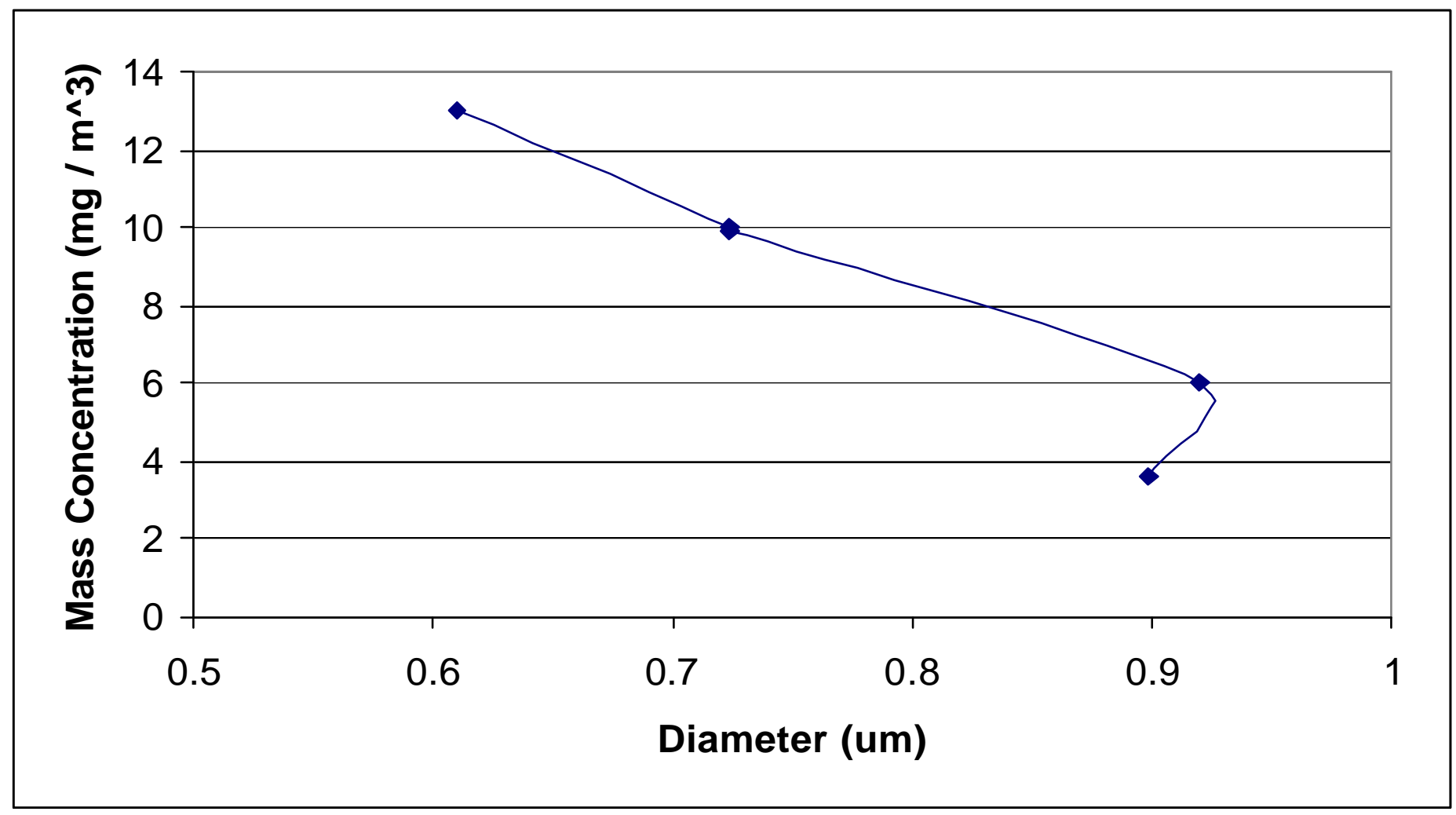

Figure 13. The combined mass median diameter for the bi-modal carbon black aerosols at 40 psi grinding nozzle pressure for various aerosol mass concentrations. (From figure ). Note: there are two data points at $10 \mathrm{mg} / \mathrm{m}^{3}$. 


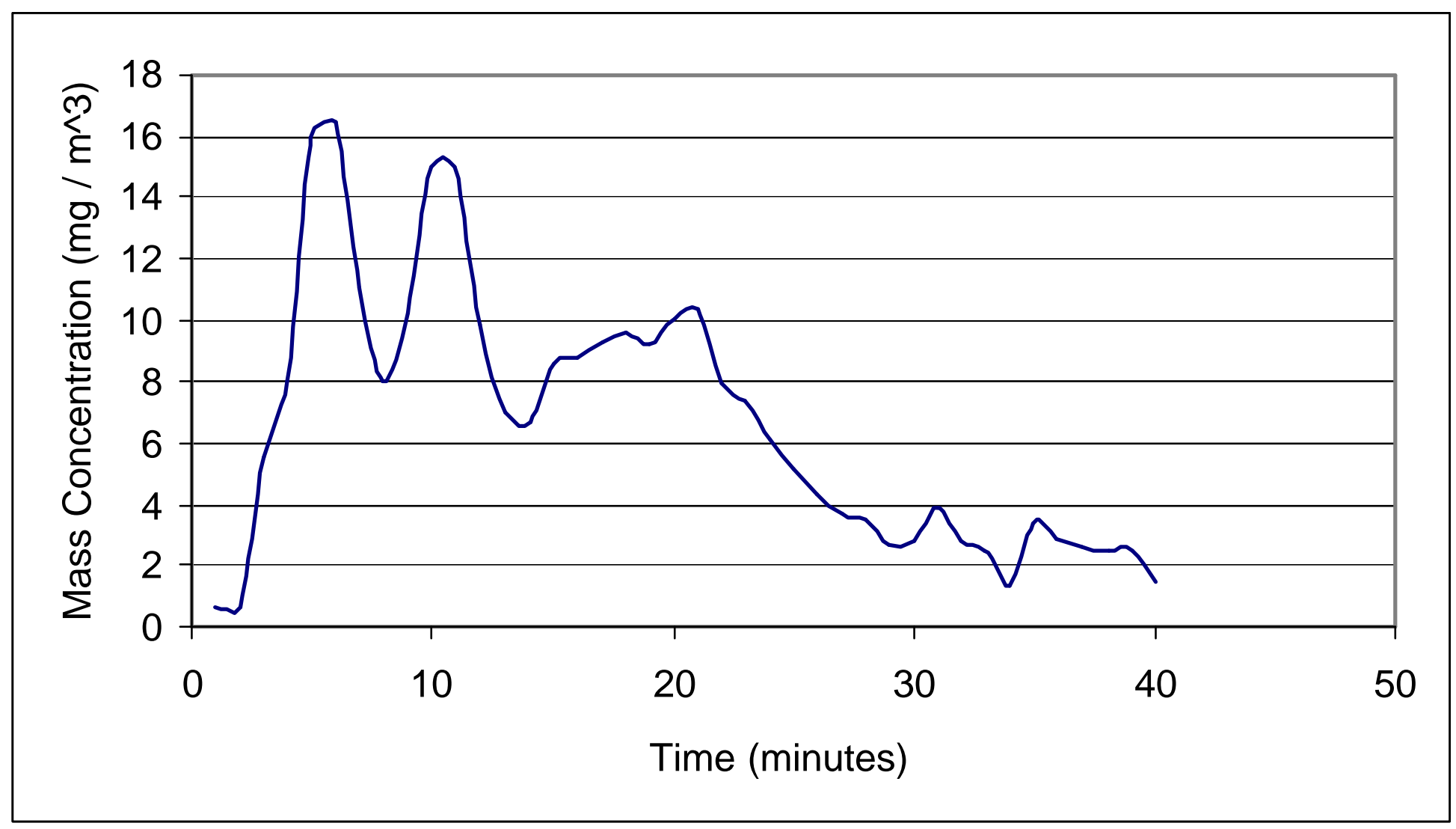

Figure 14. Resulting mass concentration for 40 minutes using $36 \mathrm{mg}$ of DEP. 


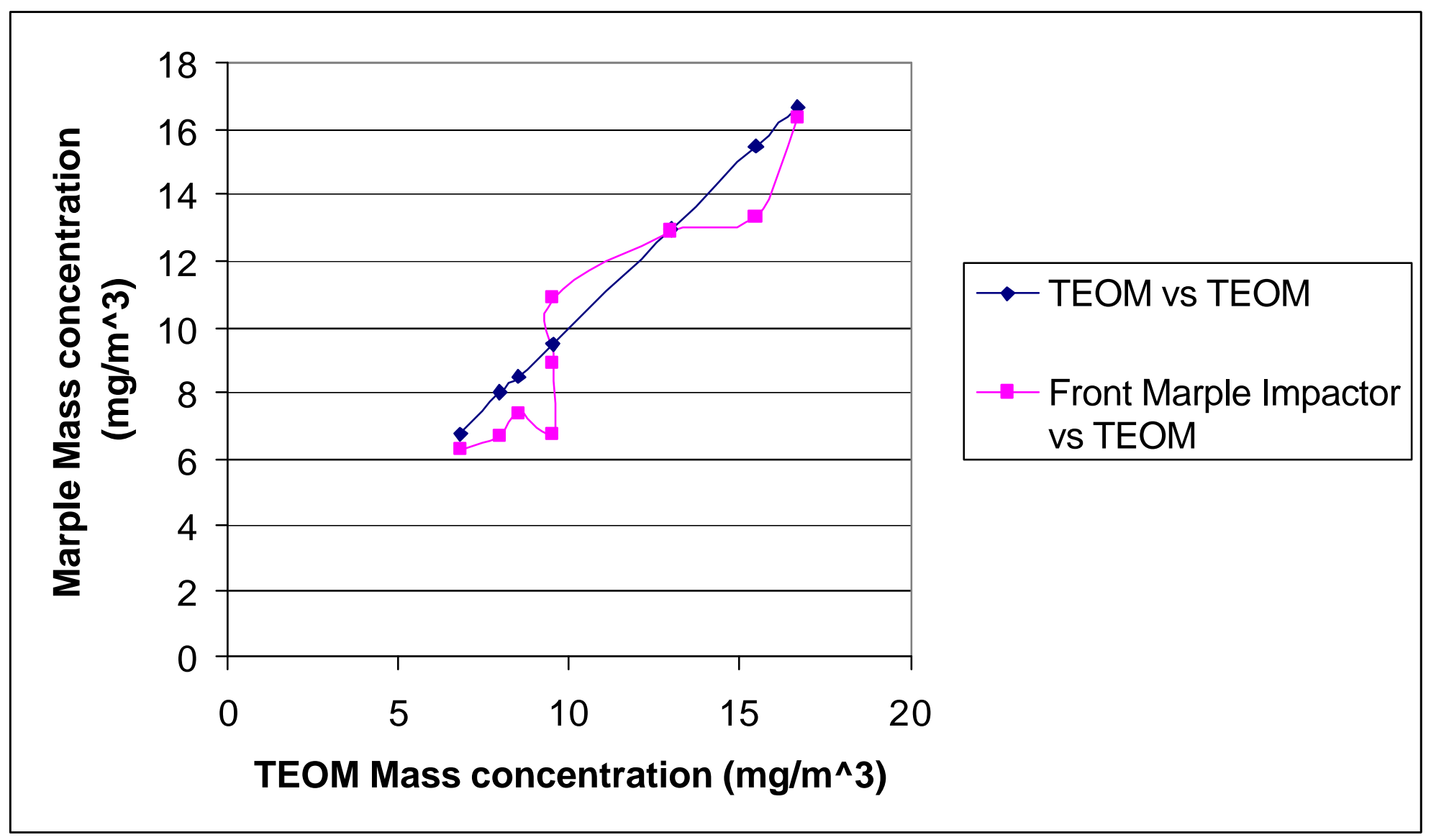

Figure 15. Comparison between TEOM and Marple Impactor placed in front section of Hazleton Chamber at various mass concentration levels of carbon black aerosol. 


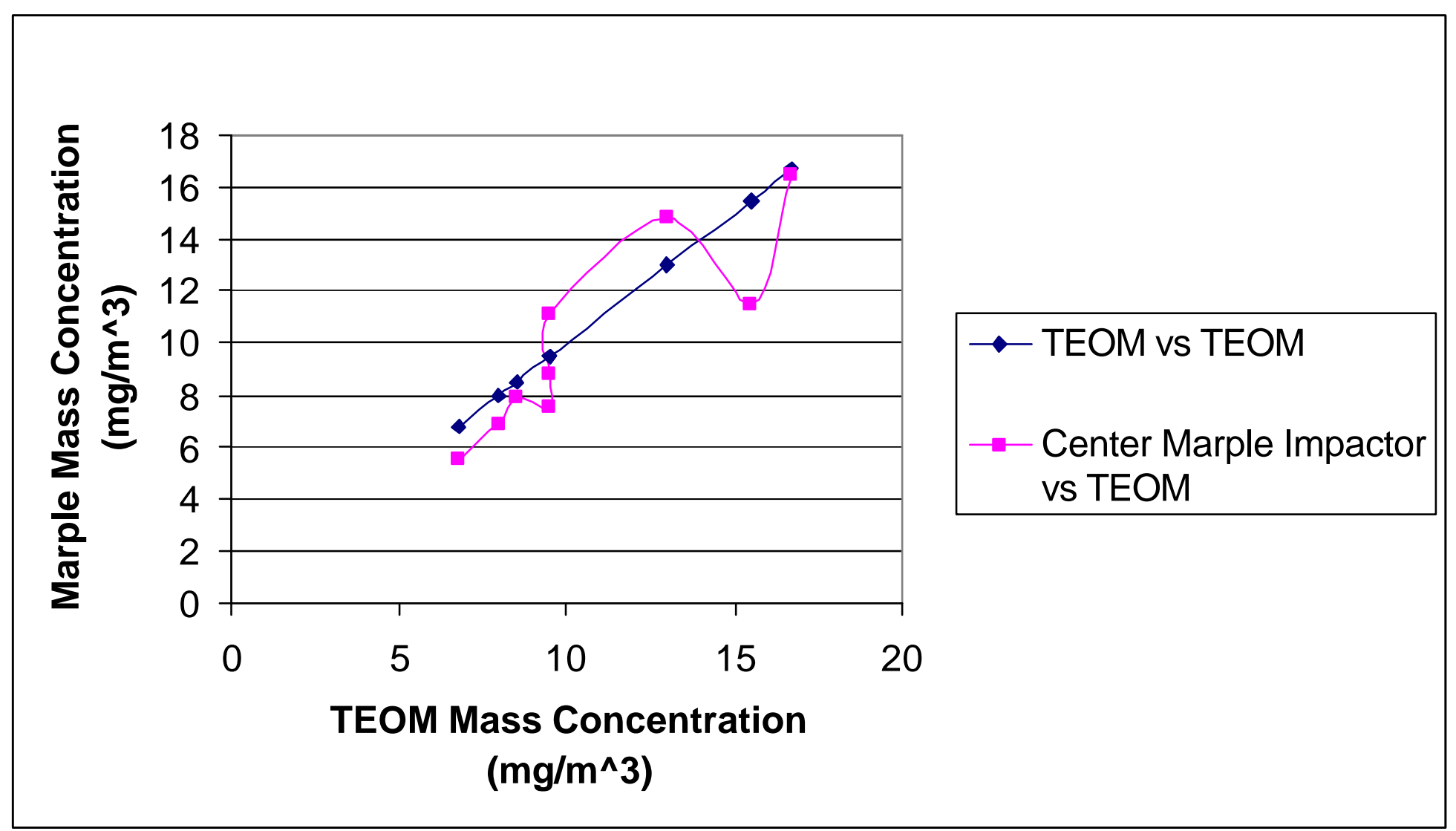

Figure 16. Comparison between TEOM and Marple Impactor placed in center section of Hazleton Chamber at various mass concentration levels of carbon black aerosol. 


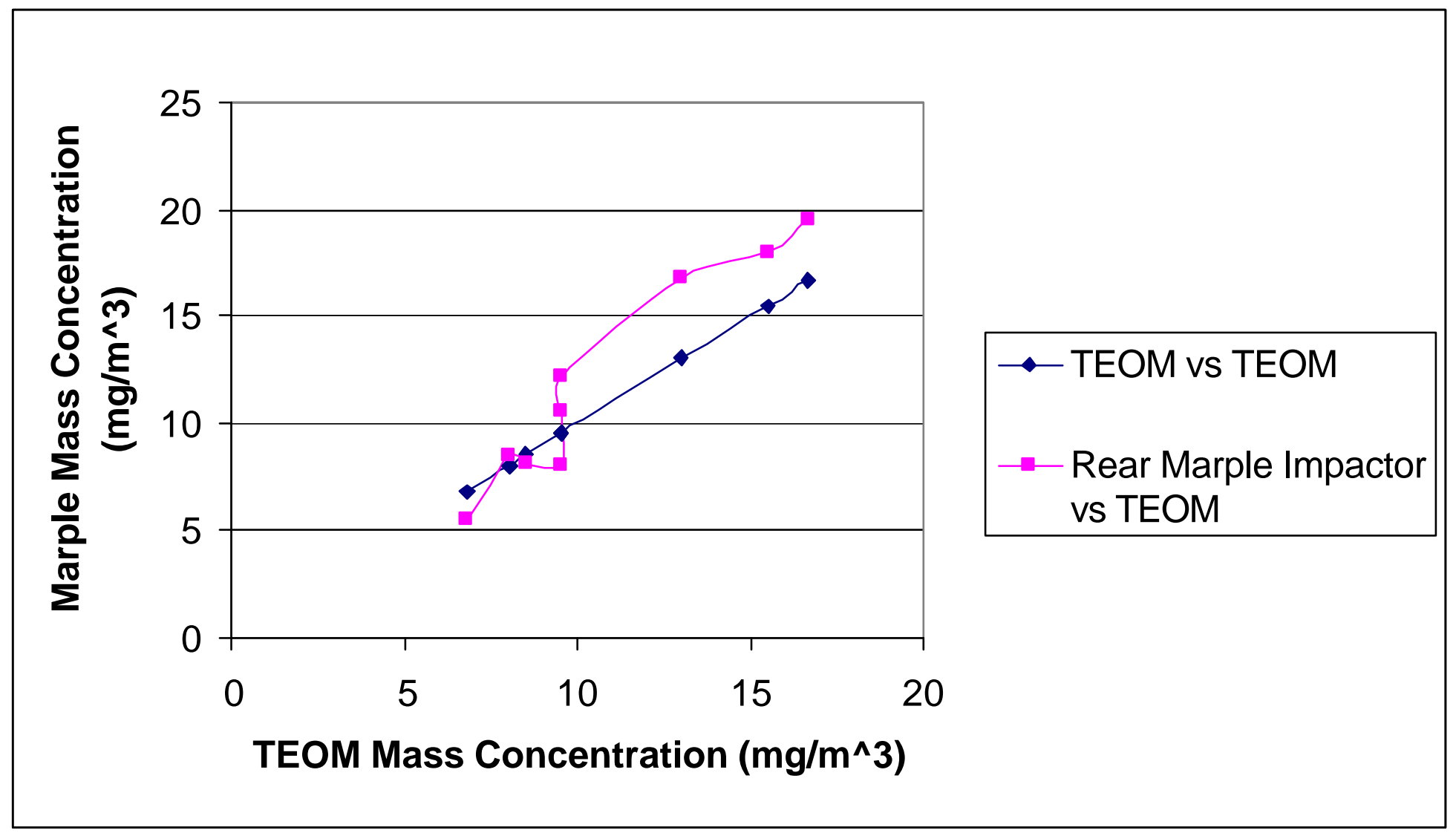

Figure 17. Comparison between TEOM and Marple Impactor placed in rear section of Hazleton Chamber at various mass concentration levels of carbon black aerosol. 
This page is intended to be blank 


\begin{tabular}{|c|c|c|c|c|}
\cline { 2 - 5 } \multicolumn{1}{c|}{} & Front & Center & Rear & Overall \\
\cline { 2 - 5 } & $\%$ & $\%$ & $\%$ & $\%$ \\
\hline $\mathrm{CB}$ & 9.0 & 4.7 & -7.9 & 1.9 \\
\hline $\mathrm{DEP}$ & 22.4 & -1.2 & 3.9 & 7.3 \\
\hline
\end{tabular}

Table 4. Marple impactors mass concentration percent less than TEOM for carbon black and DEP aerosols in the front, center, and rear of the Hazleton Chamber.

\begin{tabular}{|c|c|c|c|c|c|}
\cline { 3 - 6 } \multicolumn{1}{c|}{} & Test 1 & Test 2 & Test 3 & Test 4 \\
\cline { 2 - 6 } \multicolumn{1}{c|}{$\begin{array}{c}\text { \# of } \\
\text { screens }\end{array}$} & net weight $(\mathrm{mg})$ & net weight $(\mathrm{mg})$ & net weight $(\mathrm{mg})$ & net weight (mg) \\
\hline Cell 1 & 0 & 0.050 & 0.035 & 0.056 & 0.094 \\
\hline Cell 2 & 10 & 0.040 & 0.019 & 0.045 & 0.072 \\
\hline Cell 3 & 15 & 0.036 & 0.030 & 0.039 & 0.082 \\
\hline Cell 4 & 20 & 0.042 & 0.034 & 0.043 & 0.085 \\
\hline Cell 5 & 25 & 0.051 & 0.034 & 0.039 & 0.081 \\
\hline Cell 6 & 30 & 0.034 & 0.033 & 0.047 & 0.082 \\
\hline Cell 7 & 35 & 0.042 & 0.028 & 0.027 & 0.074 \\
\hline Tare & & 0.002 & 0.001 & 0.000 & 0.002 \\
\hline
\end{tabular}

Table 5. Net weight difference of diffusion battery cell filters. 


\section{Discussion of Results}

\subsection{Vibratory Feeder}

It can be seen on figures 4 and 5 that there is some degree of oscillation in the mass concentration inside the inhalation chamber as monitored by the TEOM. If figures 4 and 5 are compared to figures 6 and 7 after the vibratory feeder was turned off, it can be seen that much of the oscillation is not a result of the inconsistency of the vibratory feeder, but a result of the natural mass concentration fluctuation as determined by the TEOM.

The large spike at the time of 20 minutes in figure 5 is too great a spike to represent an accurate change in the actual mass concentration in the chamber. This is certain because as figures 6 and 7 indicate, the mass concentration at 10 air changes per hour even with the vibratory feeder turned off, cannot decrease by approximately $50 \%$

(25 to $12 \mathrm{mg} / \mathrm{m}^{3}$ ) within less than two minutes. The probable explanation is that a large piece of carbon black that deposited in the line entering the inhalation chamber became dislodged and fell directly into the TEOM inlet line causing this spike in the mass concentration reading.

The vibratory feeder can maintain a relatively constant mass concentration in the inhalation with some supervision. Some supervision is needed because occasionally a larger chunk of DEP or carbon black particulate, that does is not moved forward along the feeder as easily will block the flow of finer particulate. This means the vibratory feeder and aerosol system should not be left unattended for more than 15 minutes. 


\subsection{TEOM Mass Concentration Fluctuations}

The oscillations from 18 minutes on in figure 6 are more pronounced than the oscillations in figure 7.

These oscillations of up to $1.5 \mathrm{mg} / \mathrm{m}^{3}$ as predicted by the manufacturer when changing the mass averaging time and are acceptable when the goal is to find the average mass concentration over a long time period.

\subsection{Size Distribution}

As indicated in table 3 and figures 8 through 11, the fineness of the carbon black aerosol and the DEP aerosol were not affected by the changes in feed rate. The CB aerosol was not affected in feed rate changes resulting in mass concentrations ranging

from $7 \mathrm{mg} / \mathrm{m}^{3}$ to $27 \mathrm{mg} / \mathrm{m}^{3}$. The DEP aerosol was not affected by mass concentrations ranging from $2 \mathrm{mg} / \mathrm{m}^{3}$ to $11 \mathrm{mg} / \mathrm{m}^{3}$.

This was as expected as all feed rates were extremely fine at under $1 \mu \mathrm{g} / \mathrm{second}$ and not heavy enough to affect the mechanics of the jet mill.

The carbon black aerosol was bimodal and its combined mass median diameter increased in fineness from an average MMD of $0.78 \mu \mathrm{m}$ to $0.54 \mu \mathrm{m}$ as the jet mill grinding nozzle pressure was increased from 40 PSI to 80 PSI.

The DEP aerosol had a single mode and its mass median diameter increased in finedess from an average of $0.55 \mu \mathrm{m}$ to $0.33 \mu \mathrm{m}$ as the grinding nozzle pressure was increased from 40 PSI to 80 PSI. 
The 8 stage MOUDI may not have been quite consistent with the 10 stage MOUDI as can be seen in figures 9 and 10, while the size distributions in figures 8 and 11 that were measured by only the 10 stage MOUDI coincided very closely.

In figure 12, the combined mass median diameters of the $\mathrm{CB}$ aerosol are clustered around $0.5 \mu \mathrm{m}$ except for the MMD at a mass concentration of $7 \mathrm{mg} / \mathrm{m}^{3}$ which was above $0.7 \mu \mathrm{m}$. The reason for this anomaly is unknown.

In figure 13 it should be noted once again that the two lowest mass concentrations that resulted in mass median diameters above $0.9 \mu \mathrm{m}$ were obtained by using the 8 stage MOUDI while all other mass median diameters in figure 12 and 13 were found using the 10 stage MOUDI. If these two are discounted the remaining three points in figure 13 (there are two points at $10 \mathrm{mg} / \mathrm{m}^{3}$ ) are not enough to draw any definite conclusions. But the conclusion can still be clearly drawn from figure 12 that the feed rate did not affect the fineness of the aerosol.

\subsection{Reduced Volume Chamber}

The inhalation chamber system as is, cannot be run with a jet mill grinding nozzle pressure of 80 PSI. This is because at this pressure the aerosol is blown backwards through the piping into the control chamber. At 40 PSI this does not occur and $36 \mathrm{mg}$ of DEP maintained a $10 \mathrm{mg} / \mathrm{m}^{3}$ mass concentration for 16 minutes.

As table 4 indicates, the DEP aerosol was not uniformly dispersed throughout the chamber. This lack of uniformity of the DEP compared to CB occurred because the DEP was given less time to disperse throughout the chamber. (only 5 minutes versus 25 minutes for the CB aerosol). Not ensuring adequate dispersion of the aerosol throughout 
the chamber should have resulted in lower concentrations at the front and rear positioned Marples as opposed to the center Marple and the TEOM whose inlet was in the center of the chamber. Table 4 indicates that this was indeed the case.

The CB aerosol which was given approximately 25 minutes to disperse, differed in concentration from $9.9 \mathrm{mg} / \mathrm{m}^{3}$ in the front of the chamber to $11.7 \mathrm{mg} / \mathrm{m}^{3}$ in the rear of the chamber. This is a difference of $15.3 \%$ moving from the front to back of the chamber. Moss et al., (17) earlier reported uniform mixing of chamber air with concentrations that varied by as much as $14.1 \%$ with an average variation of $9.2 \%$. In relation to this study by Moss, the CB aerosol was approximately uniformly dispersed.

\subsection{Comparison of TEOM with Gravimetric Methods}

There was concern that the TEOM heated filter would volatilize some of the organic matter from the DEP aerosol and therefore indicate a lower mass concentration than actual. Possibly over longer time frames when measuring ambient outdoor air this is the case, but it was not the case in these experiments as the TEOM actually measured a $1.9 \%$ higher mass concentration than the Marples impactors when measuring the $\mathrm{CB}$ aerosol and allowing approximately 25 minutes for the $\mathrm{CB}$ aerosol to disperse.

As opposed to the $1.9 \%$ difference between the TEOM and CB aerosol, the TEOM measured a 7.2\% higher mass concentration than the Marples gravimetrically did in measuring the DEP aerosol. The greater difference can once again be explained by allowing less time for the DEP aerosol to disperse throughout the chamber and the much lower resulting mass concentration at the front of the chamber. 
The shorter time given for the dispersal of the aerosol and the lower mass concentration were due to the expense of the DEP.

So despite the literature to the contrary, the TEOM did not under measure the mass concentration. But this could be because the aerosolized CB material had a much lower percentage of volatile material than that seen in ambient conditions. The results of comparing the TEOM to the Marple with the DEP aerosol can be discounted due to the short time allowed for the aerosol to disperse throughout the chamber.

\subsection{Parallel Flow Diffusion Battery}

As table 5 indicates the net weight should decrease as the number of mesh screens increases. The penetration fraction is the net weight of each cell divided by the net weight of the first cell which has no mesh screens. A brief look at the penetration fractions of the PFDB indicates that the PFDB was not working correctly.

The PFDB has 7 cells. Cell one is a reference cell with no mesh screens, cells 2 through 7 have 10,15, 20, 25, 30, 35 mesh screens. As smaller particles diffuse they will be less likely to penetrate through the mesh screens and the penetration fraction of a monodisperse aerosol through a series of screens can be easily calculated.

For example using 145 mesh screens, with a 14 LPM flowrate, a monodisperse aerosol of 0.3 micrometers of diffusive diameter should have penetration fractions through cells 1 through 7 of $100 \%, 86 \%, 80 \%, 74 \%, 69 \%, 64 \%, 59 \%$. The penetration fraction of a polydisperse aerosol should decrease even more sharply through the seven cells than the example of the monodisperse aerosol. The actual penetration fractions 
found oscillated widely throughout the cells, increasing in higher cell numbers almost as often as decreasing. This indicated that the PFDB was definitely not working correctly. All procedures appear to have been properly followed as described in the procedures section. Despite repeated calls and e-mails the manufacturer, Intox, never offered any solutions. So the PFDB was eventually put aside and the MOUDI was used in its place. 


\section{Conclusions}

\subsection{Modifying Chamber Conclusions}

\subsubsection{Reducing the Aerosolized Material}

With $36 \mathrm{mg}$ conservatively maintaining a $10 \mathrm{mg} / \mathrm{m}^{3}$ concentration for 16 minutes, $135 \mathrm{mg}$ of DEP would be needed, or at current NIST prices of $\$ 216$ / gram of SRM 2975, this is $\$ 29 / \mathrm{hr}$. By theoretically changing the flow rate in the inhalation chamber from 60 LPM back to the previous 283 LPM as used in the study by Moss, et al., (16) it is calculated that $636 \mathrm{mg}$ of DEP would be needed, or $\$ 137 / \mathrm{hr}$. This would be saving of $\$ 108 / \mathrm{hr}$. (This is a conservative calculation in that it does not take into account any changing of the flow of air through the chamber as a result of the placement of the partition inside the inhalation chamber.)

\subsubsection{Uniform Dispersion of Aerosol}

With a reduced flow rate of 60 LPM and the flow of air through the chamber being blocked by the partition, the $\mathrm{CB}$ aerosol was approximately uniform in its dispersal.

\subsection{Equipment and Instrumentation Conclusions}

\subsubsection{Consistency of Vibratory Feeder}

The vibratory feeder can maintain a relatively constant mass concentration inside the inhalation chamber. Once the vibratory feeder and chamber have stabilized at approximately a $10 \mathrm{mg} / \mathrm{m}^{3}$ mass concentration, it should be safe to use the TEOM to monitor the concentration for only 5 to 10 minutes out of every hour. But the vibratory 
feeder cannot be left unattended for hours at a time as explained in the discussion of results section

\subsubsection{TEOM Mass Concentration Fluctuations}

The necessary reducing of the mass averaging time of the TEOM to 16 seconds in order to increase the life of the TEOM filters did not increase the fluctuations of the TEOM beyond an acceptable level for this study. There was a fluctuation of up to $1.5 \mathrm{mg}$ $/ \mathrm{m}^{3}$ which is acceptable when aiming for a $10 \mathrm{mg} / \mathrm{m}^{3}$ mass concentration over a long time period such as 4 hour a day study of a few weeks.

\subsubsection{Size Distribution}

As the feed rate was increased and subsequently the mass concentration in the chamber, the mass median diameter of the carbon black aerosol did not change.

The finess did increase as the grinding nozzle pressure was increased and the DEP aerosol was brought to a maximum finess of $0.33 \mu \mathrm{m}$ and the $\mathrm{CB}$ aerosol was aerosolized at a maximum fineness of $0.54 \mu \mathrm{m}$. These mass median diameters should cause a high level of lung deposition in rats. But a grinding nozzle pressure of 80 PSI cannot be used for an actual rat inhalation study at this time until the control chamber piping system is separated from the test chamber.

\subsubsection{Comparison of TEOM with Gravimetric Methods}

The TEOM compared well with gravimetric methods having only a $1.9 \%$ 
difference in measuring the mass concentration of the $\mathrm{CB}$ aerosol as compared to the Marple personal samplers. It cannot be said for certain whether or not this was the case when using the DEP aerosol.

\subsubsection{Parallel Flow Diffusion Battery}

The PFDB was not adequate in finding a size distribution. 


\section{Recommendations}

1. Instead of using an aerosol measuring instrument that has a filter such as TEOM which has a short lifetime to monitor the mass concentration, use a light refraction instrument (such as a Light Scattering Aerosol monitor or Laser Anemometer) to measure the concentration. The problem with light refraction is the need to calibrate for different aerosols and different size distributions of aerosols. But in an inhalation study the characteristics of the aerosol should stay relatively constant. Once a set aerosol was chosen, a light refraction instrument could be calibrated with the mass concentration found using an inexpensive Marple personal sampler. The benefits are continuous monitoring of the mass concentration plus no need to change out filters.

2. It may be possible to further increase the fineness of the aerosolized collected DEP to that originally emitted from an engine by increasing the grinding nozzle pressure. In order to do this, first the piping to the control chamber would have to be completely separated so that no aerosol would be blown back into the control chamber at higher grinding pressures. After this is accomplished the grinding nozzle pressure of 80 PSI which produced a MMD of $0.33 \mu \mathrm{m}$ could be used. Secondly a system that could produce a pressure of up to 120 PSI might cause an even smaller MMD of the DEP aerosol.

3. A screw feeder could be purchased from Fluid Energy. A screw feeder would probably need far less supervision than a vibratory feeder in keeping a constant mass concentration in the inhalation chamber. 
4. A continuously self regulating system for controlling the humidity and temperature could be engineered to better ensure the proper standard environment. 
Appendix A: Histograms and curve fitting for MOUDI size distributions. 


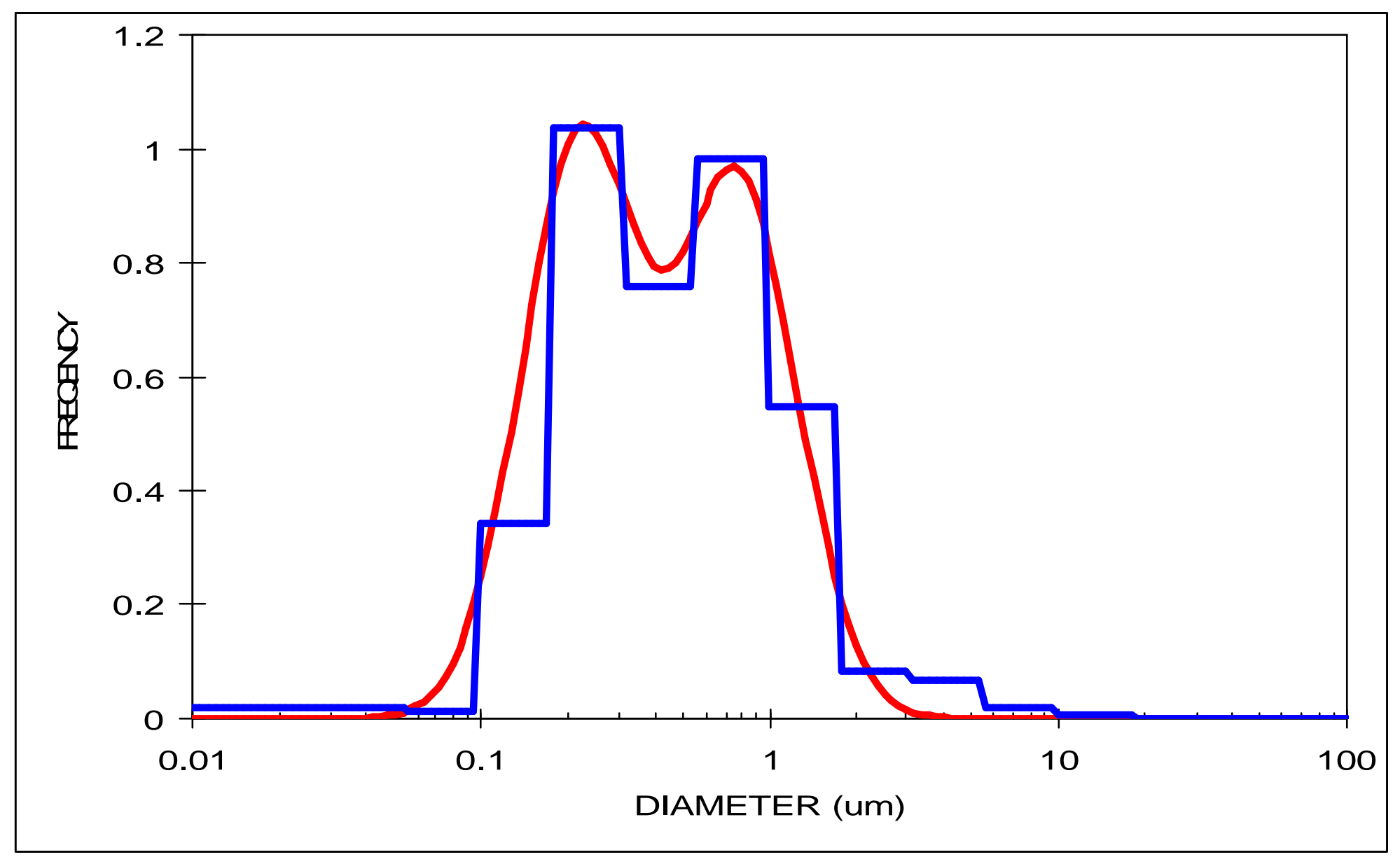

Figure 18. Mass size distribution of carbon black aerosol at mass concentration of $27 \mathrm{mg} / \mathrm{m}^{3}$ and grinding nozzle pressure of 80 PSI using the 10 stage MOUDI. 


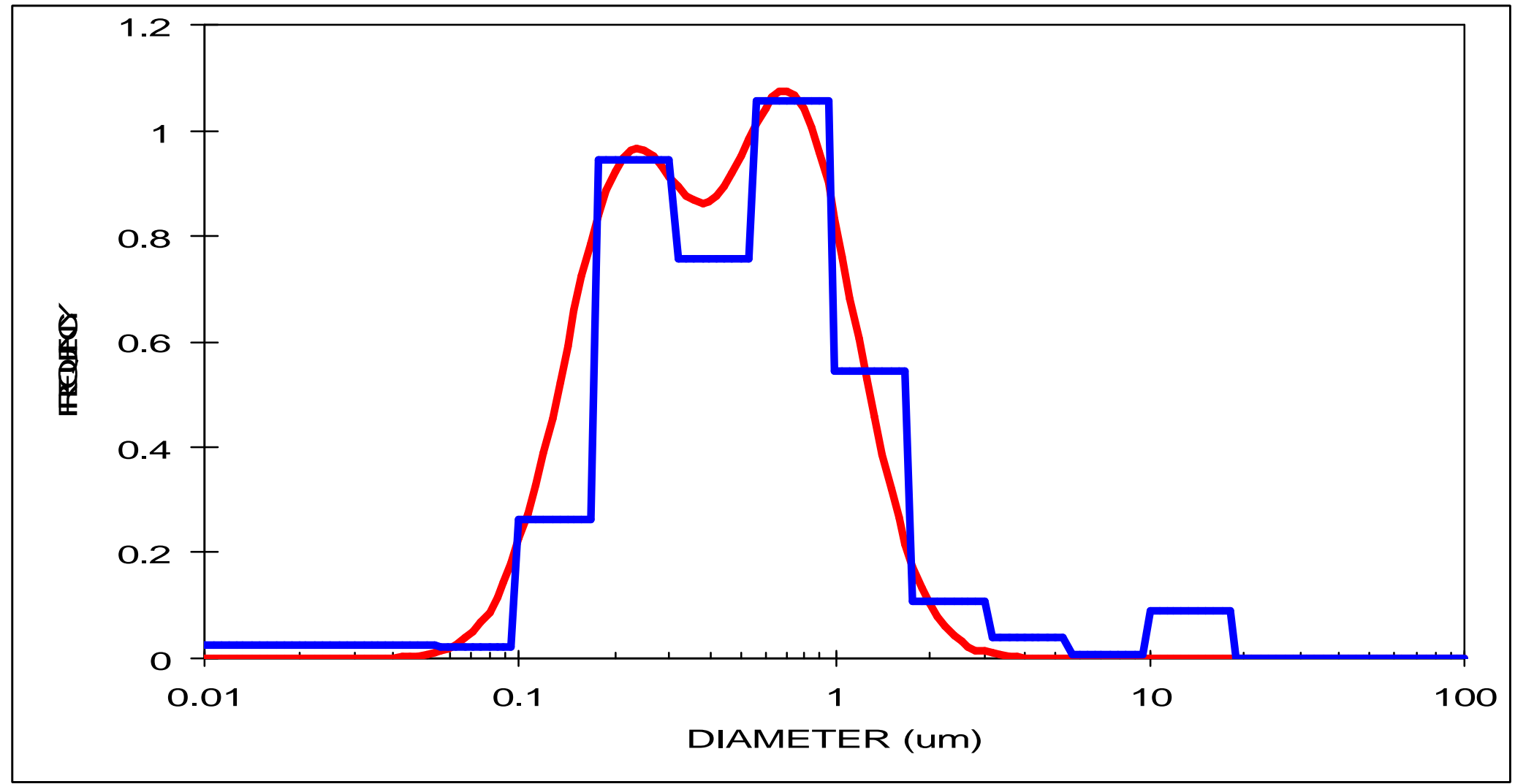

Figure 19. Mass size distribution of carbon black aerosol at mass concentration of $25 \mathrm{mg} / \mathrm{m}^{3}$ and grinding nozzle pressure of 80 PSI using 10 stage MOUDI. 


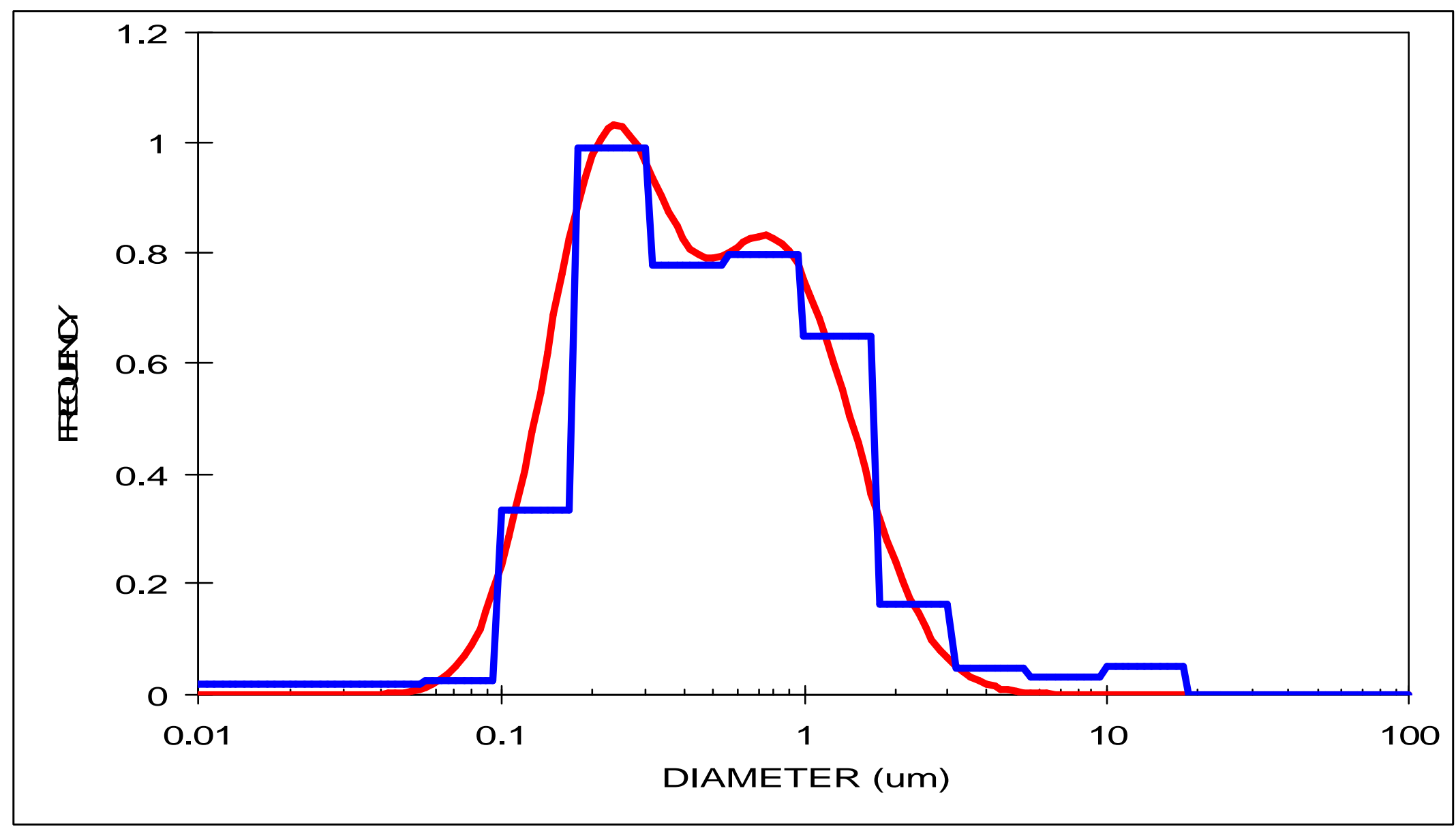

Figure 20. Mass size distribution of carbon black aerosol at mass concentration of $16 \mathrm{mg} / \mathrm{m}^{3}$ and grinding nozzle pressure of 80 PSI using the 10 stage MOUDI. 


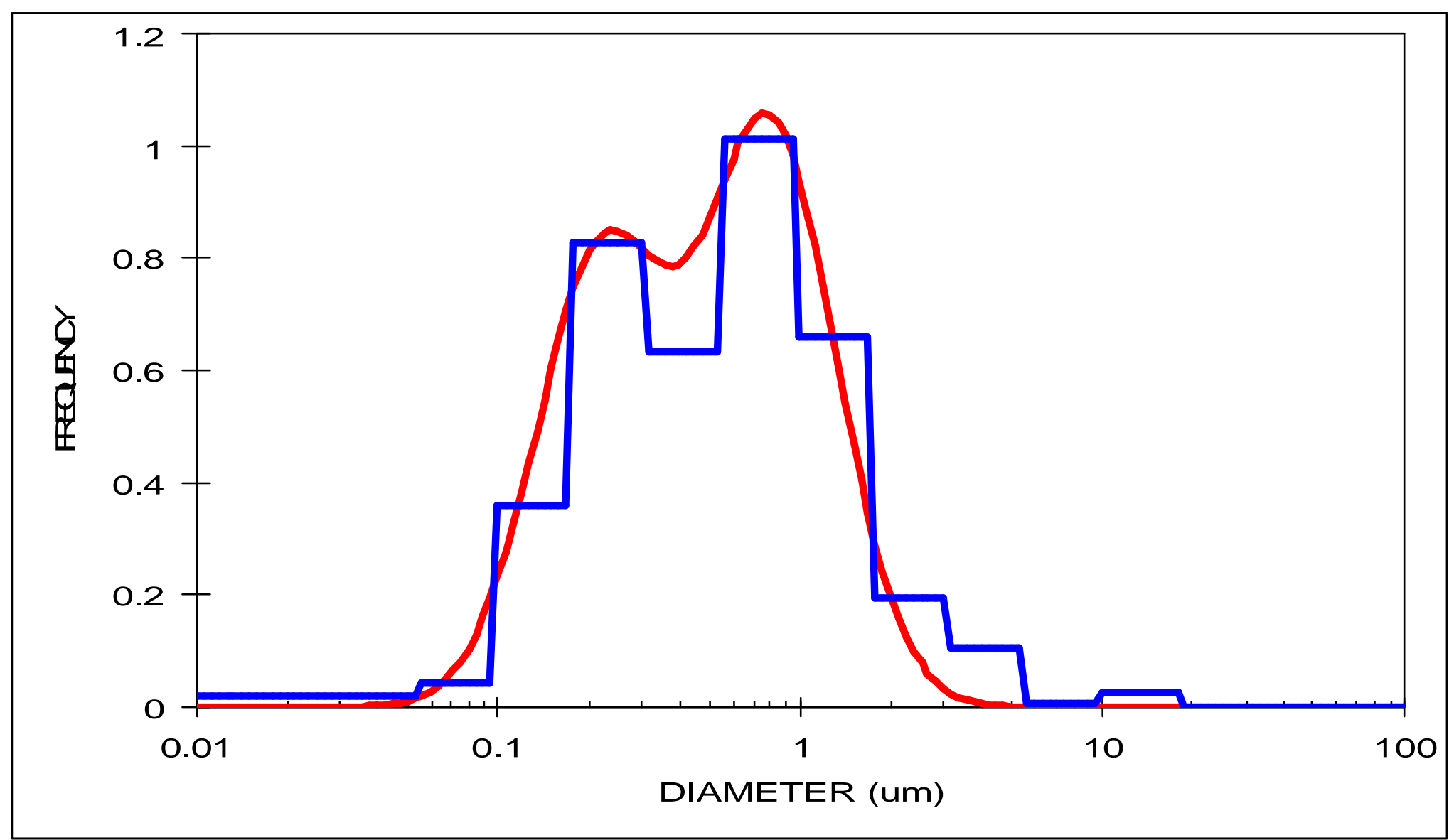

Figure 21. Mass size distribution of carbon black aerosol at mass concentration of $15 \mathrm{mg} / \mathrm{m}^{3}$ and grinding nozzle pressure of 80 PSI using the 10 stage MOUDI. 


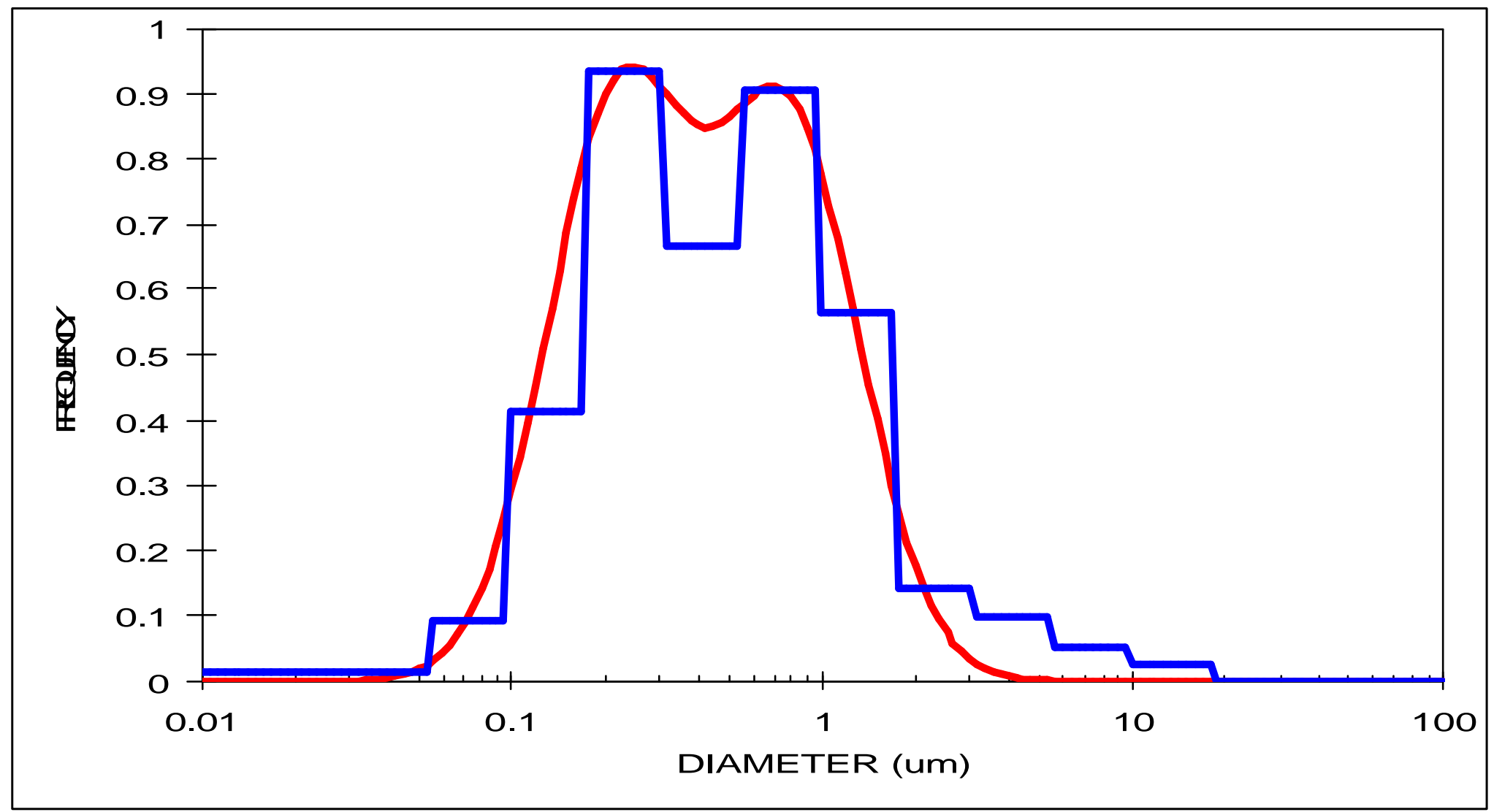

Figure 22. Mass size distribution of carbon black aerosol at mass concentration of $13 \mathrm{mg} / \mathrm{m}^{3}$ and grinding nozzle pressure of 80 PSI using the 10 stage MOUDI. 


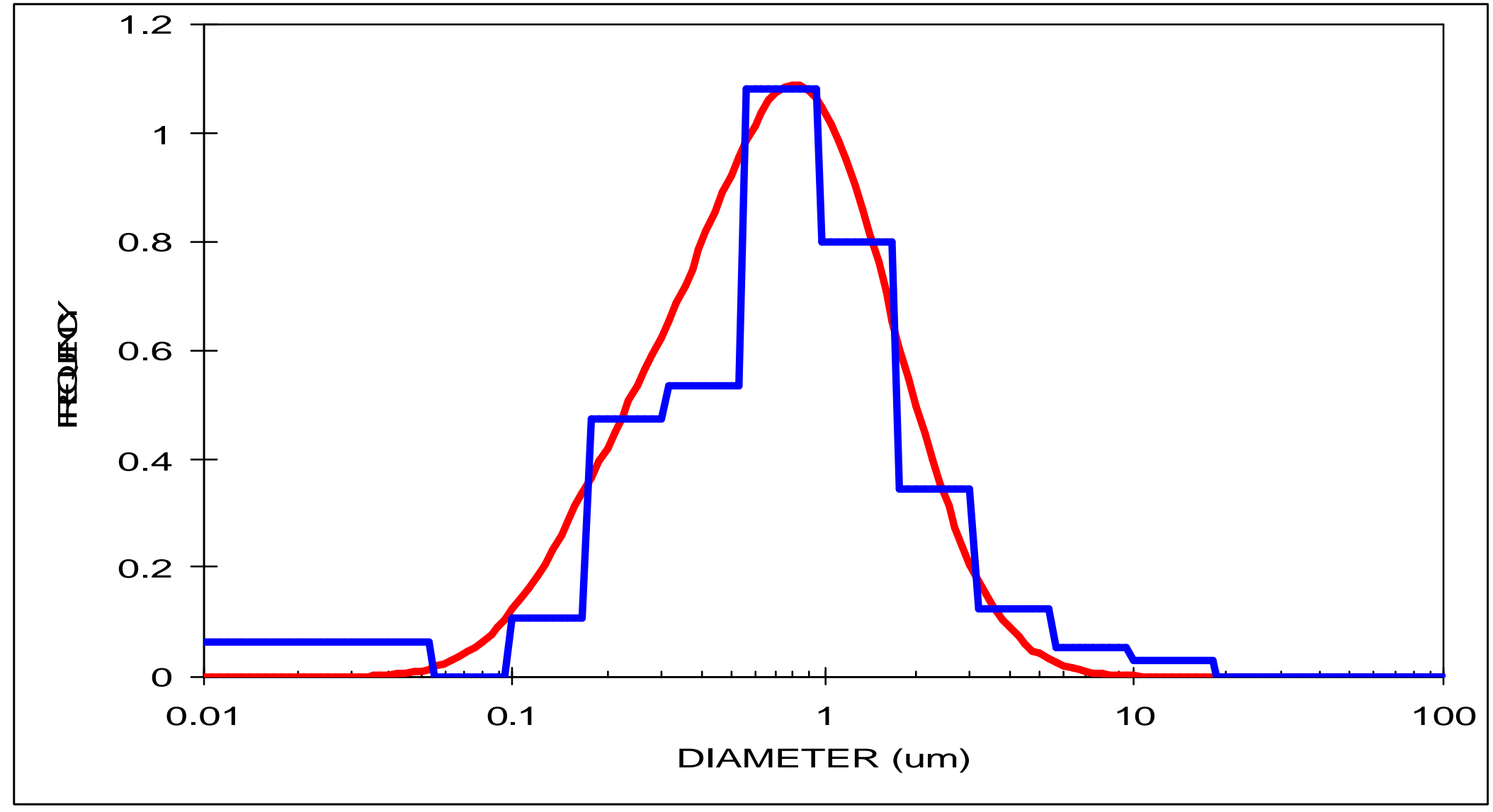

Figure 23. Mass size distribution of carbon black aerosol at mass concentration of $7 \mathrm{mg} / \mathrm{m}^{3}$ and grinding nozzle pressure of 80 PSI using the 10 stage MOUDI. 


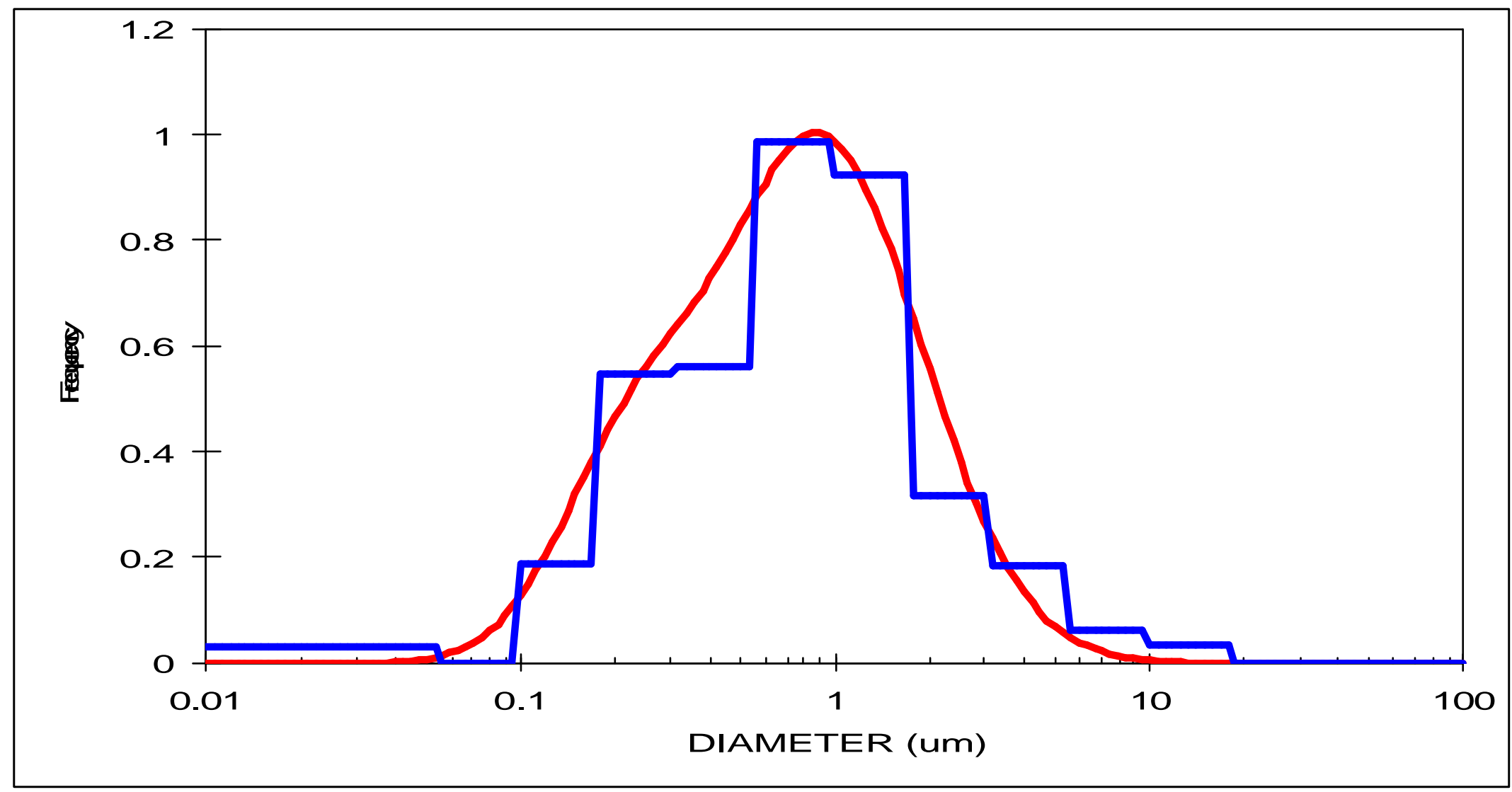

Figure 24. Mass size distribution of carbon black aerosol at mass concentration of $10 \mathrm{mg} / \mathrm{m}^{3}$ and grinding nozzle pressure of 40 PSI using the 10 stage MOUDI. 


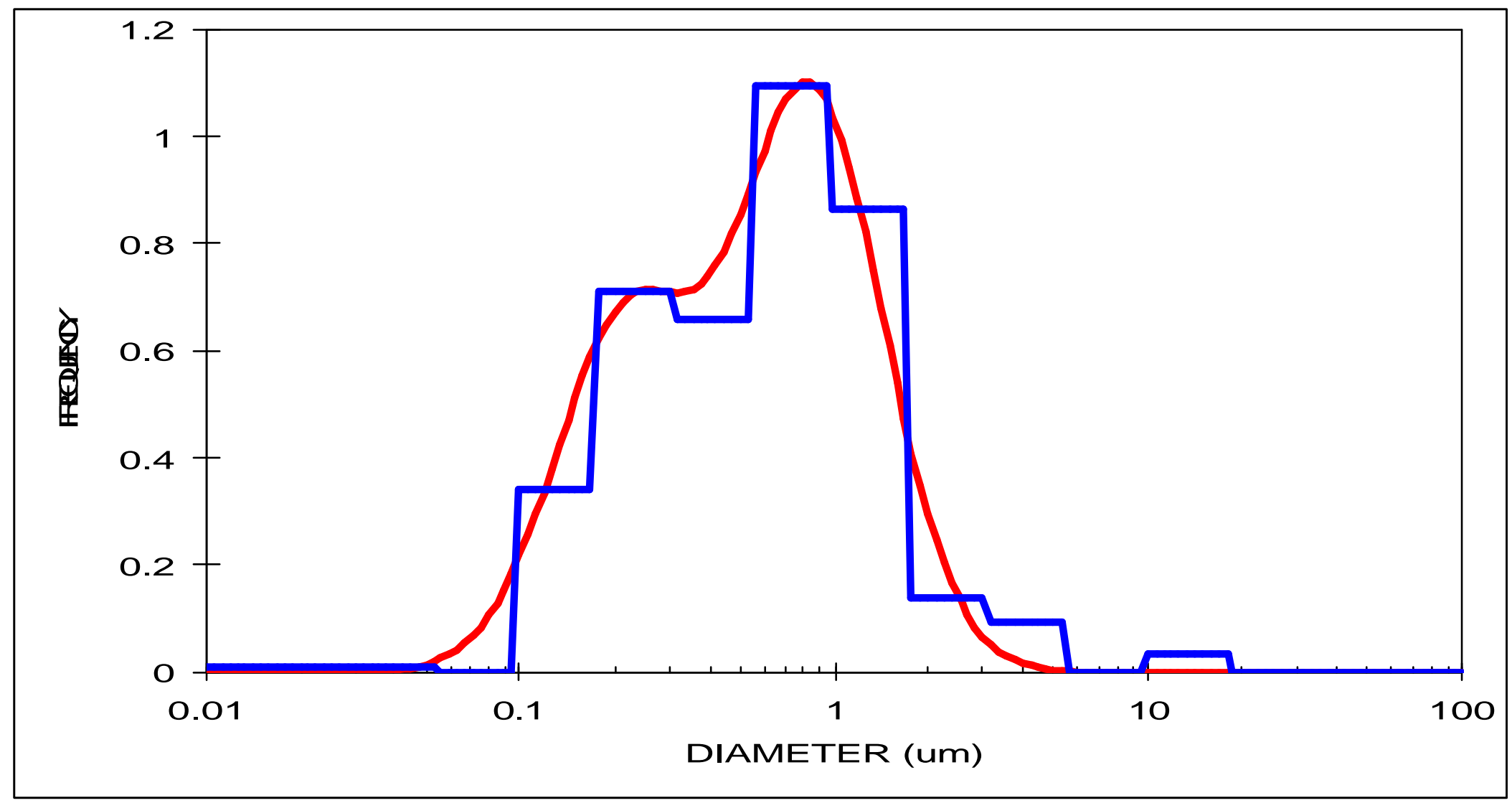

Figure 25. Mass size distribution of carbon black aerosol at mass concentration of $14 \mathrm{mg} / \mathrm{m}^{3}$ and grinding nozzle pressure of 40 PSI using the 10 stage MOUDI. 


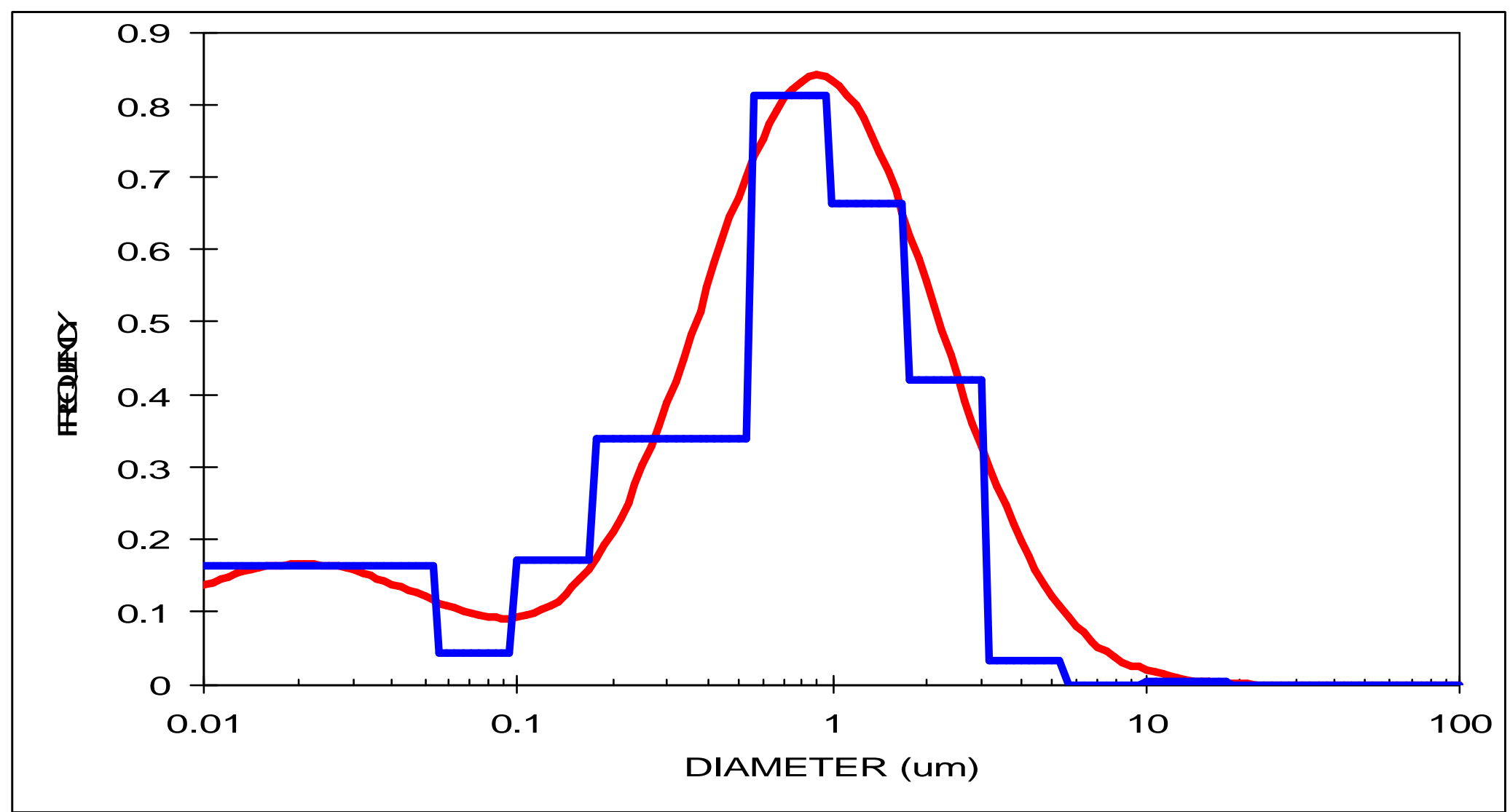

Figure 26. Mass size distribution of carbon black aerosol at mass concentration of $9 \mathrm{mg} / \mathrm{m}^{3}$ and grinding nozzle pressure of 40 PSI using the 10 stage MOUDI. 


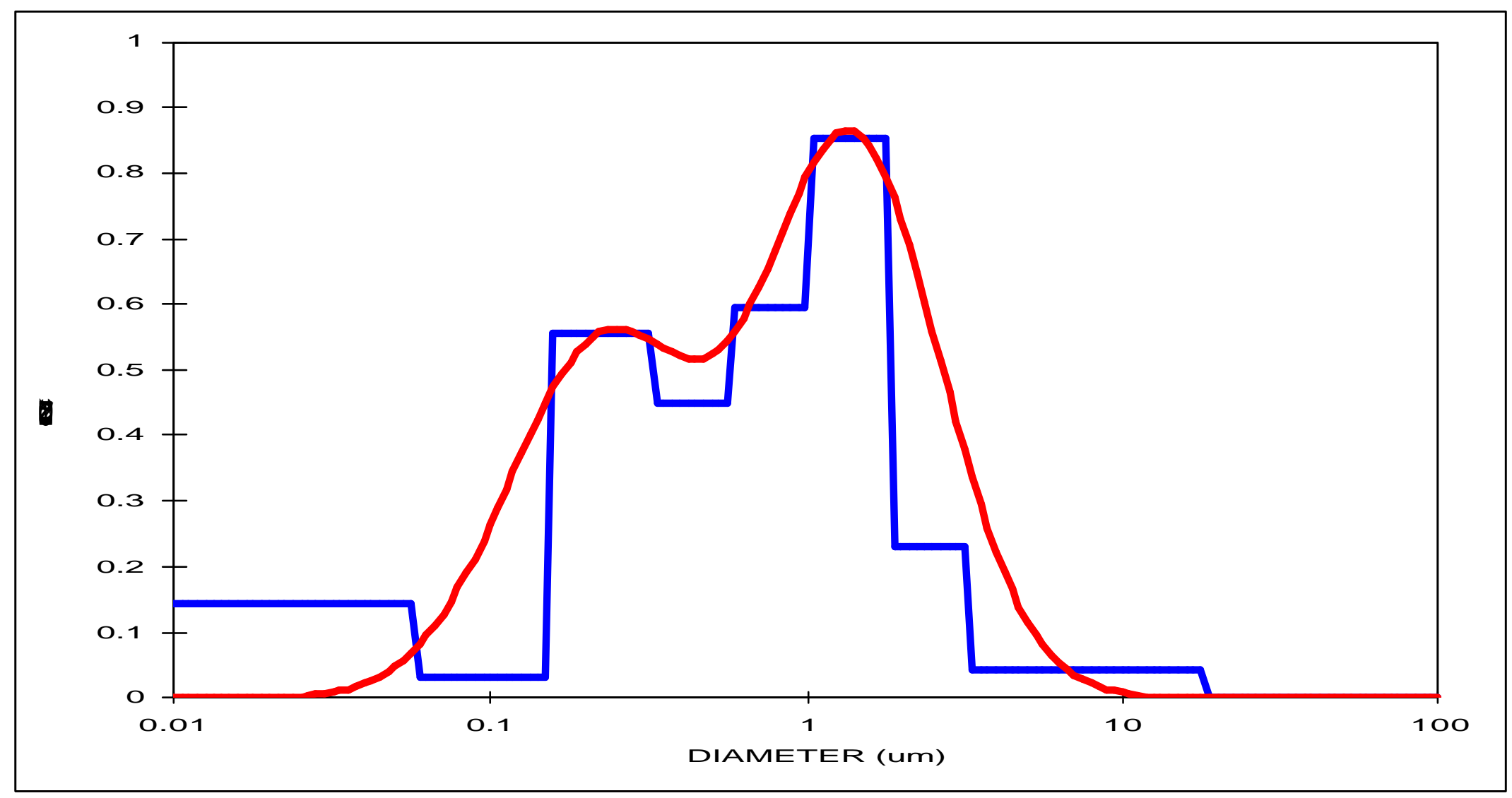

Figure 27. Mass size distribution of carbon black aerosol at mass concentration of $6.1 \mathrm{mg} / \mathrm{m}^{3}$ and grinding nozzle pressure of 40 PSI using the 8 stage MOUDI. 


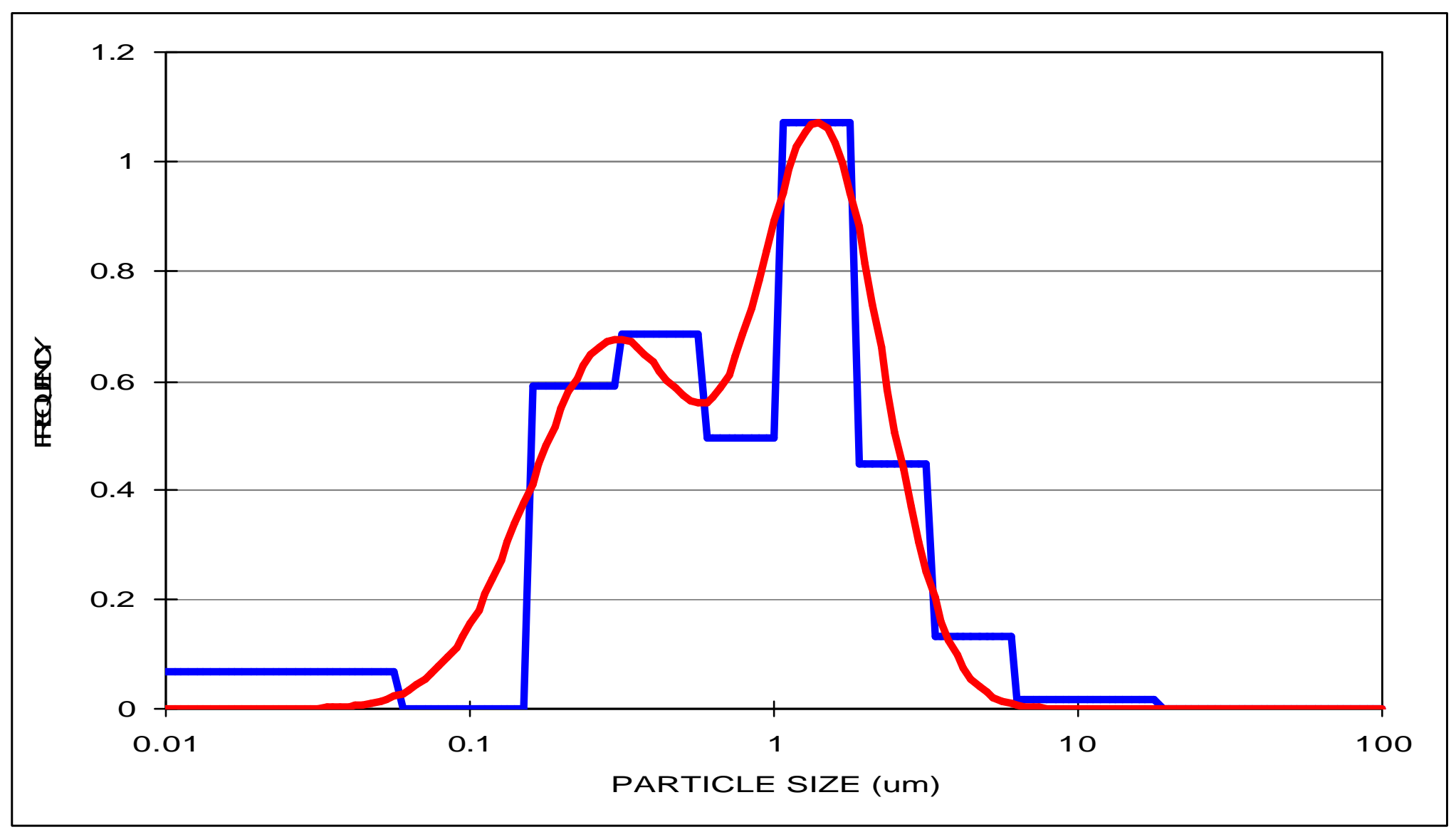

Figure 28. Mass size distribution of carbon black aerosol at mass concentration of $3.6 \mathrm{mg} / \mathrm{m}^{3}$ and grinding nozzle pressure of 40 PSI using the 8 stage MOUDI. 


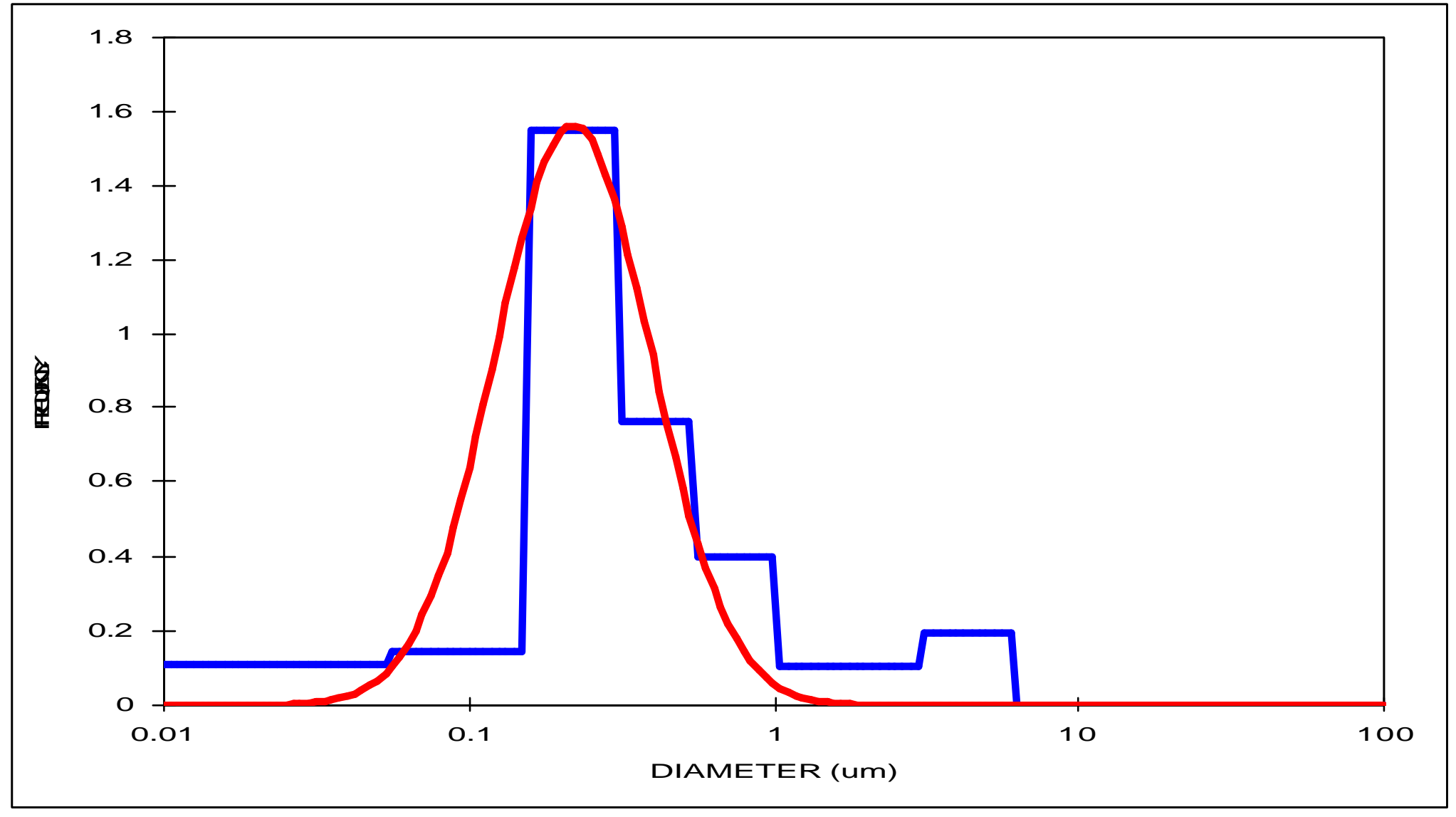

Figure 29. Mass size distribution of DEP aerosol at a mass concentration of $3.2 \mathrm{mg} / \mathrm{m}^{3}$ and grinding nozzle pressure of 80 PSI using the 8 stage MOUDI. 


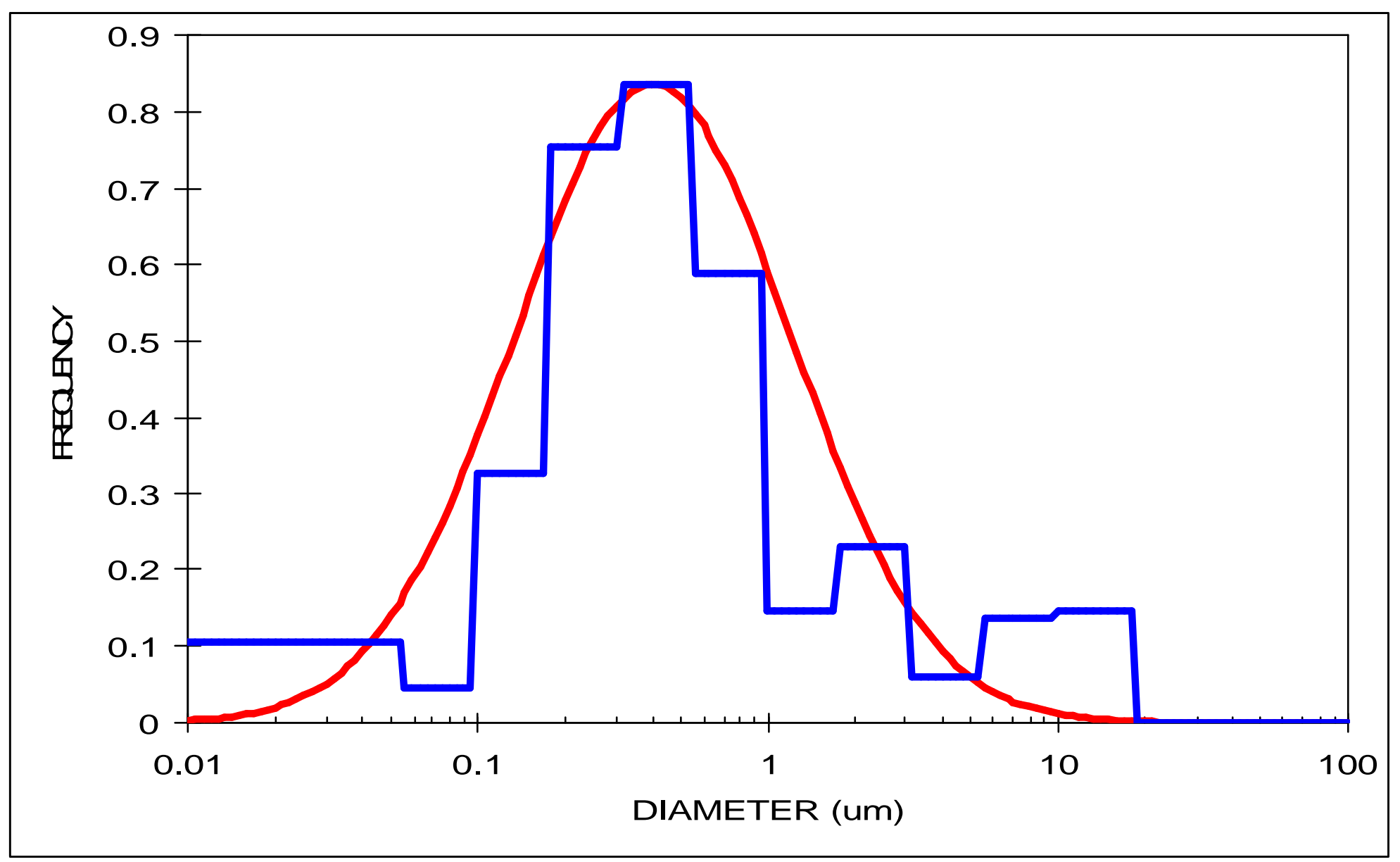

Figure 30. Mass size distribution of DEP aerosol at a mass concentration of $11 \mathrm{mg} / \mathrm{m}^{3}$ and grinding nozzle pressure of 80 PSI using the 10 stage MOUDI. 


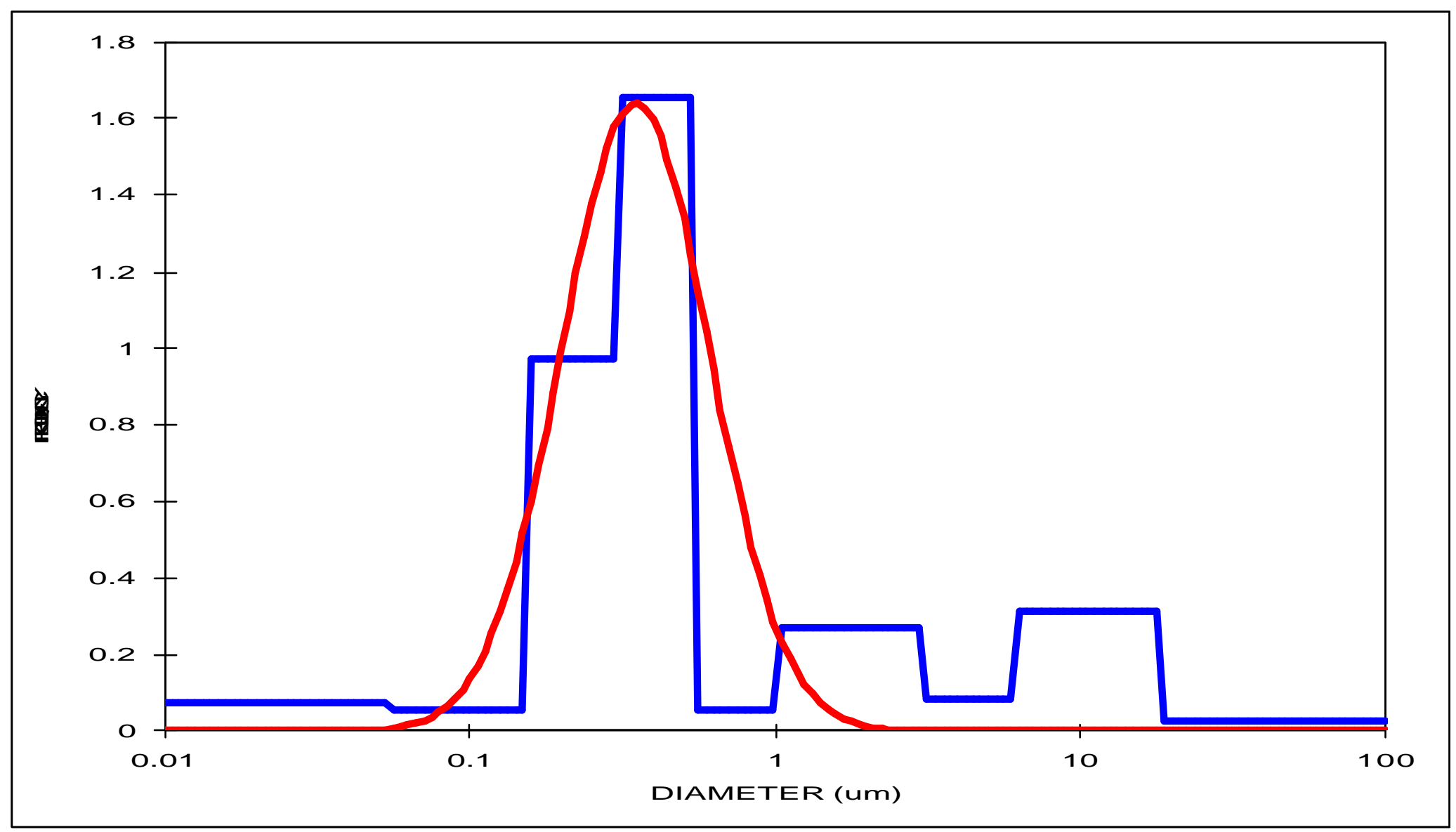

Figure 31. Mass size distribution of DEP aerosol at a mass concentration of $2.5 \mathrm{mg} / \mathrm{m}^{3}$ and grinding nozzle pressure of 80 PSI using the 8 stage MOUDI. 


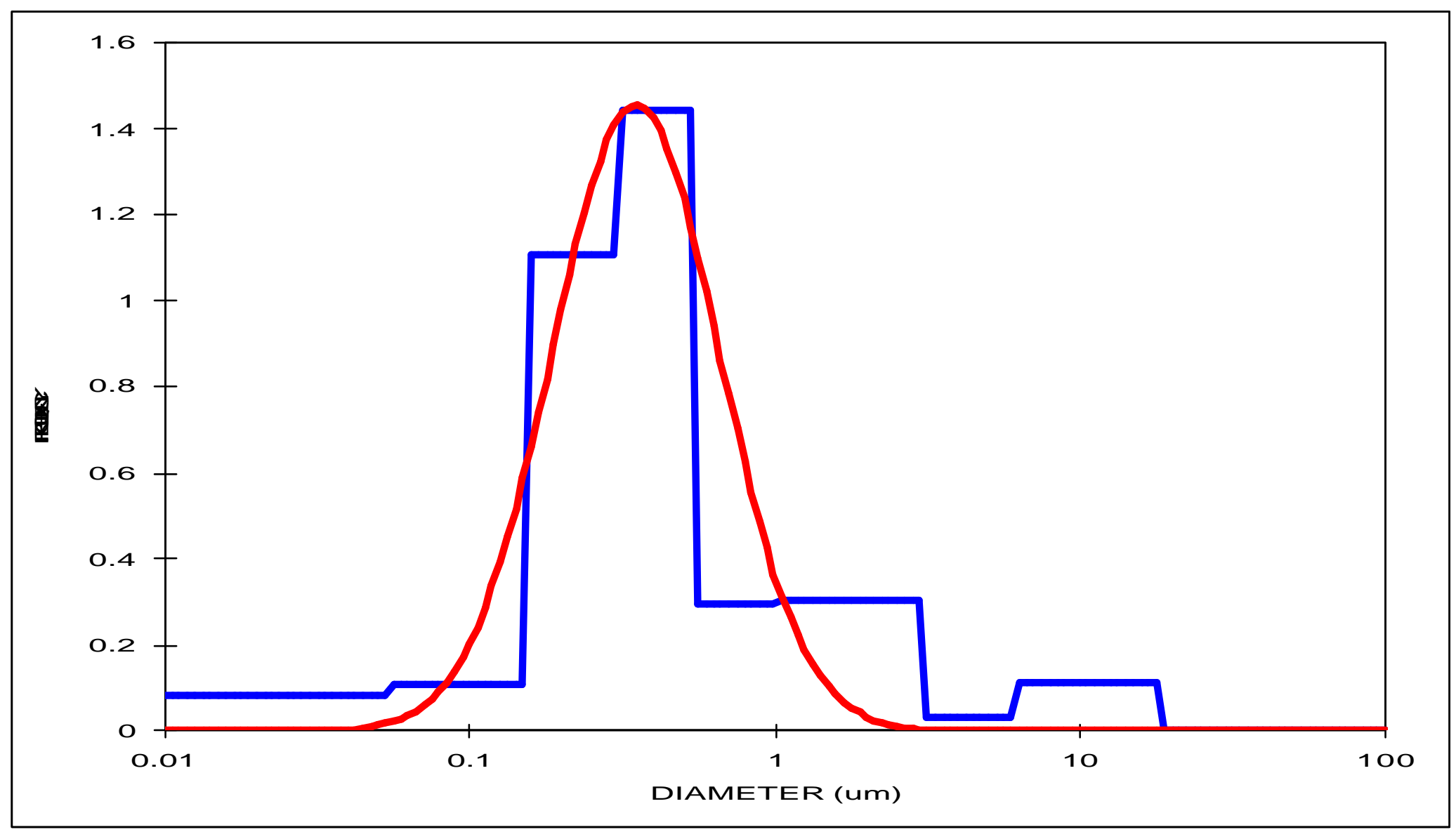

Figure 32. Mass size distribution of DEP aerosol at a mass concentration of $4 \mathrm{mg} / \mathrm{m}^{3}$ and grinding nozzle pressure of 80 PSI using the 8 stage MOUDI. 


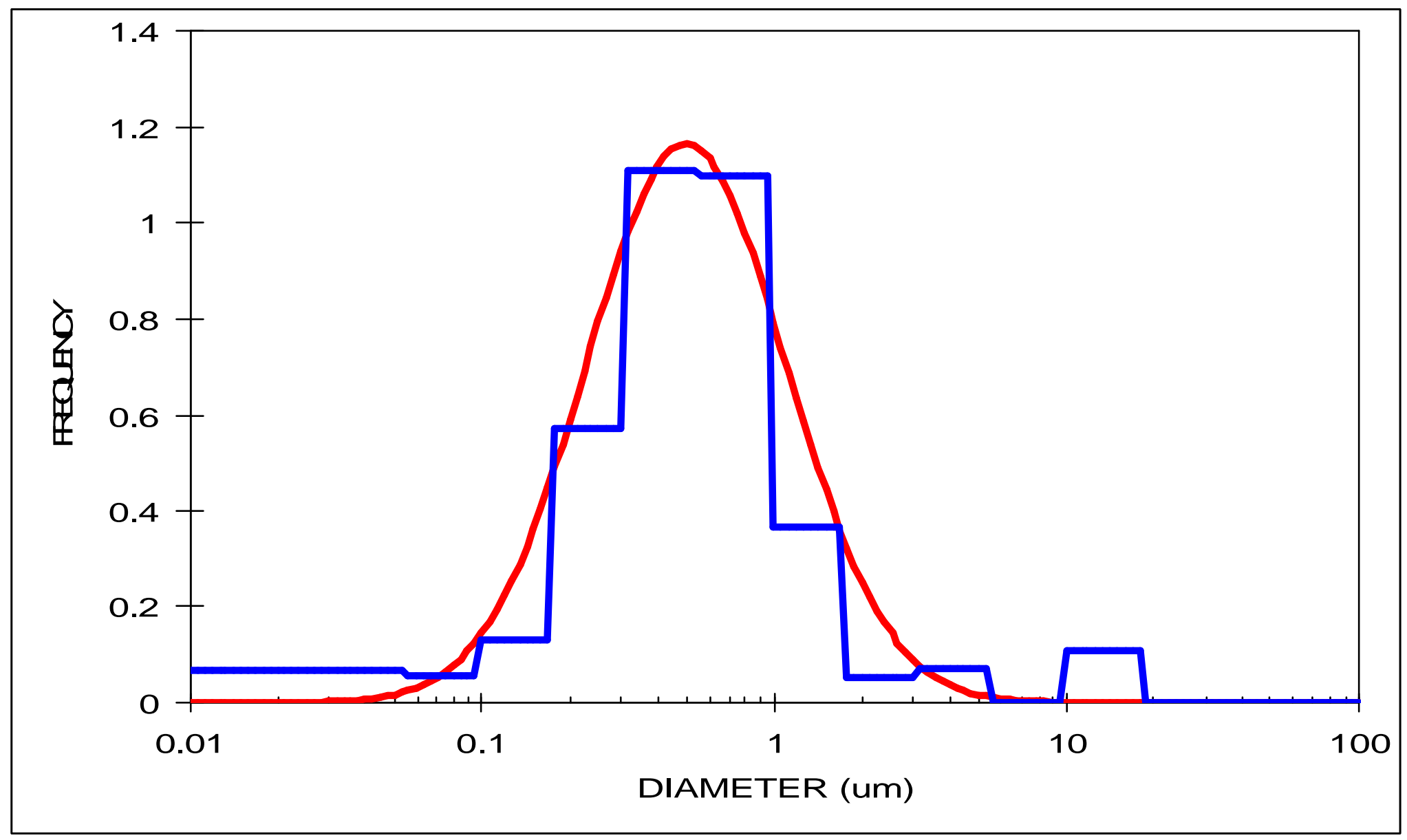

Figure 33. Mass size distribution of DEP aerosol at a mass concentration of $5.2 \mathrm{mg} / \mathrm{m}^{3}$ and grinding nozzle pressure of 40 PSI using the 10 stage MOUDI. 


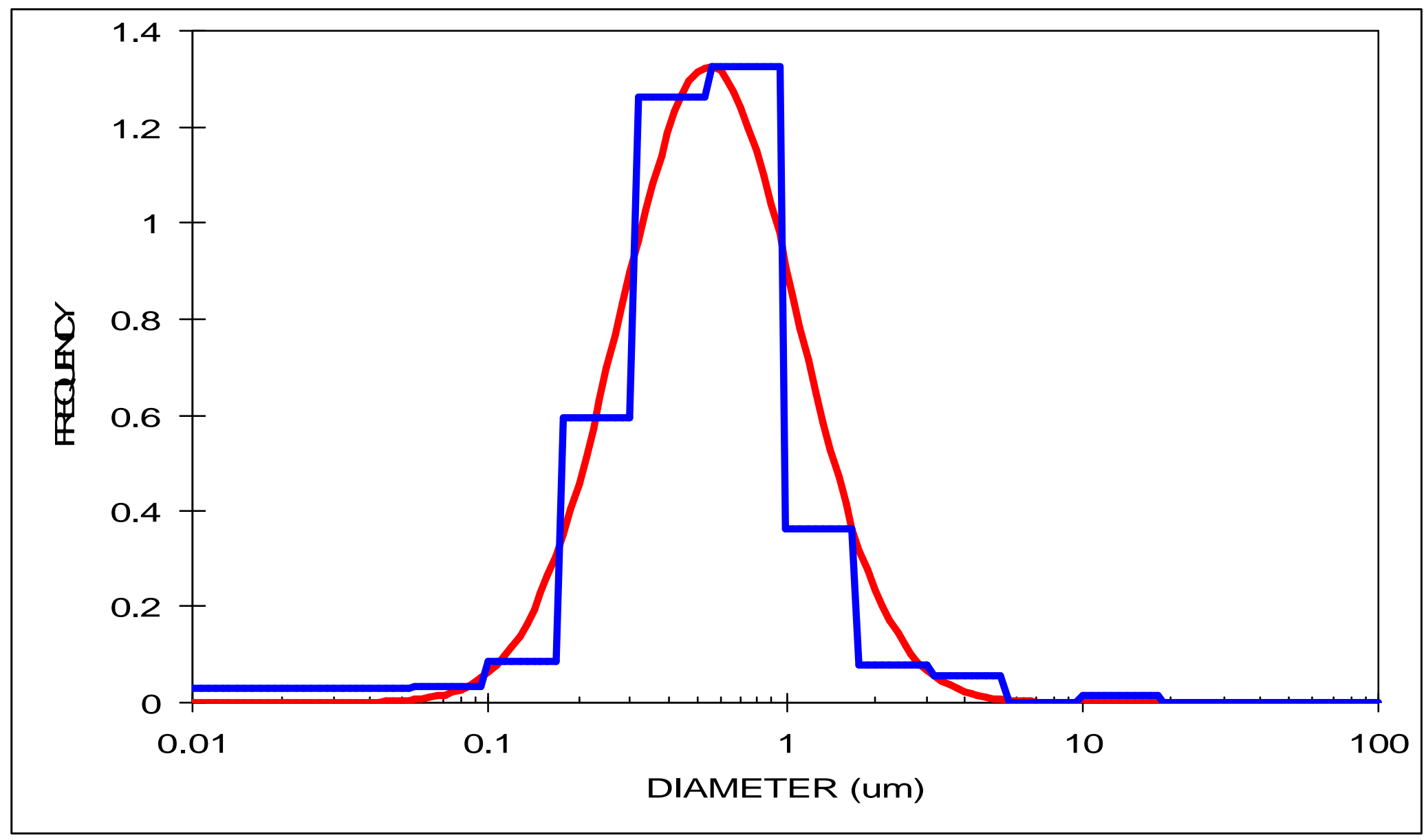

Figure 34. Mass size distribution of DEP aerosol at a mass concentration of $3.5 \mathrm{mg} / \mathrm{m}^{3}$ and grinding nozzle pressure of 40 PSI using the 10 stage MOUDI. 


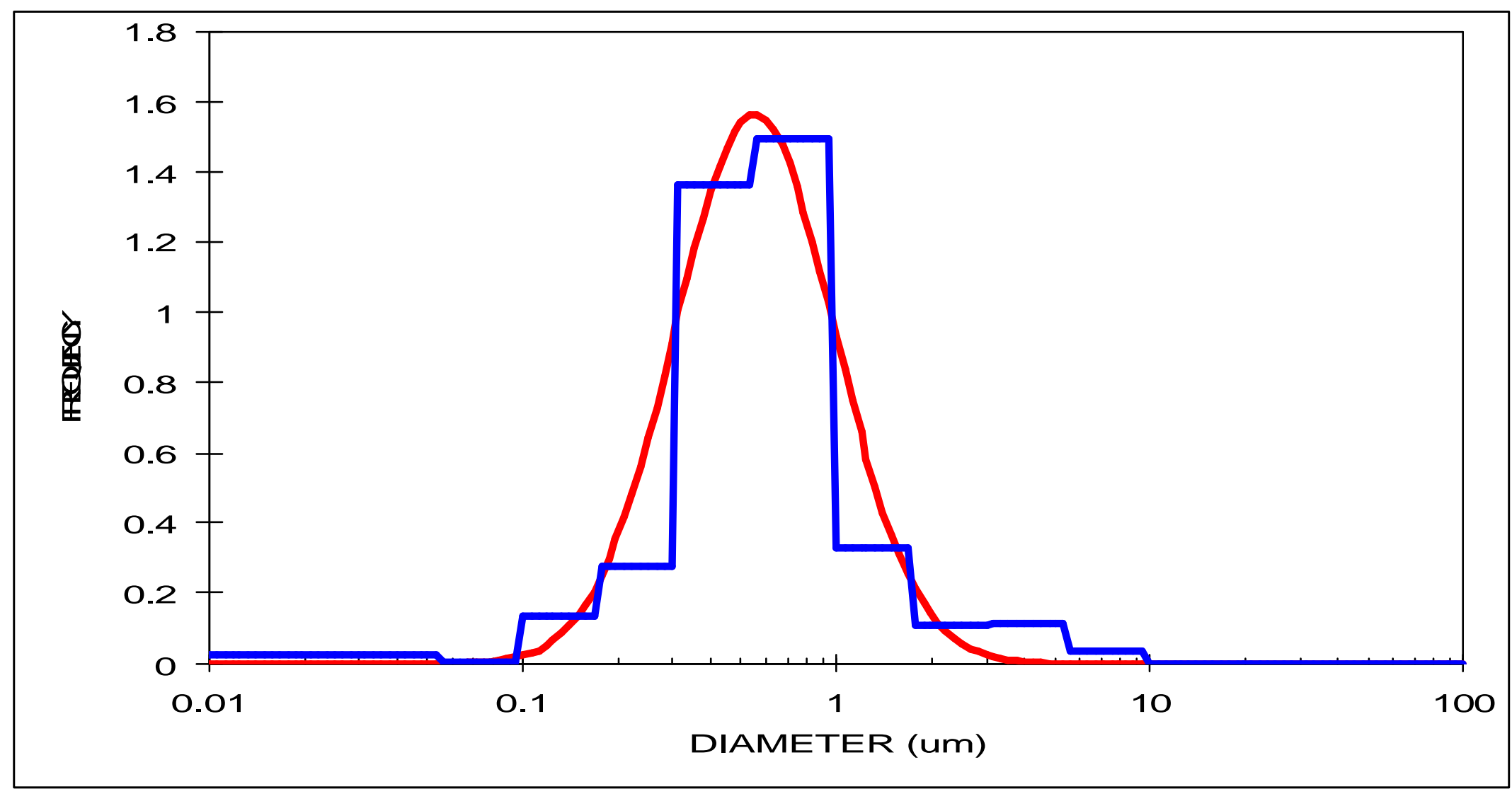

Figure 35. Mass size distribution of DEP aerosol at a mass concentration of $2 \mathrm{mg} / \mathrm{m}^{3}$ and grinding nozzle pressure of 40 PSI using the 10 stage MOUDI. 
Appendix B: MOUDI Tables 


\begin{tabular}{|c|c|c|c|c|c|c|c|}
\hline $\begin{array}{c}\text { Stage } \\
\text { number }\end{array}$ & $\begin{array}{c}\text { pre wt } \\
(\mathrm{mg})\end{array}$ & $\begin{array}{c}\text { post wt } \\
(\mathrm{mg})\end{array}$ & $\begin{array}{c}\text { net wt } \\
(\mathrm{mg})\end{array}$ & $\begin{array}{c}\text { size range } \\
\text { (um) }\end{array}$ & $\begin{array}{c}\% \text { by } \\
\text { stage }\end{array}$ & $\begin{array}{c}\text { Cum } \\
\text { mass } \\
(\%)\end{array}$ & frequency \\
\hline $\begin{array}{c}\text { Final } \\
\text { filter }\end{array}$ & 109.521 & 109.558 & 0.037 & $0.001-0.056$ & 0.03 & 1.00 & 0.00 \\
\hline 1 & 78.268 & 78.271 & 0.003 & $0.056-0.1$ & 0.00 & 0.97 & 0.02 \\
\hline 2 & 78.325 & 78.418 & 0.093 & $0.1-0.18$ & 0.09 & 0.96 & 0.06 \\
\hline 3 & 78.729 & 79.005 & 0.276 & $0.18-0.32$ & 0.26 & 0.88 & 0.08 \\
\hline 4 & 77.969 & 78.166 & 0.197 & $0.32-0.56$ & 0.18 & 0.62 & 0.58 \\
\hline 5 & 78.444 & 78.708 & 0.264 & $0.56-1$ & 0.25 & 0.43 & 0.98 \\
\hline 6 & 78.546 & 78.695 & 0.149 & $1 .-1.8$ & 0.14 & 0.18 & 0.72 \\
\hline 7 & 77.716 & 77.738 & 0.022 & $1.8-3.2$ & 0.02 & 0.04 & 1.04 \\
\hline 8 & 78.121 & 78.138 & 0.017 & $3.2-5.6$ & 0.02 & 0.02 & 0.36 \\
\hline 9 & 77.708 & 77.713 & 0.005 & $5.6-10$ & 0.00 & 0.01 & 0.01 \\
\hline 10 & 78.851 & 78.853 & 0.002 & $10-18$ & 0.00 & 0.00 & 0.14 \\
\hline 11 & & & 0 & $18-100$ & 0.00 & 0.00 & 0.00 \\
\hline Tare & 78.102 & 78.113 & \multicolumn{7}{|l}{}
\end{tabular}

Table 6. MOUDI at $80 \mathrm{psi}$ and $27 \mathrm{mg} / \mathrm{m}^{\wedge} 3$ mass concentration of carbon black aerosol. 


\begin{tabular}{|c|c|c|c|c|c|c|c|}
\hline $\begin{array}{c}\text { stage } \\
\text { number }\end{array}$ & $\begin{array}{c}\text { pre wt } \\
(\mathrm{mg})\end{array}$ & $\begin{array}{c}\text { post wt } \\
(\mathrm{mg})\end{array}$ & $\begin{array}{c}\text { Net wt } \\
(\mathrm{mg})\end{array}$ & $\begin{array}{c}\text { size range } \\
(\mathrm{um})\end{array}$ & $\begin{array}{c}\% \text { by } \\
\text { stage }\end{array}$ & $\begin{array}{c}\text { Cum } \\
\text { mass } \\
(\%)\end{array}$ & frequency \\
\hline $\begin{array}{c}\text { final } \\
\text { filter }\end{array}$ & 94.817 & 94.849 & 0.032 & $0.001-0.056$ & 0.04 & 1.00 & 0.02 \\
\hline 1 & 77.907 & 77.911 & 0.004 & $0.056-0.1$ & 0.01 & 0.96 & 0.02 \\
\hline 2 & 78.721 & 78.771 & 0.050 & $0.1-0.18$ & 0.07 & 0.95 & 0.26 \\
\hline 3 & 79.212 & 79.388 & 0.176 & $0.18-0.32$ & 0.24 & 0.88 & 0.95 \\
\hline 4 & 78.810 & 78.947 & 0.137 & $0.32-0.56$ & 0.18 & 0.65 & 0.76 \\
\hline 5 & 77.842 & 78.040 & 0.198 & $0.56-1$ & 0.27 & 0.46 & 1.06 \\
\hline 6 & 78.049 & 78.152 & 0.103 & $1 .-1.8$ & 0.14 & 0.20 & 0.54 \\
\hline 7 & 77.989 & 78.009 & 0.020 & $1.8-3.2$ & 0.03 & 0.06 & 0.11 \\
\hline 8 & 78.494 & 78.501 & 0.007 & $3.2-5.6$ & 0.01 & 0.03 & 0.04 \\
\hline 9 & 78.896 & 78.897 & 0.001 & $5.6-10$ & 0.00 & 0.02 & 0.01 \\
\hline 10 & 78.275 & 78.292 & 0.017 & $10-18$ & 0.02 & 0.02 & 0.09 \\
\hline 11 & & & 0.000 & $18-100$ & 0.00 & 0.00 & 0.00 \\
\hline tare & 78.068 & 78.069 & \multicolumn{7}{|l}{} \\
\hline
\end{tabular}

Table 7. MOUDI at $80 \mathrm{psi}$ and $25 \mathrm{mg} / \mathrm{m}^{3}$ mass concentration of carbon black aerosol. 


\begin{tabular}{|c|c|c|c|c|c|c|c|}
\hline $\begin{array}{c}\text { stage } \\
\text { number }\end{array}$ & $\begin{array}{c}\text { pre wt } \\
(\mathrm{mg})\end{array}$ & $\begin{array}{c}\text { post wt } \\
(\mathrm{mg})\end{array}$ & $\begin{array}{c}\text { net wt } \\
(\mathrm{mg})\end{array}$ & $\begin{array}{c}\text { size range } \\
(\mathrm{um})\end{array}$ & $\begin{array}{c}\% \text { by } \\
\text { stage }\end{array}$ & $\begin{array}{c}\text { Cum } \\
\text { mass } \\
(\%)\end{array}$ & frequency \\
\hline $\begin{array}{c}\text { final } \\
\text { filter }\end{array}$ & 105.184 & 105.204 & 0.020 & $0.001-0.056$ & 0.03 & 1.00 & 0.02 \\
\hline 1 & 78.829 & 78.833 & 0.004 & $0.056-0.1$ & 0.01 & 0.97 & 0.03 \\
\hline 2 & 78.885 & 78.938 & 0.053 & $0.1-0.18$ & 0.09 & 0.96 & 0.34 \\
\hline 3 & 77.551 & 77.704 & 0.153 & $0.18-0.32$ & 0.25 & 0.88 & 0.99 \\
\hline 4 & 78.665 & 78.782 & 0.117 & $0.32-0.56$ & 0.19 & 0.63 & 0.78 \\
\hline 5 & 78.425 & 78.549 & 0.124 & $0.56-1$ & 0.20 & 0.44 & 0.80 \\
\hline 6 & 77.574 & 77.676 & 0.102 & $1 .-1.8$ & 0.17 & 0.24 & 0.65 \\
\hline 7 & 78.797 & 78.821 & 0.025 & $1.8-3.2$ & 0.04 & 0.07 & 0.16 \\
\hline 8 & 78.578 & 78.585 & 0.007 & $3.2-5.6$ & 0.01 & 0.03 & 0.05 \\
\hline 9 & 78.456 & 78.461 & 0.005 & $5.6-10$ & 0.01 & 0.02 & 0.03 \\
\hline 10 & 78.390 & 78.398 & 0.008 & $10-18$ & 0.01 & 0.01 & 0.05 \\
\hline 11 & & & 0.000 & $18-100$ & 0.00 & 0.00 & 0.00 \\
\hline tare & 75.592 & 75.592 & \multicolumn{7}{l}{}
\end{tabular}

Table 8. MOUDI at $80 \mathrm{psi}$ and $16 \mathrm{mg} / \mathrm{m}^{3}$ mass concentration of carbon black aerosol. 


\begin{tabular}{|c|c|c|c|c|c|c|c|}
\hline $\begin{array}{c}\text { stage } \\
\text { number }\end{array}$ & $\begin{array}{c}\text { pre wt } \\
(\mathrm{mg})\end{array}$ & $\begin{array}{c}\text { post wt } \\
(\mathrm{mg})\end{array}$ & $\begin{array}{c}\text { net wt } \\
(\mathrm{mg})\end{array}$ & $\begin{array}{c}\text { size range } \\
(\mathrm{um})\end{array}$ & $\begin{array}{c}\% \text { by } \\
\text { stage }\end{array}$ & $\begin{array}{c}\text { Cum } \\
\text { mass } \\
(\%)\end{array}$ & frequency \\
\hline $\begin{array}{c}\text { final } \\
\text { filter }\end{array}$ & 103.801 & 103.820 & 0.019 & $0.001-0.056$ & 0.03 & 1.00 & 0.02 \\
\hline 1 & 78.268 & 78.274 & 0.006 & $0.056-0.1$ & 0.01 & 0.97 & 0.04 \\
\hline 2 & 78.404 & 78.458 & 0.054 & $0.1-0.18$ & 0.09 & 0.96 & 0.36 \\
\hline 3 & 78.800 & 78.923 & 0.123 & $0.18-0.32$ & 0.21 & 0.87 & 0.83 \\
\hline 4 & 78.379 & 78.470 & 0.091 & $0.32-0.56$ & 0.15 & 0.66 & 0.63 \\
\hline 5 & 78.657 & 78.808 & 0.151 & $0.56-1$ & 0.25 & 0.51 & 1.01 \\
\hline 6 & 78.691 & 78.791 & 0.100 & $1 .-1.8$ & 0.17 & 0.25 & 0.66 \\
\hline 7 & 77.736 & 77.765 & 0.029 & $1.8-3.2$ & 0.05 & 0.08 & 0.20 \\
\hline 8 & 78.131 & 78.146 & 0.015 & $3.2-5.6$ & 0.03 & 0.03 & 0.10 \\
\hline 9 & 77.709 & 77.710 & 0.001 & $5.6-10$ & 0.00 & 0.01 & 0.01 \\
\hline 10 & 78.851 & 78.855 & 0.004 & $10-18$ & 0.01 & 0.01 & 0.03 \\
\hline 11 & & & 0.000 & $18-100$ & 0.00 & 0.00 & 0.00 \\
\hline tare & 78.112 & 78.098 & \multicolumn{7}{l}{}
\end{tabular}

Table 9. MOUDI at $80 \mathrm{psi}$ and $15 \mathrm{mg} / \mathrm{m}^{3}$ mass concentration of carbon black aerosol. 


\begin{tabular}{|c|c|c|c|c|c|c|c|}
\hline $\begin{array}{c}\text { stage } \\
\text { number }\end{array}$ & $\begin{array}{c}\text { pre wt } \\
(\mathrm{mg})\end{array}$ & $\begin{array}{c}\text { post wt } \\
(\mathrm{mg})\end{array}$ & $\begin{array}{c}\text { net wt } \\
(\mathrm{mg})\end{array}$ & $\begin{array}{c}\text { size range } \\
(\mathrm{um})\end{array}$ & $\begin{array}{c}\% \text { by } \\
\text { stage }\end{array}$ & $\begin{array}{c}\text { Cum } \\
\text { mass } \\
(\%)\end{array}$ & frequency \\
\hline $\begin{array}{c}\text { final } \\
\text { filter }\end{array}$ & 102.742 & 102.756 & 0.014 & $0.001-0.056$ & 0.02 & 1.00 & 0.01 \\
\hline 1 & 77.909 & 77.923 & 0.014 & $0.056-0.1$ & 0.02 & 0.98 & 0.09 \\
\hline 2 & 77.459 & 77.521 & 0.062 & $0.1-0.18$ & 0.10 & 0.95 & 0.41 \\
\hline 3 & 77.822 & 77.960 & 0.138 & $0.18-0.32$ & 0.23 & 0.85 & 0.93 \\
\hline 4 & 78.837 & 78.933 & 0.096 & $0.32-0.56$ & 0.16 & 0.61 & 0.67 \\
\hline 5 & 77.957 & 78.092 & 0.135 & $0.56-1$ & 0.23 & 0.45 & 0.91 \\
\hline 6 & 78.192 & 78.277 & 0.085 & $1 .-1.8$ & 0.14 & 0.22 & 0.56 \\
\hline 7 & 78.009 & 78.030 & 0.021 & $1.8-3.2$ & 0.04 & 0.08 & 0.14 \\
\hline 8 & 78.498 & 78.512 & 0.014 & $3.2-5.6$ & 0.02 & 0.04 & 0.10 \\
\hline 9 & 78.894 & 78.902 & 0.008 & $5.6-10$ & 0.01 & 0.02 & 0.05 \\
\hline 10 & 78.291 & 78.295 & 0.004 & $10-18$ & 0.01 & 0.01 & 0.03 \\
\hline 11 & & & 0.000 & $18-100$ & 0.00 & 0.00 & 0.00 \\
\hline tare & 78.069 & 78.070 & \multicolumn{7}{l}{}
\end{tabular}

Table 10. MOUDI at $80 \mathrm{psi}$ and $13 \mathrm{mg} / \mathrm{m}^{3}$ mass concentration of carbon black aerosol. 


\begin{tabular}{|c|c|c|c|c|c|c|c|}
\hline $\begin{array}{c}\text { stage } \\
\text { number }\end{array}$ & $\begin{array}{c}\text { pre wt } \\
(\mathrm{mg})\end{array}$ & $\begin{array}{c}\text { post wt } \\
(\mathrm{mg})\end{array}$ & $\begin{array}{c}\text { Net wt } \\
(\mathrm{mg})\end{array}$ & $\begin{array}{c}\text { size range } \\
(\mathrm{um})\end{array}$ & $\begin{array}{c}\% \text { by } \\
\text { stage }\end{array}$ & $\begin{array}{c}\text { Cum } \\
\text { mass } \\
(\%)\end{array}$ & frequency \\
\hline $\begin{array}{c}\text { final } \\
\text { filter }\end{array}$ & 93.681 & 93.728 & 0.047 & $0.001-0.056$ & 0.11 & 1.00 & 0.06 \\
\hline 1 & 78.269 & 78.252 & 0.000 & $0.056-0.1$ & 0.00 & 0.89 & 0.00 \\
\hline 2 & 78.670 & 78.682 & 0.012 & $0.1-0.18$ & 0.03 & 0.89 & 0.11 \\
\hline 3 & 77.953 & 78.004 & 0.051 & $0.18-0.32$ & 0.12 & 0.86 & 0.47 \\
\hline 4 & 77.575 & 77.631 & 0.056 & $0.32-0.56$ & 0.13 & 0.74 & 0.54 \\
\hline 5 & 78.199 & 78.316 & 0.117 & $0.56-1$ & 0.27 & 0.61 & 1.08 \\
\hline 6 & 78.747 & 78.835 & 0.088 & $1 .-1.8$ & 0.20 & 0.34 & 0.80 \\
\hline 7 & 77.767 & 77.804 & 0.037 & $1.8-3.2$ & 0.09 & 0.14 & 0.34 \\
\hline 8 & 78.148 & 78.161 & 0.013 & $3.2-5.6$ & 0.03 & 0.05 & 0.12 \\
\hline 9 & 77.711 & 77.717 & 0.006 & $5.6-10$ & 0.01 & 0.02 & 0.06 \\
\hline 10 & 78.853 & 78.856 & 0.003 & $10-18$ & 0.01 & 0.01 & 0.03 \\
\hline 11 & & & 0.000 & $18-100$ & 0.00 & 0.00 & 0.00 \\
\hline tare & 78.096 & 78.098 & \multicolumn{7}{|l}{}
\end{tabular}

Table 11. MOUDI at $80 \mathrm{psi}$ and $7 \mathrm{mg} / \mathrm{m}^{3}$ mass concentration of carbon black aerosol. 


\begin{tabular}{|c|c|c|c|c|c|c|c|}
\hline $\begin{array}{c}\text { stage } \\
\text { number }\end{array}$ & $\begin{array}{c}\text { pre wt } \\
(\mathrm{mg})\end{array}$ & $\begin{array}{c}\text { post wt } \\
(\mathrm{mg})\end{array}$ & $\begin{array}{c}\text { Net wt } \\
(\mathrm{mg})\end{array}$ & $\begin{array}{c}\text { size range } \\
\text { (um) }\end{array}$ & $\begin{array}{c}\text { \% by } \\
\text { stage }\end{array}$ & $\begin{array}{c}\text { Cum } \\
\text { mass } \\
(\%)\end{array}$ & frequency \\
\hline $\begin{array}{c}\text { final } \\
\text { filter }\end{array}$ & 98.030 & 98.052 & 0.022 & $0.001-0.056$ & 0.05 & 1.00 & 0.03 \\
\hline 1 & 77.926 & 77.915 & 0.000 & $0.056-0.1$ & 0.00 & 0.95 & 0.00 \\
\hline 2 & 77.926 & 77.948 & 0.022 & $0.1-0.18$ & 0.05 & 0.95 & 0.19 \\
\hline 3 & 78.027 & 78.089 & 0.062 & $0.18-0.32$ & 0.14 & 0.90 & 0.55 \\
\hline 4 & 78.282 & 78.344 & 0.062 & $0.32-0.56$ & 0.14 & 0.77 & 0.56 \\
\hline 5 & 78.509 & 78.622 & 0.113 & $0.56-1$ & 0.25 & 0.63 & 0.99 \\
\hline 6 & 77.848 & 77.955 & 0.107 & $1 .-1.8$ & 0.24 & 0.38 & 0.92 \\
\hline 7 & 78.030 & 78.066 & 0.036 & $1.8-3.2$ & 0.08 & 0.15 & 0.32 \\
\hline 8 & 78.511 & 78.531 & 0.020 & $3.2-5.6$ & 0.04 & 0.07 & 0.18 \\
\hline 9 & 78.903 & 78.910 & 0.007 & $5.6-10$ & 0.02 & 0.02 & 0.06 \\
\hline 10 & 78.300 & 78.304 & 0.004 & $10-18$ & 0.01 & 0.01 & 0.03 \\
\hline 11 & & & 0.000 & $18-100$ & 0.00 & 0.00 & 0.00 \\
\hline tare & 78.072 & 78.074 & & & & & \\
\end{tabular}

Table 12. MOUDI at $40 \mathrm{psi}$ and $10 \mathrm{mg} / \mathrm{m}^{3}$ mass concentration of carbon black aerosol. 


\begin{tabular}{|c|c|c|c|c|c|c|c|}
\hline $\begin{array}{c}\text { stage } \\
\text { number }\end{array}$ & $\begin{array}{c}\text { pre wt } \\
(\mathrm{mg})\end{array}$ & $\begin{array}{c}\text { post wt } \\
(\mathrm{mg})\end{array}$ & $\begin{array}{c}\text { net wt } \\
(\mathrm{mg})\end{array}$ & $\begin{array}{c}\text { size range } \\
(\mathrm{um})\end{array}$ & $\begin{array}{c}\% \text { by } \\
\text { stage }\end{array}$ & $\begin{array}{c}\text { Cum } \\
\text { mass } \\
(\%)\end{array}$ & frequency \\
\hline $\begin{array}{c}\text { final } \\
\text { filter }\end{array}$ & 105.751 & 105.758 & 0.007 & $0.001-0.056$ & 0.01 & 1.00 & 0.01 \\
\hline 1 & 78.829 & 78.824 & 0.000 & $0.056-0.1$ & 0.00 & 0.99 & 0.00 \\
\hline 2 & 77.781 & 77.824 & 0.043 & $0.1-0.18$ & 0.09 & 0.99 & 0.34 \\
\hline 3 & 78.422 & 78.510 & 0.088 & $0.18-0.32$ & 0.18 & 0.90 & 0.71 \\
\hline 4 & 78.016 & 78.095 & 0.079 & $0.32-0.56$ & 0.16 & 0.72 & 0.66 \\
\hline 5 & 77.576 & 77.712 & 0.136 & $0.56-1$ & 0.28 & 0.56 & 1.09 \\
\hline 6 & 77.866 & 77.975 & 0.109 & $1 .-1.8$ & 0.22 & 0.29 & 0.86 \\
\hline 7 & 78.824 & 78.841 & 0.017 & $1.8-3.2$ & 0.03 & 0.06 & 0.14 \\
\hline 8 & 78.584 & 78.595 & 0.011 & $3.2-5.6$ & 0.02 & 0.03 & 0.09 \\
\hline 9 & 78.460 & 78.422 & 0.000 & $5.6-10$ & 0.00 & 0.01 & 0.00 \\
\hline 10 & 78.401 & 78.405 & 0.004 & $10-18$ & 0.01 & 0.01 & 0.03 \\
\hline 11 & & & 0.000 & $18-100$ & 0.00 & 0.00 & 0.00 \\
\hline tare & 105.740 & $\mathrm{X}$ & \multicolumn{7}{|l}{}
\end{tabular}

Table 13. MOUDI at $40 \mathrm{psi}$ and $13 \mathrm{mg} / \mathrm{m}^{3}$ mass concentration of carbon black aerosol. 


\begin{tabular}{|c|c|c|c|c|c|c|c|}
\hline $\begin{array}{c}\text { stage } \\
\text { number }\end{array}$ & $\begin{array}{c}\text { pre wt } \\
(\mathrm{mg})\end{array}$ & $\begin{array}{c}\text { post wt } \\
(\mathrm{mg})\end{array}$ & $\begin{array}{c}\text { Net wt } \\
(\mathrm{mg})\end{array}$ & $\begin{array}{c}\text { size range } \\
(\mathrm{um})\end{array}$ & $\begin{array}{c}\text { \% by } \\
\text { stage }\end{array}$ & $\begin{array}{c}\text { Cum } \\
\text { mass } \\
(\%)\end{array}$ & frequency \\
\hline $\begin{array}{c}\text { final } \\
\text { filter }\end{array}$ & 54.560 & 54.777 & 0.217 & $0.001-0.056$ & 0.29 & 1.00 & 0.17 \\
\hline 1 & 79.289 & 79.297 & 0.008 & $0.056-0.1$ & 0.01 & 0.71 & 0.04 \\
\hline 2 & 79.357 & 79.390 & 0.033 & $0.1-0.18$ & 0.04 & 0.70 & 0.17 \\
\hline 3 & 78.095 & 78.159 & 0.064 & $0.18-0.32$ & 0.09 & 0.66 & 0.34 \\
\hline 4 & 78.925 & 78.987 & 0.062 & $0.32-0.56$ & 0.08 & 0.57 & 0.34 \\
\hline 5 & 78.270 & 78.424 & 0.154 & $0.56-1$ & 0.21 & 0.49 & 0.81 \\
\hline 6 & 78.524 & 78.651 & 0.127 & $1 .-1.8$ & 0.17 & 0.28 & 0.66 \\
\hline 7 & 79.224 & 79.303 & 0.079 & $1.8-3.2$ & 0.11 & 0.11 & 0.42 \\
\hline 8 & 79.419 & 79.425 & 0.006 & $3.2-5.6$ & 0.01 & 0.01 & 0.03 \\
\hline 9 & 78.378 & 78.378 & 0.000 & $5.6-10$ & 0.00 & 0.00 & 0.00 \\
\hline 10 & 78.541 & 78.542 & 0.001 & $10-18$ & 0.00 & 0.00 & 0.01 \\
\hline 11 & & & 0.000 & $18-100$ & 0.00 & 0.00 & 0.00 \\
\hline tare & 78.841 & 78.842 & \multicolumn{7}{|l}{} \\
\hline
\end{tabular}

Table 14. MOUDI at $40 \mathrm{psi}$ and $10 \mathrm{mg} / \mathrm{m}^{3}$ mass concentration of carbon black aerosol. 


\begin{tabular}{|c|c|c|c|c|c|c|c|}
\hline $\begin{array}{c}\text { stage } \\
\text { number }\end{array}$ & $\begin{array}{c}\text { pre wt } \\
(\mathrm{mg})\end{array}$ & $\begin{array}{c}\text { post wt } \\
(\mathrm{mg})\end{array}$ & $\begin{array}{c}\text { Net wt } \\
(\mathrm{mg})\end{array}$ & $\begin{array}{c}\text { size range } \\
\text { (um) }\end{array}$ & $\begin{array}{c}\% \text { by } \\
\text { stage }\end{array}$ & $\begin{array}{c}\text { Cum } \\
\text { mass } \\
(\%)\end{array}$ & frequency \\
\hline $\begin{array}{c}\text { final } \\
\text { filter }\end{array}$ & 54.507 & 54.612 & 0.105 & $.001-.056$ & 0.29 & 1.00 & 0.14 \\
\hline 1 & 79.320 & 79.323 & 0.003 & $.056-.15$ & 0.01 & 0.71 & 0.03 \\
\hline 2 & 78.330 & 78.381 & 0.051 & $.15-.30$ & 0.14 & 0.71 & 0.56 \\
\hline 3 & 78.327 & 78.367 & 0.04 & $.30-.56$ & 0.11 & 0.57 & 0.45 \\
\hline 4 & 79.475 & 79.530 & 0.055 & $.56-1.0$ & 0.15 & 0.46 & 0.60 \\
\hline 5 & 79.170 & 79.250 & 0.08 & $1.0-1.8$ & 0.22 & 0.31 & 0.85 \\
\hline 6 & 78.171 & 78.192 & 0.021 & $1.8-3.1$ & 0.06 & 0.09 & 0.23 \\
\hline 7 & 78.812 & 78.817 & 0.004 & $3.1-6.1$ & 0.01 & 0.03 & 0.04 \\
\hline 8 & 79.296 & 79.304 & 0.008 & $6.1-18$ & 0.02 & 0.02 & 0.04 \\
\hline 9 & & & 0 & $18-100$ & 0.00 & 0.00 & 0.00 \\
\hline tare & 78.393 & 78.385 & & & & & \\
\end{tabular}

Table 15. MOUDI at $40 \mathrm{psi}$ and $6 \mathrm{mg} / \mathrm{m}^{3}$ mass concentration of carbon black aerosol. 


\begin{tabular}{|c|c|c|c|c|c|c|c|}
\hline $\begin{array}{c}\text { stage } \\
\text { number }\end{array}$ & $\begin{array}{c}\text { pre wt } \\
(\mathrm{mg})\end{array}$ & $\begin{array}{c}\text { post wt } \\
(\mathrm{mg})\end{array}$ & $\begin{array}{c}\text { Net wt } \\
(\mathrm{mg})\end{array}$ & $\begin{array}{c}\text { size range } \\
\text { (um) }\end{array}$ & $\begin{array}{c}\text { \% by } \\
\text { stage }\end{array}$ & $\begin{array}{c}\text { Cum } \\
\text { mass } \\
(\%)\end{array}$ & frequency \\
\hline $\begin{array}{c}\text { final } \\
\text { filter }\end{array}$ & 54.434 & 54.463 & 0.029 & $.001-.056$ & 0.13 & 1.00 & 0.07 \\
\hline 1 & 78.814 & 78.846 & 0 & $.056-.15$ & 0.00 & 0.87 & 0.00 \\
\hline 2 & 79.621 & 79.616 & 0.032 & $.15-.30$ & 0.15 & 0.87 & 0.59 \\
\hline 3 & 78.147 & 78.183 & 0.036 & $.30-.56$ & 0.17 & 0.72 & 0.69 \\
\hline 4 & 78.883 & 78.910 & 0.027 & $.56-1.0$ & 0.13 & 0.55 & 0.50 \\
\hline 5 & 78.900 & 78.959 & 0.059 & $1.0-1.8$ & 0.27 & 0.43 & 1.07 \\
\hline 6 & 79.306 & 79.330 & 0.024 & $1.8-3.1$ & 0.11 & 0.15 & 0.44 \\
\hline 7 & 78.135 & 78.142 & 0.007 & $3.1-6.1$ & 0.03 & 0.04 & 0.13 \\
\hline 8 & 78.229 & 78.231 & 0.002 & $6.1-18$ & 0.01 & 0.01 & 0.02 \\
\hline 9 & & & 0 & $18-100$ & 0.00 & 0.00 & 0.00 \\
\hline tare & 78.016 & 78.008 & & & & & \\
\cline { 1 - 2 } ftare & 54.479 & 54.479 & & &
\end{tabular}

Table 16. MOUDI at $40 \mathrm{psi}$ and $3.5 \mathrm{mg} / \mathrm{m}^{3}$ mass concentration of carbon black aerosol. 


\begin{tabular}{|c|c|c|c|c|c|c|c|}
\hline $\begin{array}{c}\text { stage } \\
\text { number }\end{array}$ & $\begin{array}{c}\text { pre wt } \\
(\mathrm{mg})\end{array}$ & $\begin{array}{c}\text { post wt } \\
(\mathrm{mg})\end{array}$ & $\begin{array}{c}\text { Net wt } \\
(\mathrm{mg})\end{array}$ & $\begin{array}{c}\text { size range } \\
\text { (um) }\end{array}$ & $\begin{array}{c}\text { \% by } \\
\text { stage }\end{array}$ & $\begin{array}{c}\text { Cum } \\
\text { mass } \\
(\%)\end{array}$ & frequency \\
\hline $\begin{array}{c}\text { final } \\
\text { filter }\end{array}$ & 54.382 & 54.423 & 0.041 & $.001-.056$ & 0.22 & 1.00 & 0.11 \\
\hline 1 & 77.602 & 77.609 & 0.007 & $.056-.15$ & 0.04 & 0.78 & 0.15 \\
\hline 2 & 79.062 & 79.135 & 0.073 & $.15-.30$ & 0.39 & 0.75 & 1.55 \\
\hline 3 & 79.479 & 79.514 & 0.035 & $.30-.56$ & 0.19 & 0.36 & 0.76 \\
\hline 4 & 78.885 & 78.904 & 0.019 & $.56-1.0$ & 0.10 & 0.17 & 0.40 \\
\hline 5 & 78.004 & 78.009 & 0.005 & $1.0-1.8$ & 0.03 & 0.07 & 0.10 \\
\hline 6 & 78.052 & 78.061 & 0.009 & $1.8-3.1$ & 0.05 & 0.05 & 0.19 \\
\hline 7 & 78.285 & 78.279 & 0 & $3.1-6.1$ & 0.00 & 0.00 & 0.00 \\
\hline 8 & 78.228 & 78.208 & 0 & $6.1-18$ & 0.00 & 0.00 & 0.00 \\
\hline 9 & & & 0 & $18-100$ & 0.00 & 0.00 & 0.00 \\
\hline tare & 75.670 & 75.659 & & & & & \\
\cline { 1 - 1 } ftare & 54.211 & 54.209 & & &
\end{tabular}

Table 17. MOUDI at $80 \mathrm{psi}$ and $3.2 \mathrm{mg} / \mathrm{m}^{3}$ mass concentration of DEP aerosol. 


\begin{tabular}{|c|c|c|c|c|c|c|c|}
\hline $\begin{array}{c}\text { stage } \\
\text { number }\end{array}$ & $\begin{array}{l}\text { Pre wt } \\
\text { (mg) }\end{array}$ & $\begin{array}{c}\text { post wt } \\
\text { (mg) }\end{array}$ & $\begin{array}{l}\text { Net wt } \\
(\mathrm{mg})\end{array}$ & $\begin{array}{l}\text { size range } \\
\text { (um) }\end{array}$ & $\begin{array}{l}\% \text { by } \\
\text { stage }\end{array}$ & $\begin{array}{c}\text { Cum } \\
\text { mass } \\
(\%)\end{array}$ & frequency \\
\hline $\begin{array}{l}\text { final } \\
\text { filter }\end{array}$ & 54.784 & 54.849 & 0.065 & $0.001-0.056$ & 0.19 & 1.00 & 0.11 \\
\hline 1 & 79.296 & 79.300 & 0.004 & $0.056-0.1$ & 0.01 & 0.81 & 0.05 \\
\hline 2 & 78.832 & 78.861 & 0.029 & $0.1-0.18$ & 0.08 & 0.80 & 0.32 \\
\hline 3 & 78.223 & 78.289 & 0.066 & $0.18-0.32$ & 0.19 & 0.72 & 0.75 \\
\hline 4 & 78.605 & 78.676 & 0.071 & $0.32-0.56$ & 0.20 & 0.53 & 0.83 \\
\hline 5 & 79.070 & 79.122 & 0.052 & $0.56-1$ & 0.15 & 0.33 & 0.59 \\
\hline 6 & 78.507 & 78.520 & 0.013 & 1. -1.8 & 0.04 & 0.18 & 0.15 \\
\hline 7 & 79.309 & 79.329 & 0.020 & $1.8-3.2$ & 0.06 & 0.14 & 0.23 \\
\hline 8 & 79.428 & 79.433 & 0.005 & $3.2-5.6$ & 0.01 & 0.09 & 0.06 \\
\hline 9 & 78.385 & 78.397 & 0.012 & $5.6-10$ & 0.03 & 0.07 & 0.14 \\
\hline 10 & 78.536 & 78.549 & 0.013 & $10-18$ & 0.04 & 0.04 & 0.15 \\
\hline 11 & & & 0.000 & $18-100$ & 0.00 & 0.00 & 0.00 \\
\hline tare & 78.842 & 78.843 & & & & & \\
\hline ftare & 54.480 & 54.478 & & & & & \\
\hline
\end{tabular}

Table 18. MOUDI at $80 \mathrm{psi}$ and $11 \mathrm{mg} / \mathrm{m}^{3}$ mass concentration of DEP aerosol. 


\begin{tabular}{|c|c|c|c|c|c|c|c|}
\hline $\begin{array}{c}\text { stage } \\
\text { number }\end{array}$ & $\begin{array}{c}\text { Pre wt } \\
(\mathrm{mg})\end{array}$ & $\begin{array}{c}\text { post wt } \\
(\mathrm{mg})\end{array}$ & $\begin{array}{c}\text { Net wt } \\
(\mathrm{mg})\end{array}$ & $\begin{array}{c}\text { size range } \\
\text { (um) }\end{array}$ & $\begin{array}{c}\text { \% by } \\
\text { stage }\end{array}$ & $\begin{array}{c}\text { Cum } \\
\text { mass } \\
(\%)\end{array}$ & frequency \\
\hline $\begin{array}{c}\text { final } \\
\text { filter }\end{array}$ & 52.900 & 52.921 & 0.021 & $.001-.056$ & 0.15 & 1.00 & 0.07 \\
\hline 1 & 79.331 & 79.333 & 0.002 & $.056-.15$ & 0.01 & 0.85 & 0.05 \\
\hline 2 & 78.840 & 78.875 & 0.035 & $.15-.30$ & 0.24 & 0.84 & 0.97 \\
\hline 3 & 79.605 & 79.663 & 0.058 & $.30-.56$ & 0.40 & 0.60 & 1.66 \\
\hline 4 & 78.293 & 78.295 & 0.002 & $.56-1.0$ & 0.01 & 0.19 & 0.06 \\
\hline 5 & 78.984 & 78.994 & 0.01 & $1.0-1.8$ & 0.07 & 0.18 & 0.27 \\
\hline 6 & 78.189 & 78.192 & 0.003 & $1.8-3.1$ & 0.02 & 0.11 & 0.08 \\
\hline 7 & 78.810 & 78.821 & 0.011 & $3.1-6.1$ & 0.08 & 0.09 & 0.31 \\
\hline 8 & 79.305 & 79.307 & 0.002 & $6.1-18$ & 0.01 & 0.01 & 0.03 \\
\hline 9 & & & 0 & $18-100$ & 0.00 & 0.00 & 0.00 \\
\hline tare & 78.380 & 78.383 & & & & & \\
\cline { 2 - 5 }
\end{tabular}

Table 19. MOUDI at $80 \mathrm{psi}$ and $2.5 \mathrm{mg} / \mathrm{m}^{3}$ mass concentration of DEP aerosol. 


\begin{tabular}{|c|c|c|c|c|c|c|c|}
\hline $\begin{array}{c}\text { stage } \\
\text { number }\end{array}$ & $\begin{array}{c}\text { Pre wt } \\
(\mathrm{mg})\end{array}$ & $\begin{array}{c}\text { post wt } \\
(\mathrm{mg})\end{array}$ & $\begin{array}{c}\text { Net wt } \\
(\mathrm{mg})\end{array}$ & $\begin{array}{c}\text { size range } \\
\text { (um) }\end{array}$ & $\begin{array}{c}\text { \% by } \\
\text { stage }\end{array}$ & $\begin{array}{c}\text { Cum } \\
\text { mass } \\
(\%)\end{array}$ & frequency \\
\hline $\begin{array}{c}\text { final } \\
\text { filter }\end{array}$ & 55.034 & 55.075 & 0.041 & $.001-.056$ & 0.22 & 1.00 & 0.08 \\
\hline 1 & 79.612 & 79.619 & 0.007 & $.056-.15$ & 0.04 & 0.78 & 0.11 \\
\hline 2 & 78.146 & 78.217 & 0.071 & $.15-.30$ & 0.38 & 0.74 & 1.11 \\
\hline 3 & 77.634 & 77.724 & 0.019 & $.30-.56$ & 0.10 & 0.36 & 1.44 \\
\hline 4 & 79.552 & 79.571 & 0.019 & $.56-1.0$ & 0.10 & 0.26 & 0.29 \\
\hline 5 & 78.459 & 78.479 & 0.02 & $1.0-1.8$ & 0.11 & 0.16 & 0.30 \\
\hline 6 & 79.330 & 79.332 & 0.002 & $1.8-3.1$ & 0.01 & 0.05 & 0.03 \\
\hline 7 & 78.147 & 78.154 & 0.007 & $3.1-6.1$ & 0.04 & 0.04 & 0.11 \\
\hline 8 & 78.231 & 78.231 & 0 & $6.1-18$ & 0.00 & 0.00 & 0.00 \\
\hline 9 & & & 0 & $18-100$ & 0.00 & 0.00 & 0.00 \\
\hline tare & 78.005 & 78.007 & & & & & \\
\hline
\end{tabular}

Table 20. MOUDI at $80 \mathrm{psi}$ and $4 \mathrm{mg} / \mathrm{m}^{3}$ mass concentration of DEP aerosol. 


\begin{tabular}{|c|c|c|c|c|c|c|c|}
\hline $\begin{array}{c}\text { stage } \\
\text { number }\end{array}$ & $\begin{array}{c}\text { Pre wt } \\
(\mathrm{mg})\end{array}$ & $\begin{array}{c}\text { post wt } \\
(\mathrm{mg})\end{array}$ & $\begin{array}{c}\text { Net wt } \\
(\mathrm{mg})\end{array}$ & $\begin{array}{c}\text { size range } \\
\text { (um) }\end{array}$ & $\begin{array}{c}\text { \% by } \\
\text { stage }\end{array}$ & $\begin{array}{c}\text { Cum } \\
\text { mass } \\
(\%)\end{array}$ & frequency \\
\hline $\begin{array}{c}\text { final } \\
\text { filter }\end{array}$ & 54.519 & 54.644 & 0.125 & $0.001-0.056$ & 0.11 & 1.00 & 0.07 \\
\hline 1 & 77.624 & 77.639 & 0.015 & $0.056-0.1$ & 0.01 & 0.89 & 0.05 \\
\hline 2 & 77.636 & 77.672 & 0.036 & $0.1-0.18$ & 0.03 & 0.87 & 0.13 \\
\hline 3 & 77.373 & 77.530 & 0.157 & $0.18-0.32$ & 0.14 & 0.84 & 0.57 \\
\hline 4 & 77.549 & 77.845 & 0.296 & $0.32-0.56$ & 0.27 & 0.70 & 1.11 \\
\hline 5 & 77.347 & 77.650 & 0.303 & $0.56-1$ & 0.28 & 0.43 & 1.10 \\
\hline 6 & 77.458 & 77.560 & 0.102 & $1 .-1.8$ & 0.09 & 0.15 & 0.36 \\
\hline 7 & 77.939 & 77.953 & 0.014 & $1.8-3.2$ & 0.01 & 0.06 & 0.05 \\
\hline 8 & 77.537 & 77.556 & 0.019 & $3.2-5.6$ & 0.02 & 0.04 & 0.07 \\
\hline 9 & 78.063 & 78.058 & 0.000 & $5.6-10$ & 0.00 & 0.03 & 0.00 \\
\hline 10 & 77.570 & 77.600 & 0.030 & $10-18$ & 0.03 & 0.03 & 0.11 \\
\hline 11 & & & 0.000 & $18-100$ & 0.00 & 0.00 & 0.00 \\
\hline tare & 79.393 & 79.393 & \multicolumn{7}{|l}{} \\
\cline { 1 - 5 }
\end{tabular}

Table 21. MOUDI at $40 \mathrm{psi}$ and $5.2 \mathrm{mg} / \mathrm{m}^{3}$ mass concentration of DEP aerosol. 


\begin{tabular}{|c|c|c|c|c|c|c|c|}
\hline $\begin{array}{c}\text { stage } \\
\text { number }\end{array}$ & $\begin{array}{c}\text { Pre wt } \\
(\mathrm{mg})\end{array}$ & $\begin{array}{c}\text { post wt } \\
(\mathrm{mg})\end{array}$ & $\begin{array}{c}\text { Net wt } \\
(\mathrm{mg})\end{array}$ & $\begin{array}{c}\text { size range } \\
\text { (um) }\end{array}$ & $\begin{array}{c}\text { \% by } \\
\text { stage }\end{array}$ & $\begin{array}{c}\text { Cum } \\
\text { mass } \\
(\%)\end{array}$ & frequency \\
\hline $\begin{array}{c}\text { final } \\
\text { filter }\end{array}$ & 54.703 & 54.741 & 0.038 & $0.001-0.056$ & 0.05 & 1.00 & 0.03 \\
\hline 1 & 77.683 & 77.689 & 0.006 & $0.056-0.1$ & 0.01 & 0.95 & 0.03 \\
\hline 2 & 77.808 & 77.824 & 0.016 & $0.1-0.18$ & 0.02 & 0.94 & 0.09 \\
\hline 3 & 77.446 & 77.555 & 0.109 & $0.18-0.32$ & 0.15 & 0.92 & 0.59 \\
\hline 4 & 77.345 & 77.570 & 0.225 & $0.32-0.56$ & 0.31 & 0.77 & 1.26 \\
\hline 5 & 77.614 & 77.859 & 0.245 & $0.56-1$ & 0.33 & 0.46 & 1.33 \\
\hline 6 & 77.794 & 77.862 & 0.068 & $1 .-1.8$ & 0.09 & 0.13 & 0.36 \\
\hline 7 & 77.441 & 77.455 & 0.014 & $1.8-3.2$ & 0.02 & 0.04 & 0.08 \\
\hline 8 & 77.879 & 77.889 & 0.010 & $3.2-5.6$ & 0.01 & 0.02 & 0.06 \\
\hline 9 & 77.640 & 77.636 & 0.000 & $5.6-10$ & 0.00 & 0.00 & 0.00 \\
\hline 10 & 77.661 & 77.664 & 0.003 & $10-18$ & 0.00 & 0.00 & 0.02 \\
\hline 11 & & & 0.000 & $18-100$ & 0.00 & 0.00 & 0.00 \\
\hline tare & 77.743 & 77.754 & \multicolumn{7}{|l}{} \\
\cline { 1 - 6 }
\end{tabular}

Table 22. MOUDI at $40 \mathrm{psi}$ and $3.5 \mathrm{mg} / \mathrm{m}^{3}$ mass concentration of DEP aerosol. 


\begin{tabular}{|c|c|c|c|c|c|c|c|}
\hline $\begin{array}{c}\text { stage } \\
\text { number }\end{array}$ & $\begin{array}{c}\text { Pre wt } \\
(\mathrm{mg})\end{array}$ & $\begin{array}{c}\text { post wt } \\
(\mathrm{mg})\end{array}$ & $\begin{array}{c}\text { Net wt } \\
(\mathrm{mg})\end{array}$ & $\begin{array}{c}\text { size range } \\
\text { (um) }\end{array}$ & $\begin{array}{c}\text { \% by } \\
\text { stage }\end{array}$ & $\begin{array}{c}\text { Cum } \\
\text { mass } \\
(\%)\end{array}$ & frequency \\
\hline $\begin{array}{c}\text { final } \\
\text { filter }\end{array}$ & 53.831 & 53.855 & 0.024 & $0.001-0.056$ & 0.04 & 1.00 & 0.02 \\
\hline 1 & 77.399 & 77.400 & 0.001 & $0.056-0.1$ & 0.00 & 0.96 & 0.01 \\
\hline 2 & 77.810 & 77.831 & 0.021 & $0.1-0.18$ & 0.03 & 0.96 & 0.14 \\
\hline 3 & 78.746 & 78.788 & 0.042 & $0.18-0.32$ & 0.07 & 0.92 & 0.28 \\
\hline 4 & 78.321 & 78.523 & 0.202 & $0.32-0.56$ & 0.33 & 0.86 & 1.36 \\
\hline 5 & 79.144 & 79.373 & 0.229 & $0.56-1$ & 0.38 & 0.52 & 1.49 \\
\hline 6 & 77.700 & 77.751 & 0.051 & $1 .-1.8$ & 0.08 & 0.15 & 0.33 \\
\hline 7 & 77.789 & 77.806 & 0.017 & $1.8-3.2$ & 0.03 & 0.06 & 0.11 \\
\hline 8 & 77.805 & 77.822 & 0.017 & $3.2-5.6$ & 0.03 & 0.04 & 0.11 \\
\hline 9 & 77.591 & 77.596 & 0.005 & $5.6-10$ & 0.01 & 0.01 & 0.03 \\
\hline 10 & 77.770 & 77.766 & 0.000 & $10-18$ & 0.00 & 0.00 & 0.00 \\
\hline 11 & & \multicolumn{7}{|l|}{0.000} & $18-100$ & 0.00 & 0.00 & 0.00 \\
\hline tare & 78.503 & 78.501 & & & & \\
\cline { 1 - 2 } ftare & 54.144 & 54.151 & &
\end{tabular}

Table 23. MOUDI at $40 \mathrm{psi}$ and $2.5 \mathrm{mg} / \mathrm{m}^{3}$ mass concentration of DEP aerosol. 


\begin{tabular}{|c|c|}
\hline Time & $\begin{array}{l}\text { Mass } \\
\text { Conc. }\end{array}$ \\
\hline (seconds) & $\begin{array}{l}(\mathrm{mg} / \\
\left.\mathrm{m}^{\wedge} 3\right)\end{array}$ \\
\hline 1 & 12.3 \\
\hline 2 & 11.7 \\
\hline 3 & 11.4 \\
\hline 4 & 13 \\
\hline 5 & 13.4 \\
\hline 6 & 12.4 \\
\hline 7 & 12.1 \\
\hline 8 & 11.9 \\
\hline 9 & 10 \\
\hline 10 & 10.7 \\
\hline 11 & 10.8 \\
\hline 12 & 10.5 \\
\hline 13 & 9.6 \\
\hline 14 & 9.2 \\
\hline 15 & 9.4 \\
\hline 16 & 8.8 \\
\hline 17 & 8.9 \\
\hline 18 & 9 \\
\hline 19 & 9.7 \\
\hline 20 & 9.4 \\
\hline 21 & 9.5 \\
\hline 22 & 9.3 \\
\hline 23 & 9.6 \\
\hline 24 & 10.2 \\
\hline 25 & 10.6 \\
\hline 26 & 10.4 \\
\hline 27 & 9.8 \\
\hline 28 & 9.8 \\
\hline 29 & 9.7 \\
\hline 30 & 9.4 \\
\hline 31 & 10.2 \\
\hline 32 & 10.6 \\
\hline 33 & 11.4 \\
\hline 34 & 11.7 \\
\hline 35 & 11 \\
\hline 36 & 10.5 \\
\hline
\end{tabular}

\begin{tabular}{|c|c|c|c|}
\hline Time & $\begin{array}{l}\text { Mass } \\
\text { Conc. }\end{array}$ & Time & $\begin{array}{l}\text { Mass } \\
\text { Conc. }\end{array}$ \\
\hline (seconds) & $\left(\mathrm{mg} / \mathrm{m}^{\wedge} 3\right)$ & (seconds) & $\begin{array}{l}(\mathrm{mg} / \\
\left.\mathrm{m}^{\wedge} 3\right)\end{array}$ \\
\hline 1 & 8.5 & 39 & 13.4 \\
\hline 2 & 9.2 & 40 & 10.4 \\
\hline 3 & 9.6 & 41 & 10.7 \\
\hline 4 & 13.2 & 42 & 10.4 \\
\hline 5 & 11.4 & 43 & 12.1 \\
\hline 6 & 11.4 & 44 & 11.6 \\
\hline 7 & 11.1 & 45 & 10 \\
\hline 8 & 10.8 & 46 & 10 \\
\hline 9 & 10.1 & 47 & 12.8 \\
\hline 10 & 11.7 & 48 & 10.6 \\
\hline 11 & 11.8 & 49 & 10.2 \\
\hline 12 & 11.4 & 50 & 9.3 \\
\hline 13 & 10.3 & & \\
\hline 14 & 13.4 & & \\
\hline 15 & 13.2 & & \\
\hline 16 & 10.4 & & \\
\hline 17 & 8.9 & & \\
\hline 18 & 9.4 & & \\
\hline 19 & 10.7 & & \\
\hline 20 & 24.7 & & \\
\hline 21 & 16.5 & & \\
\hline 22 & 11.5 & & \\
\hline 23 & 12.3 & & \\
\hline 24 & 12.1 & & \\
\hline 25 & 10.9 & & \\
\hline 26 & 11.4 & & \\
\hline 27 & 10.1 & & \\
\hline 28 & 11.6 & & \\
\hline 29 & 10.3 & & \\
\hline 30 & 11.7 & & \\
\hline 31 & 11.4 & & \\
\hline 32 & 11.1 & & \\
\hline 33 & 10.6 & & \\
\hline 34 & 10.8 & & \\
\hline 35 & 13.8 & & \\
\hline 36 & 10.2 & & \\
\hline 37 & 9.6 & & \\
\hline 38 & 16 & & \\
\hline
\end{tabular}

Table $24 \& 25$. Consistency of mass concentration level. (Corresponds to figures $1 \& 2$.) 


\section{Appendix C: Sampling losses}

The transmission efficiency was estimated for anisokinetic and anisoaxial inertial deposition, diffusional deposition, and horizontal sedimentation.

\section{Anisoaxial Inertial Deposition}

The equation for inertial deposition in a bend is:

?bend,inert $=\left[\left(1+(\mathrm{stk} / 0.171)^{\wedge}[(0.452 * \mathrm{stk} / .171)]+2.242\right]^{\wedge}(-2 *\right.$ theta/3.14159) $1.1 \mathrm{~A}$

Also the following graph can be used:

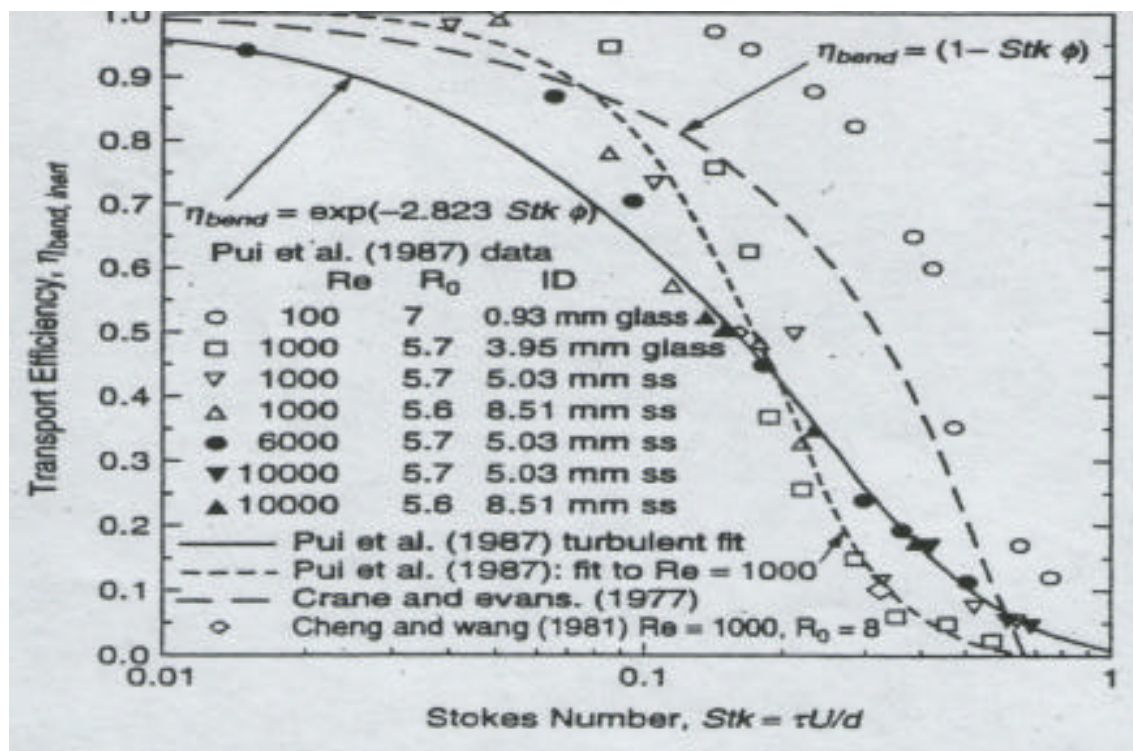

Figure 36. Plot of the transport efficiency, ?bend,inert, of particles undergoing inertial deposition in a bend as a function of Stokes number (27). 
Where ?bend,inert is plotted versus Stokes number for a 90 degree bend for both turbulent (nbend $=\exp (-2.823$ Stk theta)) and laminar flow (nbend $=1-$ Stk theta).

The Stokes number is found from the following equation:

$$
\mathrm{Stk}=? \mathrm{pd}_{\mathrm{p}} \wedge 2 \mathrm{CcU} / 9 \mu \mathrm{db}
$$

Where $? \mathrm{p}$ is the particle density $\left(2620 \mathrm{~kg} / \mathrm{m}^{\wedge} 3\right), \mathrm{d}_{\mathrm{p}}$ is the particle diameter, $\mathrm{C}_{\mathrm{c}}$ is the Cunningham slip correction factor, $\mu$ is the gas viscosity $\left(1.81 \times 10^{\wedge}-5\right)$, and $\mathrm{db}$ is the body diameter.

The Cunningham slip correction factor is found as follows:

$$
\mathrm{C}=1+\mathrm{Kn}[\mathrm{a}+\operatorname{Bexp}(-? / \mathrm{Kn})
$$

Where for solid particles a is $1.142, \beta$ is 0.558 , ? is 0.999 , and $\mathrm{Kn}$ is $2 ? / \mathrm{d}_{\mathrm{p}}$, and where ? is the mean free path, 0.0664 .

The Stokes diameter for a 1 micron diameter particle is $5.4 \times 10^{\wedge}-5$, therefore $100 \%$ transmission efficiency is expected through the first bend. And as smaller particles have less inertia a 0.5 micron dia meter particle will also have a $100 \%$ transmission efficiency.

\section{Horizontal Deposition}

Following this is a horizontal section of pipe approximately 1.2 meters in length.

For laminar flow in a circular horizontal tube the transmission efficiency is given by:

$$
? \text { tube,grav }=1-2 / \mathrm{p}\left[2 \mathrm{e}\left(1-\mathrm{e}^{\wedge} 2 / 3\right)^{\wedge} 0.5-\mathrm{e}^{\wedge} 1 / 3\left(1-\mathrm{e}^{\wedge} 2 / 3\right)^{\wedge} 0.5+\arcsin \left(\mathrm{e}^{\wedge} 1 / 3\right)\right] \quad 1.4 \mathrm{~A}
$$

With, 


$$
\mathrm{e}=(3 * \mathrm{~L} * \mathrm{Vts}) /(4 * \mathrm{~d} * \mathrm{U})
$$

Where $\mathrm{L}$ is the length of the tube, Vts is the terminal velocity which is a function of the particle size, $\mathrm{d}$ is the inside diameter of the tube, and $\mathrm{U}$ is the velocity of the particle.

\section{Anisokinetic Inertial Deposition}

Near the end of the horizontal section is a valve that has a smaller cross-sectional area than the main pipe. This causes anisokinetic flow. Figure 34 indicates that a 1 micron particle with a Stokes number of $5.4 \times 10^{\wedge}-5$, the transmission efficiency should be approximately $100 \%$ in anisokinetic flow.

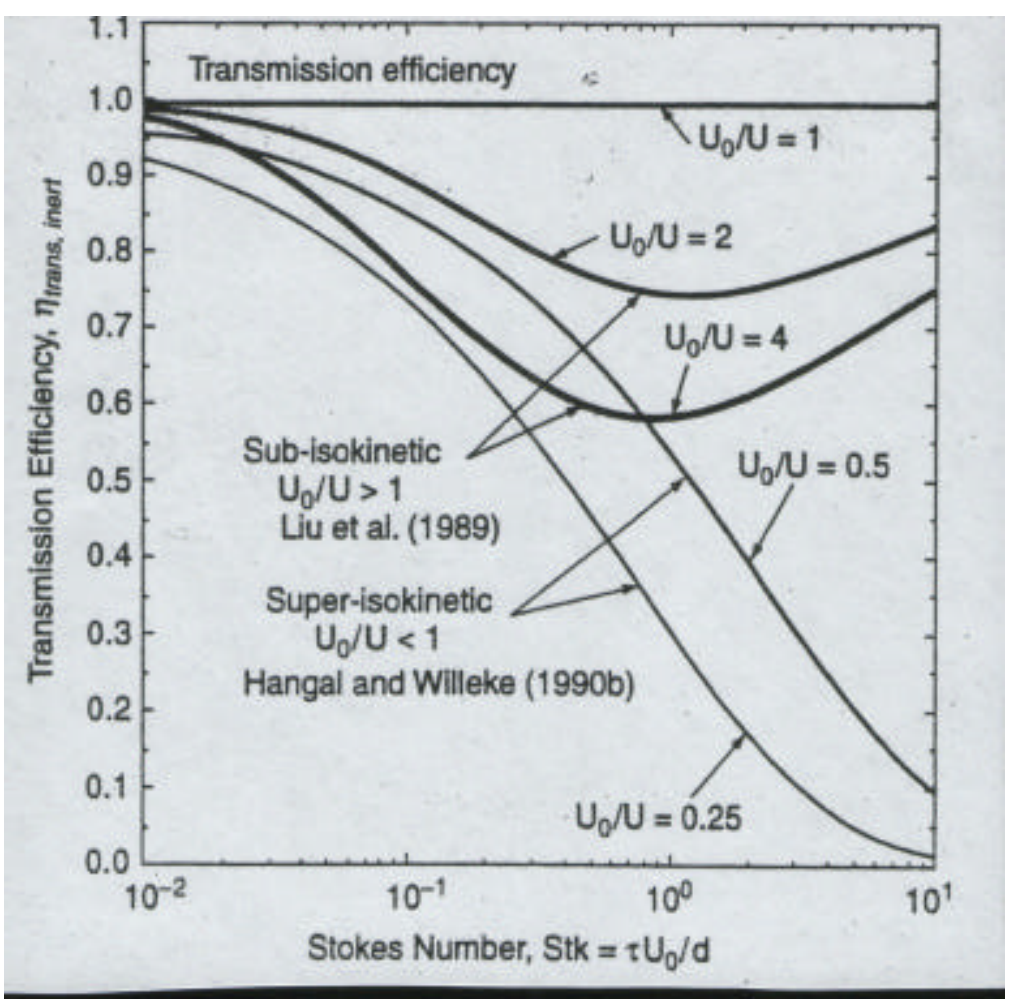

Figure 37. Plot of the transmission efficiency, ?bend,inert, for a thin-walled nozzle as a function of the Stokes number (27). 


\section{Diffusive Transport Efficiency}

The diffusive transport efficiency, ?tube,diff, is:

$$
? \text { tube,diff }=1-2.56 ?^{\wedge} 2 / 3+1.2 ?+0.177 ?^{\wedge} 4 / 3
$$

for $?<0.02$.

With,

$$
?=\mathrm{pDL} / \mathrm{Q}
$$

Where $\mathrm{D}$ is the particle diffusion coefficient, $\mathrm{L}$ is the tube length, and $\mathrm{Q}$ is the volumetric flowrate.

The particle diffusion coefficient is found from:

$$
\mathrm{D}=\mathrm{kTC} / 3 \mathrm{p} \mu \mathrm{d}_{\mathrm{j}}
$$

Where $\mathrm{k}$ is the Boltzman constant of $1.38 \times 10^{\wedge}-21 \mathrm{~N}^{*} \mathrm{~s} / \mathrm{K}, \mathrm{T}$ is the absolute temperature of $293 \mathrm{~K}, \mathrm{C}$ is the Cunningham slip correction factor, $\mu$ is the gas viscosity $\left(1.81 \times 10^{\wedge}-5 \mathrm{~N}^{*} \mathrm{~s} / \mathrm{m}^{\wedge} 2\right), \mathrm{d}_{\mathrm{j}}$ is the particle diameter.

The sampling losses and transmission efficiencies depend upon particle size. It is conservatively estimated that virtually no particle will be larger than 5 microns and no measurable particle mass will consist of particles less than 0.004 microns in diameter. Based on this the sampling losses from anisokinetic, anisoaxial, and diffusion are negligible. The transmission efficiency for inertial deposition caused by anisoaxial sampling for 0.004 micron particles is $100 \%$, for 5 micron particles it is $99.99 \%$. The transmission efficiency for inertial deposition caused by isokinetic sampling is estimated to be $100 \%$ for particles from 0.004 microns in diameter, (Stk \#2.8 x 10^^-8), and still 100\% for 5 micron particles, (Stk \# 0.003). The transmission efficiency for diffusional deposition is $100 \%$ for particles 0.004 microns and bigger. 
On this basis the sampling losses caused by anisokinetic and anisoaxial inertial deposition and diffusional deposition are negligible.

The losses from horizontal deposition (sedimentation) could be significant. For monodisperse particles of 0.5 microns, the transmission efficiency for horizontal deposition is $87 \%$.

(Note: it was found experimentally that the losses from horizontal deposition were also negligible for aerosols less than 1 micron in mass median diameter. 


\section{Appendix D: Equipment}

Equipment:

1. TEOM Series 1400a

Rupprecht \& Patashnick Co., Inc.

2. Jet Mill Model 00 Jet-O-Mizer Serial \#Z1277E

Fluid Energy

3. Vibratory Feeder Model F-30-C Serial \#GPMF58288

Fluid Energy

4. Kenmore evaporative table top cool air humidifier

Model 437.14113

5. Bransonic 200 Ultrasonic Cleaner

6. Bubble Flow Meter

Model No. VA22439 150mm

Flowmeter stainless steel frame, glass float, Serial No. 124088-34.

7. MOUDI Model 110 Serial No. MDI-149-1

MSP Corporation

8. Parallel Flow Diffusion Battery

Model No. 02-2000 Style LBR-R

Intox Products

9. Multi Jet Cascade Impactor

Model No. 02-220

Intox Products 
10. Car Muffler

Defender 8 x 13 x 3.5 inches

11. Brass Piping

12. Marple Personal Impactors

Model No. 290 


\section{Bibliography}

1. Walsh M. P. Global Trends in Diesel Emissions Control - A 1997 Update, SAE paper 970179, 1997.

2. Donaldson K., X. Y. Liu, and W. NacNee. "Ultrafine (Nanometre) Particle Mediated Lung Injury”. J. Aerosol Science. Vol. 29, pp 553-560, 1998.

3. Shi J. P., Harrison R. M., Brear F. Particle Size Distribution from a Modern Heavy Duty Diesel Engine. Science of the Total Environment. Vol. 235 (1999), pp305-317.

4. Abdul-Khalek I. S., Kittelson D. B., Brear F. Diesel Trap Performance: Particle Size Measurements and Trends. SAE paper 982599, 1998.

5. Ahlvik P., Ntziachristos L., Keskinen J., Virtanen A. Real Time Measurements of Diesel Particle Size Distribution with an Electrical Low Pressure Impactor. SAE paper $980410,1998$.

6. K. J. Nikula, M. B. Snipes et al Comparative Pulmonary Toxicities and Carconogenicities of Chronically Inhaled Diesel Exhaust and Carbon Black in F344 Rats. Fundamental and Applied Toxicology 25, 80-94 (1995)

7. O. Cruetzenberg et al. Clearance and retention of inhaled diesel exhaust particles, carbon black and titanium dioxide in rats at lung overload conditions. J. Aerosol Sci. Vol 21, Suppl. 1, pp. S455-S458, 1990.

8. Mauderly, J. L., Snipes, M. B., Barr, E. B., Belinsky, S. A., Bond, J. A., Brooks, A. L., Chang, I., Cheng, Y. S., Gillett, N. A., Griffith, W. C., Henderson, R. F., Mitchell, C. E., Nikula, K. J., Thomassen, D. G., Pulmonary Toxicity of Inhaled 
Diesel Exhaust and Carbon Black in Chronically Exposed Rats. Investigators Report Part 1 of Health Effects Institute Research Report Number 68. (1994)

9. H. Yang, J. Y. C. Ma, V. Castranova, J. K. H. Ma, Effects of Diesel Exhaust Particles on the Release of Interleukin-1 and Tumor Necrosis Factor-Alpha from Rat Alveolar Macrophages. Experimental Lung Research, 23:269-284, 1997.

10. H. Yang, J. M. Antonini, M. W. Barger, L. Butterworth, J. R. Roberts, J. K. H. Ma, V. Castranova, J. Y. C. Ma, Diesel Exhaust Particles Suppress Macrophage Function and Slow the Pulmonary Clearance of Listeria monocytogenes in Rats. Environmental Health Perspectives. Volume 109 Number 5 515-521, May 2001.

11. N. H. Al Humadi, P. D. Siegel, D. M. Lewis, M. W. Barger, J. Y. C. Ma, D. N. Weissman, J. K. H. Ma, The Effect of Diesel Exhaust Particles (DEP) and Carbon Black (CB) on Thiol Changes in Pulmonary Ovalbumin Allergic Sensitized Brown Norway Rats. Experimental Lung Research. 28:339-349, 2002.

12. M. Dahlback. S. Eirefelt. Total Deposition of Flourescent Monodisperse Particles in Rats. Ann. Occup. Hyg. VOl. 38, Supplement 1, pp. 127-134.)

13. Otto G. Raabe et al. Regional Deposition of Inhaled Monodisperse Coarse and Fine Aerosol Particles in Small Laboratory Animals. Ann. Occup. Hyg., Vol. 32, pp.53-63 Supplement 1, 1988.

14 W. C. Hinds. Aerosol Technology: Properties, Behavior, and Measurements of Airborne Particles ISBN 0-41-08726-2.

15 J. L. Mauderly. R. J. McCunney. Particle Overloading in the Rat Lung and Lung: Implications for Human Risk Assessment. Taylor \& Francis, London, 1996. ISBN $1-56032-543-7$. 
16. Morris Snipes. Current Information on Lung Overload in NonRodent Mammals: Contrats with Rats. Inhalation Toxicology, 8(supp):91-109, 1996 0895-8378/96.

17. O. R. Moss, J. R. Decker, W. C. Cannon. Aerosol Mixing in an animal exposure chamber having three levels of caging with excreta pans. American Industrial Hygiene Association Journal (43) 1982.

18. Pisano, F. McCawley, M. Hinton, D., Stanley, C., Lantz, R.C. Evaluation of the size distribution of aerosols greater than 5 micrometers in the hazelton animal exposure chamber. Aerosols: Science, Technology, and Industrial Applications of Airborne Particles, Proceedings of the First International Aerosol Conference pg 1055-1057 ISBN: 0-444-00947-7.

19. Patashnick H. Rupprecht E. G., Cont inous PM-10 Measurements Using the Tapered Element Oscillating Microbalance. J. Air Waste Manage. Assoc. 41: 1079-1083 ISSN 1047-3289.

20. Meyer M., Lijek, J., Ono, D., 1992. Continous PM10 measurements in a woodsmoke environment, PM10 Standards and Nontraditional Particulate Source Controls. In: Chow, J.C., Ono, D.M. (Eds.), Air and Waste Management Association, T R-22 1, pp. 24-38.

21. Allen G, G., Sioutas, C., Koutrakis, P., Reiss, R., Lurmann, F.W., Roberts, P.T., 1997. Evaluation of the TEOM method for measurement of ambient particulate mass in urban areas. Journal of Air and Waste Management Association 47, 682689. 
22. Anne Soutar, Monika Watt et al. Comparison between a personal PM10 sampling head and the tapered element oscillating microbalance (TEOM) system. Amtospheric Environment 33 (1999) 4373-4377.

23. G. P. Ayers M. D. Keywood, J.L. Gras. TEOM vs. manual gravimetric methods for determination of PM2.5 aerosol mass concentrations. Atmospheric Environment 33 (1999) 3717-3721.

24. Cheng, Y. S., Keating, J. A., and Kanapilly, G. M. (1980). J. Aerosol Sci. 11:549556.

25. Barr, E. B., Cheng, Y., Yeh, H., Wolff, R. K., Size Characterization of Carbonaceous Particles Using a Lovelace Multijet Cascade Impactor / Paraller Flow Diffusion Battery Serial Sampling Train. Aerosol Science and Technology 10:205-212 (1989).

26. Marple V. A., Olson B. A., Rubow K. L., Inertial, Gravitational, Centrifugal, and Thermal Collection Techniques. Aerosol Measurement: Principles, Techniques, and Applications, Second Edition, 2001. ISBN 0-471-35636-0.

27. Brockman J. E., Sampling and Transport of Aerosols. Aerosol Measurement: Principles, Techinques, and Applications, Second Edition, pp. 143-196. 2001 ISBN 0-471-35636-0. 